Portland State University

PDXScholar

Summer 8-30-2016

\title{
Use of Water Indices Derived from Landsat OLI Imagery and GIS to Estimate the Hydrologic Connectivity of Wetlands in the Tualatin River National Wildlife Refuge
}

Debra Sue Blackmore

Portland State University

Follow this and additional works at: https://pdxscholar.library.pdx.edu/open_access_etds

Part of the Remote Sensing Commons, and the Water Resource Management Commons Let us know how access to this document benefits you.

\section{Recommended Citation}

Blackmore, Debra Sue, "Use of Water Indices Derived from Landsat OLI Imagery and GIS to Estimate the Hydrologic Connectivity of Wetlands in the Tualatin River National Wildlife Refuge" (2016). Dissertations and Theses. Paper 3205.

https://doi.org/10.15760/etd.3196

This Thesis is brought to you for free and open access. It has been accepted for inclusion in Dissertations and Theses by an authorized administrator of PDXScholar. Please contact us if we can make this document more accessible: pdxscholar@pdx.edu. 


\title{
Use of Water Indices Derived from Landsat OLI Imagery and GIS
}

to Estimate the Hydrologic Connectivity of Wetlands in the

\author{
Tualatin River National Wildlife Refuge
}

by

Debra Sue Blackmore

A thesis submitted in partial fulfillment of the requirements for the degree of

\author{
Master of Science \\ in \\ Geography \\ Thesis Committee: \\ Jiunn-Der Duh, Chair \\ Heejun Chang \\ Joseph Maser \\ Portland State University \\ 2016
}




\section{Abstract}

This study compared two remote sensing water indices: the Normalized Difference Water Index (NDWI) and the Modified NDWI (MNDWI). Both indices were calculated using publically-available data from the Landsat 8 Operational Land Imager (OLI). The research goal was to determine whether the indices are effective in locating open water and measuring surface soil moisture. To demonstrate the application of water indices, analysis was conducted for freshwater wetlands in the Tualatin River Basin in northwestern Oregon to estimate hydrologic connectivity and hydrological permanence between these wetlands and nearby water bodies. Remote sensing techniques have been used to study wetlands in recent decades; however, scientific studies have rarely addressed hydrologic connectivity and hydrologic permanence, in spite of the documented importance of these properties. Research steps were designed to be straightforward for easy repeatability: 1) locate sample sites, 2) predict wetness with water indices, 3) estimate wetness with soil samples from the field, 4) validate the index predictions against the soil samples from the field, and 5) in the

demonstration step, estimate hydrologic connectivity and hydrological permanence. Results indicate that both indices predicted the presence of large, open water features with clarity; that dry conditions were predicted by MNDWI with more subtle differentiation; and that NDWI results seem more sensitive to sites with vegetation. Use of this low-cost method to discover patterns of surface moisture in the landscape could directly improve the ability to manage wetland environments. 


\section{Acknowledgements}

I would like to thank Dr. Heejun Chang for the opportunity to work as his Research Assistant on the Oregon Wetlands Explorer Statewide Wetland Prioritization Tool, a twoyear grant funded by the U.S. Environmental Protection Agency. Extensive research and studies for the EPA project formed the foundation for my thesis work. I wish to acknowledge my advisor, Dr. Jiunn-Der (Geoffrey) Duh for his flexibility and steadfast commitment to my success. Many thanks to Dr. Joseph Maser, who offered insight and support for my interest in wetlands, encouraging me to get out in the field in all weather and water conditions. To Dr. Martin Lafrenz for assistance in understanding wetland soils and especially for use of the Soils Lab. To Dan Craver, who introduced me to staff at the Tualatin River National Wildlife Refuge and to Curt Mykut, the Wildlife Biologist at the Refuge, who made my field work possible. To Dr. Megler for advice and support - and humor. And finally, to Jeff, for encouragement, flexibility, patience and well-timed diversions. 


\section{Table of Contents}

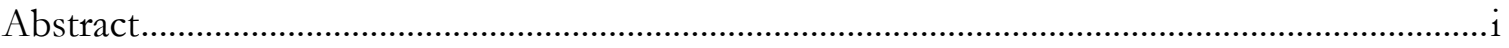

Acknowledgements ........................................................................................................................

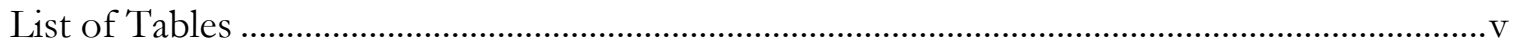

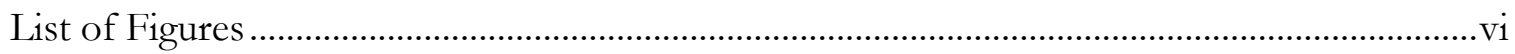

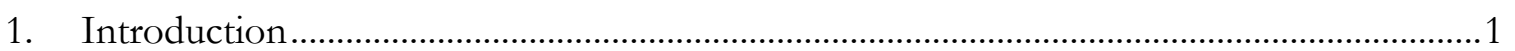

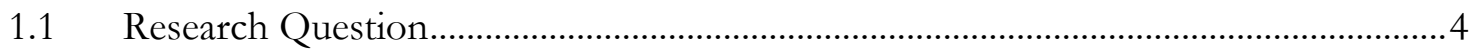

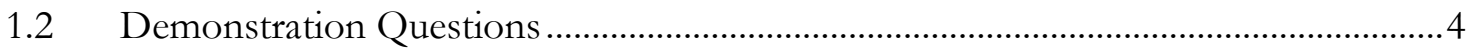

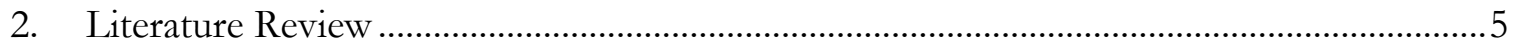

2.1 Remote Sensing and Soil Moisture Quantification........................................................ 5

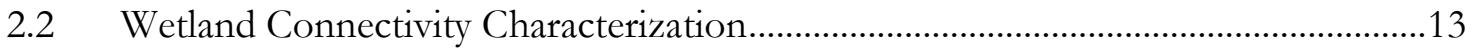

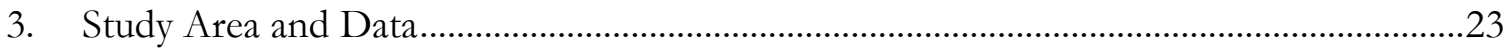

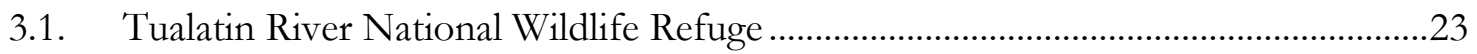

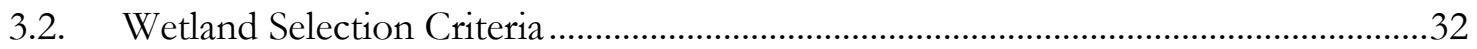

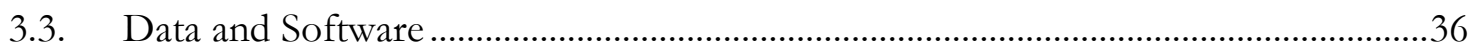

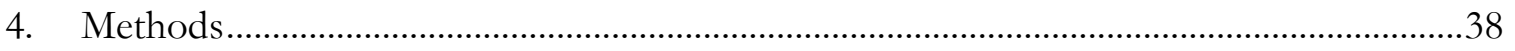

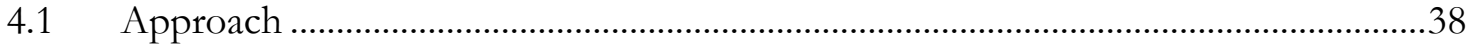

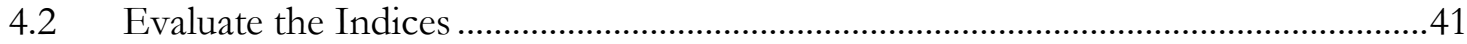

Step 1 - Determine sampling sites ...................................................................................41

Step 2 - Predict surface wetness with remote sensing indices .............................................42

Step 3 - Estimate surface wetness with in-situ soil surveys .................................................. 45

Step 4 - Validate surface moisture indices with in-situ soil surveys.....................................52

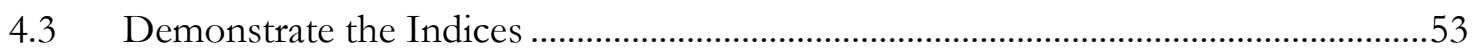

Step 5 - Categorize hydrologic connectivity and hydrological permanence .......................53

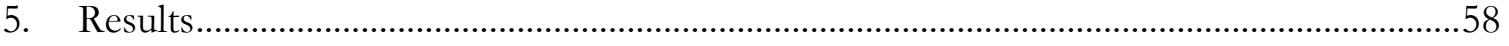

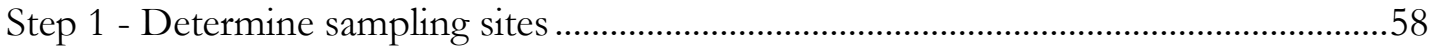

Step 2 - Predict surface wetness with remote sensing indices...............................................59

Step 3 - Estimate surface wetness with in-situ soil surveys ..................................................66

Step 4 - Validate surface moisture indices with in-situ soil surveys .....................................71

Step 5 - Categorize hydrologic connectivity and hydrological permanence ........................73

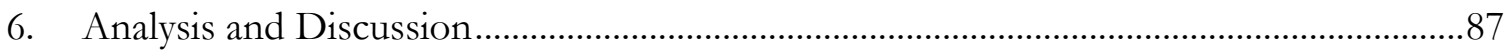


6.1 Challenges using ArcMap to determine sampling sites...............................................87

6.2 The pros and cons of using NDWI \& MNDWI in detecting surface moisture .......87

6.3 Hydrologic connectivity and hydrological permanence ..............................................94

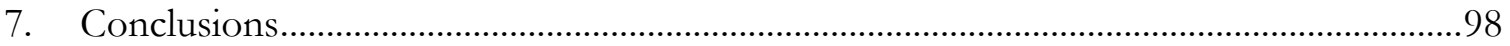

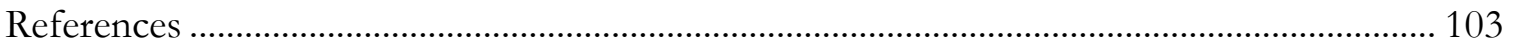

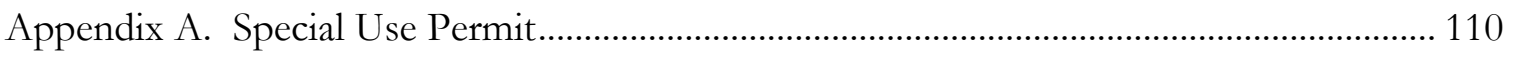

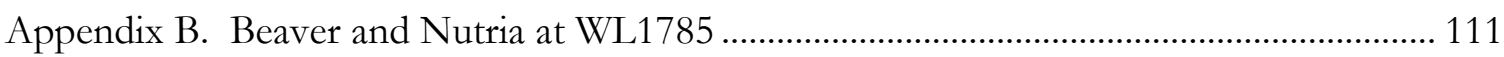

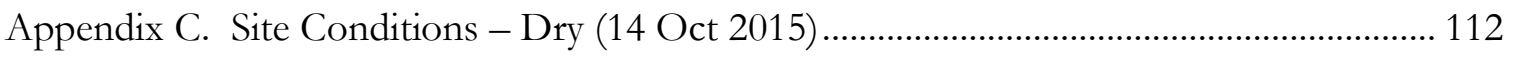

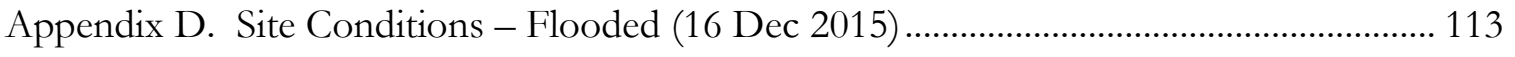

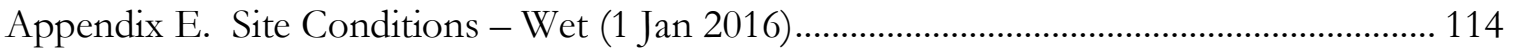

Appendix F. Soil Laboratory Examples................................................................................. 115 


\section{List of Tables}

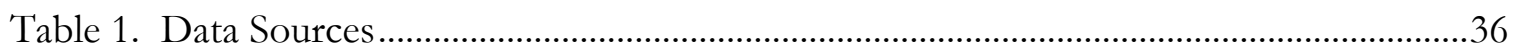

Table 2. Sample attribute table showing hydrologic connectivity (HC) and hydrological permanence $(\mathrm{HP})$ for study wetlands. For $\mathrm{HC}, \mathrm{Y}=$ yes, $\mathrm{N}=$ no. For $\mathrm{HP}, \mathrm{P}=$ perennial,

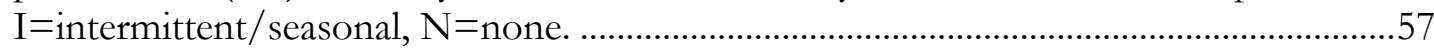

Table 3. Site Log showing Landsat satellite fly-over dates (L8) and on-site sample dates......66

Table 4. Sample data on 14 October 2015 with calculations for dry-weight analysis of soil

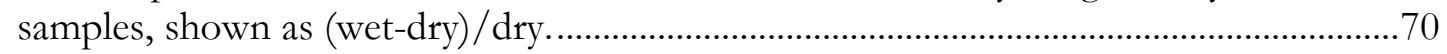

Table 5. . Sample data on 1 January 2016 with calculations for dry-weight analysis of soil

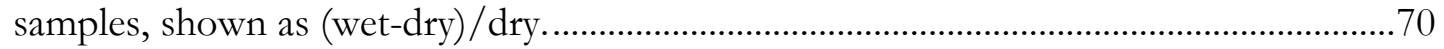

Table 6. Regression results for dry-weight estimates vs. NDWI (top) and MNDWI (bottom)

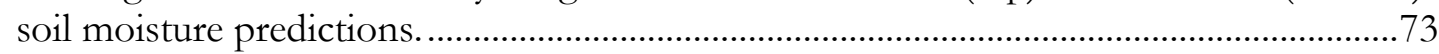

Table 7. Precipitation totals (inches) at weather station WS0096 Sherwood 2.0 NW near the study area (NOAA 2015, 2016). 


\section{List of Figures}

Figure 1. Spectral signatures for grass and selected materials (Jensen 2005, p 193)..................

Figure 2. Spectral reflectance characteristics of land cover in a LANDSAT ETM+ image

(Ho et al. 2010). Bands 2, 3, 4 and 5 in ETM+ images correspond to visible green, visible red, near infrared and mid infrared spectrums, respectively.

Figure 3. Study Sites in the Tualatin River National Wildlife Refuge........................................23

Figure 4. Land Cover in the Tualatin River Basin in northwest Oregon (INR 2010). ............26

Figure 5. Elevation in the Tualatin River Basin in northwest Oregon (USGS 2015a). ..........27

Figure 6. Precipitation in the Tualatin River Basin in northwest Oregon, 30-year average

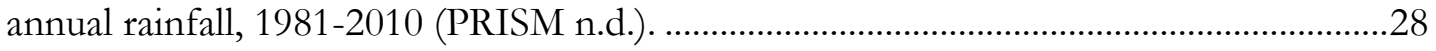

Figure 7. Weather stations near study area (NOAA 2015, 2016)............................................29

Figure 8. Monthly average precipitation near study area, in inches, at Global Historical Climatology Network (GHNC) weather stations (Menne et al. 2012, WRCC 2016)......30

Figure 9. Landsat 8 images comparing a wet period (left, 30 January 2015), with a dry period (right, 9 July 2015) (USGS 2015b). Bands 2, 3 and 4, (visible blue, green and red respectively) were used to simulate natural color.

Figure 10. Wetland Connectivity - National Land Cover Database values near study sites within the Tualatin River National Wildlife Refuge (USGS 2014b)...................................35

Figure 11. Steps used to estimate surface wetness with remote sensing water indices.

Figure 12. Method for calculating flow path from a wetland (polygon) to the nearest stream segment (polyline).

Figure 13. Landsat 8 imagery on 13 October 2015 (path 46, row 28) showing relative position of study area and Tualatin River subbasin. (USGS 2015b).

Figure 14. Wetland 151, flow accumulation pattern calculated using terrain analysis showing aerial imagery and location of gate.

Figure 15. Wetland 1785, flow accumulation pattern calculated using terrain analysis showing aerial imagery and location of gate.

Figure 16. Wetland 2905, flow accumulation pattern calculated using terrain analysis showing aerial imagery.

Figure 17. Example of soil sampling technique, showing sampling hole, space, sample site flag. Note water table near surface. Wetland 151 on 22 April 2016. ................................51

Figure 18. Hydrological Permanence based on whether a wetland is connected and for what duration, i.e., perennial, intermittent or ephemeral (Fritz et al. 2006, Leibowitz et al. 2008).

Figure 19. Satellite imagery 1. Landsat 8 imagery (path 46, row 28) showing study sites for dates in 2015 (format: yyyymmdd-julian date) (USGS 2015b).... 
Figure 20. Satellite imagery 2. Landsat 8 imagery (path 46, row 28) showing study sites for dates from January to March 2016 (format: yyyymmdd-julian date) (USGS 2015b).......61

Figure 21. Satellite imagery 3. Landsat 8 imagery (path 46, row 28) showing study sites for dates from March to May in 2016 (format: yyyymmdd-julian date) (USGS 2015b)........62

Figure 22. Soil moisture predictions based on NDWI \& MNDWI for Wetland 151 in dry (left) and wet conditions (right). Date format is yyyymmdd-julian date.

Figure 23. Soil moisture predictions based on NDWI \& MNDWI for Wetland 1785 in dry (left) and wet conditions (right). Date format is yyyymmdd-julian date...........................64

Figure 24. Soil moisture predictions based on NDWI \& MNDWI for Wetland 2905 in dry (left) and wet conditions (right). Date format is yyyymmdd-julian date...........................64

Figure 25. Boxplots showing distribution of values for water indices NDWI and MNDWI for all three wetlands in dry conditions (left: L5286 - 13/14 October 2015) and wet conditions (right: L6001 - 1 January 2016)....

Figure 26. Daily precipitation in $\mathrm{mm}$ at NOAA weather station WS0096 Sherwood 2.0 NW showing dates when soil samples were taken from October 2015 to May 2016 (NOAA 2015, 2016). Note: Julian dates across the x-axis are extended beyond 2015 (J365) into 2016 for sake of visual continuity.

Figure 27. Scatterplot showing estimates from sampling sites on the $\mathrm{X}$-axis vs. water index values NDWI and MNDWI on Y-axis. All usable sample data is shown.

Figure 28. Boxplots showing distribution of values for water indices NDWI and MNDWI for all three wetlands in dry conditions (L-R: L5190 - 9 July 2015, L5238 - 26 August 2015, L5270 - 27 September 2015)

Figure 29. Boxplots showing distribution of values for water indices NDWI and MNDWI for all three wetlands in wet conditions (L-R: L5030 - 30 January 2015, L5062 - 3 March 2015, L5110 - 20 April 2015).

Figure 30. Soil moisture classifications for NDWI \& MNDWI for Wetland 151 in dry (left, 13/14 October 2015) and wet conditions (right, 1 January 2016).......................................78

Figure 31. Soil moisture classifications for NDWI \& MNDWI for Wetland 1785 in dry (left, 13/14 October 2015) and wet conditions (right, 1 January 2016)......................................79

Figure 32. Soil moisture classifications for NDWI \& MNDWI for Wetland 2905 in dry (left, 13/14 October 2015) and wet conditions (right, 1 January 2016). .80

Figure 33. Soil moisture classifications for time series, WL151 dry: NDWI \& MNDWI for Wetland 151 for a dry period, L-R, 9 July 2015, 26 August 2015 and 27 September 2015.

Figure 34. Soil moisture classifications for time series, WL151 wet. NDWI \& MNDWI for Wetland 151 for a wet period, L-R, 30 January 2015, 3 March 2015 and 20 April 2015.

Figure 35. Soil moisture classifications for time series, WL1785 dry. NDWI \& MNDWI for Wetland 1785 for a dry period, L-R, 9 July 2015, 26 August 2015 and 27 September 2015. 
Figure 36. Soil moisture classifications for time series, WL1785 wet. NDWI \& MNDWI for Wetland 1785 for a wet period, L-R, 30 January 2015, 3 March 2015 and 20 April 2015.

Figure 37. Soil moisture classifications for time series, WL2905 dry. NDWI \& MNDWI for Wetland 2905 for a dry period, L-R, 9 July 2015, 26 August 2015 and 27 September 2015

Figure 38. Soil moisture classifications for time series, WL2905 wet. NDWI \& MNDWI for Wetland 2905 for a wet period, L-R, 30 January 2015, 3 March 2015 and 20 April 2015.

Figure 39. Scatterplot showing estimates from sampling sites on the $\mathrm{X}$-axis vs. water index values NDWI and MNDWI on Y-axis, also on y-axis, average index results within 10meter buffer. All usable sample data is shown.

Figure 40. Hydrologic connectivity. Demonstration of water indices, specifically estimates of hydrologic connectivity (HC) by wetland for study sites at the Tualatin River National Wildlife Refuge from January 2015 to May 2016.

Figure 41. Results - Hydrological permanence. Demonstration of water indices, specifically the summary of hydrologic connectivity (HC) and hydrological permanence (HP) by wetland for study sites at the Tualatin River National Wildlife Refuge from January 2015 to May 2016. Note: For HC, internal = intermittent/seasonal connectivity, $\mathrm{N}=$ none. For HP, I = intermittent/seasonal permanence, $\mathrm{N}=$ none. 


\section{Introduction}

Water covers an estimated $71 \%$ of the Earth's surface (Williams 2014). Water can be found in glaciers, oceans, lakes, rivers, wetlands, etc. over an area of approximately 510,000 $\left(10^{3} \mathrm{~km}^{2}\right)$ and where that water exists is of extreme importance to humans (Palaniappan \& Gleick 2009). Methods for measuring or estimating the location of surface water features include on-the-ground and remote sensing. Unfortunately, on-the-ground methods for locating surface water or soil moisture can be extremely resource-intensive (Famiglietti et al. 1998, Leibowitz \& Nadeau 2003) or they can produce results which represent specific locations, rather than describing spatially distributed patterns of wetness (Tian \& Philpot 2015). For delineating surface water and surface moisture, remote sensing may be a feasible alternative (Klemas 2013a).

In this study, two water indices derived from Landsat 8 satellite data were used to predict surface wetness, specifically the Normalized Difference Water Index (NDWI) and the Modified Normalized Difference Water Index (MNDWI). Evaluating the indices was performed in four steps: 1) determine the location of sampling sites at each wetland (also used to focus satellite analysis), 2) predict surface moisture using the water indices, 3) estimate surface wetness using in-situ soil surveys, and 4) validate the water index predictions using data from the soil surveys. The study period extended seven months, from midOctober 2015 to early May 2016, for a total of fourteen (14) cycles of data collection. These four steps were conducted to determine the applicability of the water indices in these specific wetland locations, especially to set threshold values for categories of dry, moist or wet-toinundated surfaces. A demonstration of the water index approach was performed in the fifth and final step of the study, focused on wetlands in the Tualatin River National Wildlife 
Refuge in Sherwood, Oregon. The demonstration could have been conducted using satellite data only, with results indicating relative areas of high or low surface wetness. However, to simplify presentation of the results, threshold values were generated for categories of surface moisture (dry, moist and wet-to-inundated) based on the correlation equations produced in Step 4 (above). Maps of the categorized water indices were generated for satellite images captured over a one-year period (2015) to estimate the existence or absence of connectivity between wetlands and nearby water features and the permanence of these connections, if any.

Why use remote sensing to detect open water and surface moisture? On-the-ground methods for locating surface water features rely on functional metrics, e.g., hydrologic flows (USEPA 2015, 2-49), which often require data collection in the field. For example, measurements of hydrologic flows typically require contact with the water, e.g. the velocityarea method or continuous flow methods using a well, flume or weir (Davie 2008). Unfortunately, hydrologic interactions can be costly and time-consuming to determine at the process-level (Arnold et al. 2001, Leibowitz \& Nadeau 2003). Even when available, these measurements at individual locations help describe point or plot features but may not, by themselves, capture spatial patterns and variations (Band \& Moore 1995, Tian \& Philpot 2015). Many ground-based observations may be required to profile an entire landscape (e.g., Jencso et al. 2009) and it may be difficult to collect data at a spatial extent and frequency required for the analysis at hand. Famiglietti et al. (1998) stated that "ground-based methods... are far too labor or equipment intensive to remain feasible with increasing spatial scale and space/time sampling frequencies". 
Why use remote sensing to study wetlands and connectivity? Wetlands have historically been neglected and destroyed by humans with significant negative consequence (e.g., Mitsch \& Gosselink 2007). Interest in restoring and protecting wetlands has increased in recent decades, especially since the Ramsar Convention, a treaty signed in 1971 to conserve wetland resources on a global scale (Matthews 1993). Mitsch \& Gosselink (2007, p 3) summed up a prevailing point of view with their statement that "wetlands are among the most important ecosystems on Earth". The study of wetlands is inherently tied to remote sensing, which is considered by some to be "...the most important tool for the identification and monitoring of wetlands" (Pietroniro \& Leconte 2005). Applications of remote sensing for wetlands are many. An interesting challenge is that wetlands tend to be shallow (compared to lakes) and the water tends to be turbid, i.e., not clear, often containing biomass and/or sediments (Mitsch \& Gosselink 2007). These characteristics complicate measurements and delineation efforts using remote sensing techniques (Klemas 2013b, Singh et al. 2016). In addition, “...most wetland studies do not investigate wetland effects on downstream waters or, if they do, they rarely address connectivity explicitly" (USEPA 2015, p 4-39). The work presented here addresses the documented gap in research, demonstrating a cost-effective technique for estimating wetland connectivity.

Use of remote sensing water indices are proposed to estimate surface water and soil moisture and subsequently estimate hydrologic connectivity and hydrological permanence at a landscape-scale using low-cost, readily-available data. This technique may: 1) reduce the time and money required to evaluate and compare wetlands (when compared to field observations alone), 2) provide information about timing and site selection for wetland studies, thereby improving the efficiency of field work, 3) enhance existing field data with an 
objective measure of hydrologic connectivity, possibly improving comparisons of wetland environments, and 4) inform the parameters and methods for modelling of wetland environments. The use of these techniques from a landscape perspective, rather than an individual wetland point of view, could directly improve the ability to "assess wetlands for conservation and restoration" (Ward et al. 2002).

\subsection{Research Question}

The goal of this research is to investigate the use of water indices to quantify surface wetness and soil moisture and demonstrate the use of such techniques in wetland connectivity characterization.

The research question is: Are water indices derived from Landsat 8 OLI satellite imagery, specifically the Normalized Difference Water Index (NDWI) and the Modified NDWI (MNDWI), effective in identifying open water and quantifying surface moisture?

\subsection{Demonstration Questions}

To demonstrate my research, I will use the water indices in wetland environments to answer two questions. First, is a wetland hydrologically connected to a nearby water feature on a specific day ( $\mathrm{Y}$ or $\mathrm{N})$ ? Second, what is the hydrological permanence of the hydrologic connectivity between a wetland and a nearby water feature over the course of a year (ephemeral, intermittent or perennial)?

Water indices derived from remote sensing will be used to predict patterns of surface wetness and soil moisture, including open water. This will indicate whether a wetland is hydrologically connected to a nearby water feature. The extent of these patterns and the duration of their presence will indicate the hydrological permanence of the connectivity. 


\section{Literature Review}

\subsection{Remote Sensing and Soil Moisture Quantification}

Remote sensing is the "science and art of obtaining information about an object, area, or phenomenon through analysis of data acquired by a device that is not in contact with the object, area, or phenomenon under investigation" (Lillesand et al. 2008, p 1). Remote sensing technology includes passive detectors which record the electromagnetic energy reflected by the surface and active sensors which emit their own energy then measure the reflections which return to the sensor (Lillesand et al. 2008). Examples of passive remote sensors include aerial photography (which captures the reflections in the visual or near infrared spectrum, or both), multi- and hyper-spectral devices, thermal cameras, and passive microwave. Active remote sensors include active microwave, e.g., radar (radio detection and ranging) and lidar (light detection and ranging).

Remote sensing techniques measure the reflected energy from surfaces on the Earth, such as soil and water. Remote sensing is effective in locating water because, in detecting surface reflection, there is a significant difference in the way land, vegetation and dry soil reflect sunlight and the way moist soil and vegetation and open water absorb the sun's energy, especially beyond the visible wavelengths (McFeeters 1996). Clear water bodies effectively absorb all wavelengths longer than the visible blue-green range of the electromagnetic spectrum due to selective absorption in the red part of the visible spectrum (Braun \& Smirnov 1993). The presence of water has an impact on remote sensor capabilities whether that water occurs as atmospheric vapor, open water bodies, in soil, in vegetation, etc. Also, in most bodies of water, the existence of biomass, sediment or turbidity changes the reflectance characteristics (e.g., Li et al. 2003). These reflectance properties complicate the 
ability of remote sensing to identify water features. Basically, the higher the water content at the surface or in the near-surface soil, the lower the penetration rate because the majority of electromagnetic waves are absorbed rather than reflected. As a result, remote sensing of soil is highly dependent on the water content of the soil and the frequency or wavelength of the sensor (Schmugge et al. 2002). In detecting soil moisture content, responses are possible to a depth of several tens of meters in dry sand and gravel using active radar (Huisman et al. 2003); however, in wet or moist environments, depths of only five centimeters may be distinguishable (Davie 2008). As a result, use of remote sensing for estimates of moisture is best suited to evaluating wetness at the surface.

Applications of remote sensing technologies for environmental studies include weather and geologic hazards, land use and land cover changes, water resources, climate variability, resource development and environmental restoration (Dodge \& Congalton 2013). Further examples include the identification of open water (McFeeters 1996, Xu 2006) and of temporary ponds or flooding events (Ho et al. 2010, Soti et al. 2009). The effectiveness of remote sensing for surveying hydrologic features has been highlighted in several studies (e.g., Schmugge et al. 2002). Rango and Shalaby (1998) enumerated factors which favor the use of remote sensing techniques in the study of hydrology including the ability to 1) measure spatial patterns rather than point or plot data, 2) gather data over large areas of the Earth's surface, 3) create long-term data sets and 4) acquire spatial information at a relatively low cost when compared to conventional means. Pietroniro and Leconte (2005) evaluated remote sensing studies in Canada, including the delineations of surface water, wetlands and soil moisture and interpretations of information such as land cover or geological features. They concluded that the ability to interpret remote sensing imagery is considered the most 
cost-effective means of obtaining selected information types relative to conventional or field observation methods. Klemas (2013a) reviewed hundreds of remote sensing studies focused on coastal zones in categories such as delineation, landscape elevation, bathymetry, water temperatures and salinity, soil moisture, change detection, studies of submerged aquatic vegetation, beach profiling, etc. Klemas (2013a) agreed with Pietroniro \& Leconte, stating that "...remote sensors can monitor and assess long-term trends and short-term changes of vegetation and hydrology faster, more completely, and at lower cost per unit area than field or ship surveys alone".

Applications of radar and lidar are wide-ranging, however these technologies pose specific challenges. Radar has the advantage that it can penetrate clouds and can acquire imagery in daylight or darkness (Rencz 1999). Applications of radar include mapping of surface features, hydrology, soil moisture, land use and land cover for forestry, geology, oceanography, snow/ice/clouds/atmospheric analysis, urban analysis/settlement detection/population estimation, and archeology (Henderson \& Lewis 1998). Unfortunately, radar imagery is relatively coarse in spatial resolution (Tian \& Philpot 2015). For example, the Soil Moisture Active Passive mission launched by NASA in January of 2015 captures imagery at resolutions ranging from 1 - $10 \mathrm{~km}$ (Entekhabi et al. 2014). While this is an improvement over the precision of previous radar satellite systems $(\sim 40 \mathrm{~km})$, it is still rather imprecise for studies of wetlands or river features. Lidar is often used to provide detailed measurements of the ground and surface features, producing highly-accurate data (Huang et al. 2014). Applications of lidar include forestry, natural hazards (floods, landslides, etc.), corridor mapping of transmission lines, transportation engineering, airport surveying, building extraction, coastal management and shoreline mapping, land cover 
classification, etc. (Lang et al. 2012, Murphy et al. 2009, Renslow 2012, Yan et al. 2012). Lidar can be extremely precise but is often cited for the high data cost and historically limited data availability (e.g., Huang et al. 2014). Terrestrial lidar, which is based on laser systems operated in the near-infrared wavelength, has limited applications in soil moisture and water feature detection due the absorption of near-infrared by water.

A review of conceptual hydrologic models informed the design of remote sensing research for this thesis. Conceptual models are simplified representations of hydrologic processes. Modeling methods use structural metrics of physical landscape features, e.g., topography or spatial arrangement (USEPA 2015), to quantify or predict the movement and storage of water, i.e., hydrology. A sample of relevant modeling topics includes efforts to estimate streamflow triggers (Western et al. 2001) or upslope contributing area, i.e., the Topographic Wetness Index (Beven \& Kirkby 1979), to predict watershed wetness and expected patterns of hydrologic connectivity (Golden et al. 2014) and estimate patterns of soil moisture, i.e., the Soil Wetness Index, which Murphy et al. (2009) evaluate in comparison to the Depth-To-Water index. Distributed hydrologic models, which take into account the spatial variability of water distribution, use meteorological inputs (e.g., precipitation, wind) in addition to characterizations of terrain, soils, vegetation and land use. An established example is TOPMODEL, developed by Beven \& Kirkby (1979), which uses storage-contributing area and soil water response to predict basin response. Another widely studied hydrologic modeling tool is the Soil and Water Assessment Tool or SWAT (Arnold et al. 2001), which incorporates land use and soil type. Each model has specific process representations, site parameters (i.e., structural metrics), and boundary conditions. One of the many common factors is the inclusion of soil characteristics and soil moisture. In fact, 
Pietroniro and Leconte (2005) state that [soil moisture] is “...the most important flux boundary in hydrology". Therefore, estimates of soil moisture were added to this study which uses remote sensing to detect surface water.

Remote sensing of hydrology involves the direct measurement of surface or nearsurface features, such as open water or soil moisture (Pietroniro \& Leconte 2005). Surface features tend to have identifiable spectral response patterns, i.e., their measured reflectance is often distinguishable on the electromagnetic spectrum from the reflectance of other features (Jensen 2005). A spectral reflectance curve can be creating for a surface feature by plotting the typical spectral responses for each wavelength (band). For example, grass has a lower response in the visible blue range $(\sim 0.4$ micrometers), a stronger response in the green and red visible ranges $(\sim 0.5$ and $\sim 0.6$ micrometers, respectively), and a significantly higher

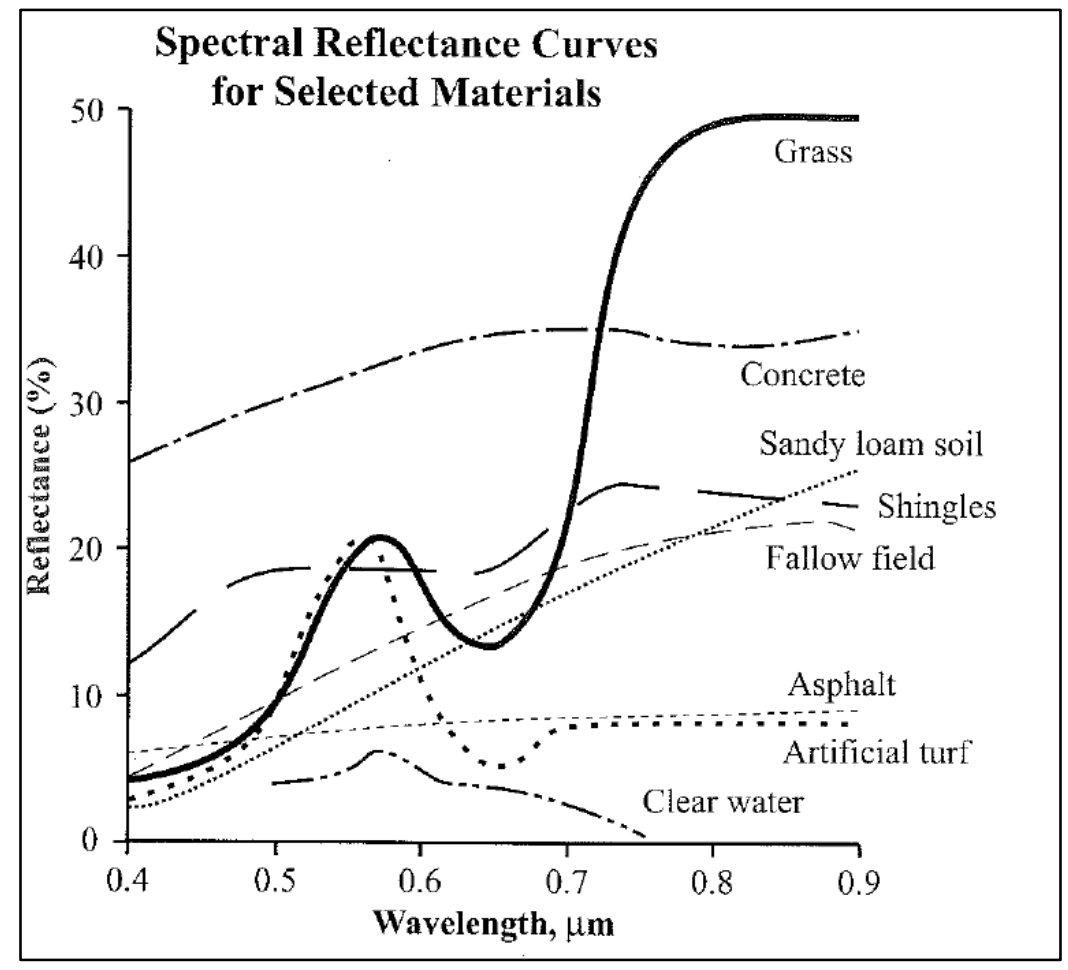

Figure 1. Spectral signatures for grass and selected materials (Jensen 2005, p 193). 
response in the near-infrared range ( $\sim 0.8$ to $\sim 0.9$ micrometers). The spectral reflectance curve for grass and other selected materials is shown in Figure 1. Interference such as atmospheric conditions can negatively influence the reliability and uniqueness of a particular feature's reflectance. Jensen (2005) describes the value of band ratioing to reduce the effects of atmospheric and other environmental conditions. Accordingly, specific remote sensing ratios or indices have been developed to estimate specific surface characteristics. For example, a widely-used ratio is the normalized difference vegetation index or NDVI (Tucker 1980), which is based on the different responses in the visible red band and the near-infrared band: (NIR-red)/(NIR+red). Studies related to NDVI informed the selection of water indices for my research. For example, Hwang et al. (2012) observed that average increases in the vegetation index (NDVI) corresponded to unit increases of the topographic wetness index. They proposed that variations in vegetation and patterns of growth, a hydrologic vegetation gradient, can be an indicator of "lateral [surface] connectivity". The Hwang study (2012) also found that topography was more dominant in determining remote sensing response during periods of high flow but that vegetation responses had more significant impact on results in low flow periods, i.e., drier periods. Gao (1996) explored another vegetation index, which evaluates near-infrared NIR and mid-infrared MIR in the same equation: (NIR-MIR)/(NIR+MIR). Gao's technique has been deemed by researchers (Soti et al. 2009, Xu 2006) to be more effective in detecting vegetation liquid rather than open water. Zhang et al. (2013) and others (e.g., Gao 1996) state that the near-infrared indices are good predictors of surface moisture, especially vegetation water content, where vegetation cover is moderate to dense. They suggest that more sparsely vegetated or bare soil surfaces are better evaluated with bands other than near-infrared. Zhang et al. (2013) specifically 
analyzed the ability of these other bands, the moisture-sensitive SWIR bands (as used in the MNDWI index here), to delineate areas lacking in moisture.

Based on analysis of ratios for detecting open water and soil moisture, and studies regarding the responses of near-infrared vs. mid-infrared for these surface features, I chose to compare the Normalized Difference Water Index (NDWI) by McFeeters (1996) and the Modified Normalized Difference Water Index (MNDWI) proposed by Xu (2006).

Jensen (2005, p 275) analyzed remote sensing ratios and concluded that the "lower the correlation between the bands, the greater the information content of the band-ratioed image”. NDWI exemplifies the value of lower correlation between bands. Open water features generally have low reflectance in the both the visible red and near-infrared NIR frequencies (McFeeters 1996). In contrast, water has a higher light reflectance in the green spectrum (compared to red), resulting in a lower correlation with the NIR band. Based on this relationship, especially for maximizing estimates of liquid water content, McFeeters (1996) proposed the Normalized Difference Water Index (NDWI). The NDWI ratio is:

\section{Equation 1:}

$$
\text { NDWI }=[(\text { Green }- \text { NIR }) /(\text { Green }+ \text { NIR })]
$$

Green or visible green usually refers to a wavelength between $0.53-0.59$ micrometers while near-infrared or NIR wavelengths typically range from $0.85-0.88$ micrometers (USGS 2014a). 
MNDWI bands have even lower correlation than NDWI. Xu (2006) analyzed problems associated with NDWI detection of open water features in urban settings (high correlation) and proposed a modification to NDWI using the mid-infrared MIR bands (lower correlation) rather than the near-infrared band in the McFeeters (1996) equation. Xu's Modified NDWI is considered one of the most widely used water indices (Feyisa et al. 2014). In one study evaluating the Xu MNDWI, Ho et al. (2010) expanded Xu's findings, particularly for urban areas where reflections from urban features were correlated with the response from water features in both the green and near-infrared bands, causing errors in feature identification. Ho et al. demonstrated that responses in the mid-infrared or MIR showed greater distinctions (lower correlation) between reflectance values for urban features compared to moist soil and open water (Figure 2). Further studies describe how the MIR channels are sensitive to water content in both soil and vegetation, therefore providing value in identifying water features using ratio calculations (Zhang et al. 2013). The modified MNDWI ratio is:

Equation 2:

$$
\text { MNDWI }=[(\text { Green }- \text { MIR }) /(\text { Green }+ \text { MIR })]
$$

The MNDWI ratio uses green wavelengths, which range from $0.53-0.59$ micrometers, and mid-infrared MIR wavelengths, usually between 1.55-1.75 micrometers (USGS 2014a). 


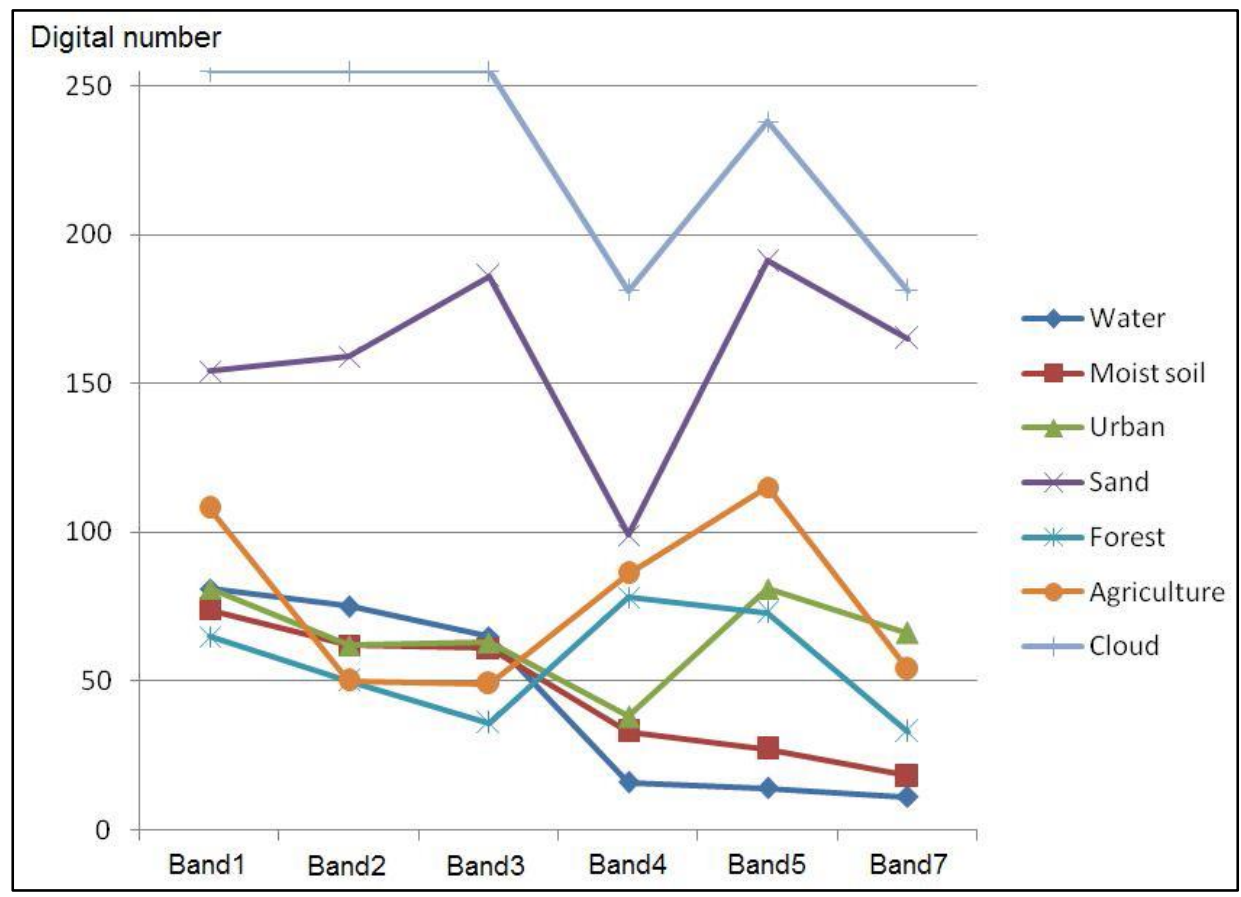

Figure 2. Spectral reflectance characteristics of land cover in a LANDSAT ETM+ image (Ho et al. 2010). Bands 2, 3, 4 and 5 in ETM+ images correspond to visible green, visible red, near infrared and mid infrared spectrums, respectively.

\subsection{Wetland Connectivity Characterization}

The U.S. government defines wetlands in Section 404 of the Clean Water Act as "those areas that are inundated or saturated by surface or ground water at a frequency and duration sufficient to support, and that under normal circumstances do support, a prevalence of vegetation typically adapted for life in saturated soil conditions" (Clean Water Section 404, 1988). The U.S. Army Corps of Engineers (USACE) and the U.S. Environmental Protection Agency (USEPA) use this definition when determining federal jurisdiction. Three characteristics are required for a federal wetland determination (USACE 2009). The first characteristic is vegetation, presence of hydrophytes or plants which thrive in wet conditions. The second characteristic of a 
wetland is soil, developed in conditions in which soil oxygen is limited by the presence of saturated soil for long periods during the growing season, also referred to as hydric soil. The third characteristic is hydrology, the presence of water at or above the soil surface for a sufficient period of the year to significantly influence the plant types and soils that occur in the area.

By definition then, water is crucial to wetland existence and function (Tiner 2010). Smith et al. (1995) defined function as "the normal or characteristic activities that take place in wetland ecosystems or simply the things that wetlands do" whereas an ecosystem is defined as "a dynamic complex of plant, animal, and microorganism communities and the nonliving environment interacting as a functional unit” (MEA 2005). Wetland functions related to hydrologic processes include short- and long-term storage of sub- and surface water, moderation of groundwater flow / discharge and dissipation of energy. Along with chemical and biologic processes, physical processes such as hydrology will influence wetland plants, animals, soil, climate, the flow of air and water and nutrients, etc. Therefore, it is important to determine where, when and how much water is available, as well as whether the wetland is connected to other water features in the landscape (Arnold et al. 2001, USEPA 2015).

Connectivity is a "central tenet of stream hydrology and ecology", one of many conclusions in a recent scientific report by the U.S. Environmental Protection Agency (USEPA), "Connectivity of Streams and Wetlands to Downstream Waters: A Review and Synthesis of the Scientific Evidence” or Connectivity Report (USEPA 2015). Over 1,350 references are summarized, about $86 \%$ of them peer-reviewed articles, which describe the "current scientific understanding about the connectivity and mechanisms by which streams 
and wetlands, singly or in aggregate, affect the physical, chemical, and biological integrity of downstream waters" (USEPA 2015, ES-1).

What is connectivity? The definition of connectivity has evolved over time, with roots in the study of landscape ecology. Connectivity is often defined in terms of landscape linkages and corridors, patterns and flows of wind, water, materials and biota between habitats (Forman 1995, Merriam 1984, Wiens 1995). Bennett (1998) summarizes this linkage as the "continuity of ecological processes through the landscape". Note that the term landscape does not have an exact spatial description but rather, is defined as "a set of patches (areas with similar structure or composition) whose spatial extent is defined by the organism or process of interest" (Wiens 1989). Ward (1989) contributed to the landscape view of hydrologic connectivity, proposing a four-dimensional framework for upstreamdownstream interactions: 1) temporal, 2) longitudinal, along the downhill path of a waterway, 3) lateral, across riparian and floodplain areas and 4) vertical, riverine-groundwater interactions. Ward relies on work by Hynes (1975) who studied waterways and landscapes, especially their catchment area. Ward also builds on the River Continuum Concept outlined by Vannote et al. (1980), who describe a longitudinal “energy equilibrium” in river systems. Stanford and Ward (1993) emphasized the "holistic perspective of rivers", of riverine connectivity, and suggested the need for thorough understanding of the connectivity between ecosystem components.

Connectivity became a more hotly debated topic after a series of cases decided by the U.S. Supreme Court, all of which sought to clarify U.S. jurisdiction over surface waters (including wetlands) and regulatory requirements under the Clean Water Act (1972). In 1985, United States v. Riverside Bayview Homes (Riverside 1985) established that that CWA 
authority "extended to wetlands located adjacent" to navigable [jurisdictional]) waters. Later, in 2001, Solid Waste Agency of Northern Cook County v U.S. Army Corps of Engineers 2001 (SWANCC 2001) the Court ruled to exclude adjacent wetlands from CWA jurisdiction if the distinction was based solely on use by migratory birds. And in a divided opinion in 2006, in Rapanos v. United States 2006 (Rapanos 2006), the Court explained that a "significant nexus" to navigable (jurisdictional) waters was required to indicate CWA authority. What followed was confusion and opposition, including an EPA technical guidance document being withdrawn after public opposition in 2011 (Wenning 2014).

Wetland research after 2001 often reflects the broader post-Rapanos definition of landscape connectivity, sometimes referring to an isolation-continuum, and sometimes commenting on the 2001 and 2006 U.S. Supreme Court decisions directly. Less direct references include Amoros \& Bornette (2002), who outlined the role of hydrologic connectivity in "riverscapes", describing how "all floodplain waterbodies are more or less connected through surface or subsurface waterways to the river, alluvial aquifer or hillslope aquifer". Ward et al. (2002) expanded on his earlier four-dimensional framework, describing an array of landscape elements which influence river connectivity including surface water, aquifers, riparian systems and geomorphic features, using an earlier definition of hydrological connectivity by Amoros and Roux (1988), "the exchange of matter, energy and biota between different elements of the riverine landscape via the aqueous medium". Pringle (2001, 2003) also expands the spatial extent for studies of aquatic (wetland) function beyond the immediate water features to include the "hydroscape" or landscape juxtaposition with respect to water bodies, aquifers, wind and precipitation patterns and climate. More direct references to the court cases include Leibowitz (2003), who detailed the profound impact 
that the SWANCC decision (2001) had on isolated wetlands in particular. In a later study by Leibowitz and Nadeau (2003), the authors noted that "the manner in which wetlands interact in the isolation-connectivity continuum plays a significant role in the study of wetland function", a sentiment repeated again by Freeman et al. (2007).

Efforts to inform rulemaking on the definition of "waters of the United States" motivated development of the Connectivity Report (USEPA 2015), which synthesizes decades of research on the landscape effects of streams and wetlands. The review concluded that wetlands are physically, chemically, and biologically integrated with rivers either directly (riparian wetlands) or in a gradient of connectivity (non-riparian wetlands). It also concluded that river networks are integrated at multiple spatial and temporal scales by flows of surface water and ground water, transport and transformation of physical and chemical materials, and movements of organisms; that water movement is the primary physical mechanism providing physical connectivity between a river and elements of the surrounding landscape, such as wetlands; and that all parts of a watershed are connected to some degree (USEPA 2015). The EPA Connectivity Report summarizes the scientific research, defining connectivity as "the degree to which components of a river system are joined, or connected, by various transport mechanisms" (USEPA 2015, A-2). These connectivity mechanisms might be chemical, biological, or physical (such as hydrologic). Variations in the degree of connectivity influence the range of functions provided by wetlands and streams as determined by the presence of 1) pathways that enable (or inhibit) the transport of materials or organisms or 2) functions within the features that alter the quality or quantity of materials or organisms transported along the pathways. 
In spite of the importance of hydrologic connectivity, it is extremely difficult to quantify. The U.S. Supreme Court cases highlighted the need for interpretation of the concept and for measures to demonstrate connectivity. Unfortunately, as Ward et al. (2002) pointed out, “...connectivity has not been afforded the attention it deserves". Later, Wenning (2014) echoed this point, emphasizing that "The scientific community has struggled to develop a single, well-accepted definition of 'connectivity' that spans the varying spatial scales associated with watersheds and wetland landscapes." The EPA's Connectivity Report elaborated, stating that “...connectivity cannot be established without specific information on frequency and magnitude of precipitation events, soil infiltration rate, wetland storage capacity, hydraulic gradients, etc.-information that is only rarely available in publications" (USEPA 2015, 4-41). Further, the Connectivity Report concluded that "...there is no consensus on the best methods or metrics to quantify or predict hydrologic or chemical connectivity" (USEPA 2015, 2-50). After issuing the Connectivity Report, the U.S. EPA issued the Clean Water Rule (2015), effective August 2015, which was directed at modifying the legal definition of connectivity based on the scientific research presented in the Connectivity Report. The Clean Water Rule did attempt to quantify certain characteristics of connectivity. For example, adjacent waters / wetlands are defined as “...waters adjacent to jurisdictional waters within a minimum of 100 feet and within the 100 -year floodplain to a maximum of 1,500 feet of the ordinary high water mark." The more difficult to define isolated or "other" waters include "... specific waters that are similarly situated: [e.g., prairie pothole] "... when they have a significant nexus" and also includes "... waters with a significant nexus within the 100 -year floodplain of a traditional navigable water, interstate water, or the territorial seas, as well as waters with a significant nexus within 4,000 feet of 
jurisdictional waters.” (Clean Water Rule 2015). It is unclear what impact this ruling will have on environmental activities; however, lawsuits were anticipated as soon as the proposed rule was open for public comment, long before the ruling was finalized (Wenning 2014).

A natural, complicating factor in the study of hydrologic connectivity is that wetland function is heavily influenced by the hydroperiod, the length of time a wetland might be seasonally flooded (Sonenshein 1996, Tiner 1999). Hydroperiod varies season to season and year to year. Ward (1989) described the temporal variations in lotic (river) systems but also the high degree of spatio-temporal heterogeneity. Jencso et al. (2009) emphasized the importance of spatiotemporal dimensions in determining flow path continuity, especially when comparing wet and dry periods. This temporal component has multiple facets, e.g., intermittent surface-water connections (Stanford and Ward 1993), recurrence frequency (Leibowitz and Vining 2003), timing of hydrologic inputs such as groundwater travel time (Winter and LaBaugh 2003) and hydrological permanence (Fritz et al. 2006, Leibowitz et al. 2008). Although hydroperiod is considered a major factor in estimating wetland delineation and function, hydrologic data for wetland areas are often sparse or nonexistent, and as a result, hydroperiods are rarely known with a high degree of certainty (Mitsch and Gosselink 2007). Therefore, in addition to hydrologic connectivity, which is determined by the presence of water as a transport mechanism (USEPA 2015, 1-4), this study addresses the duration or length of time a wetland is hydrologically coupled by surface flows to nearby water features. Leibowitz et al. (2008) defined this bydrological permanence as the "maximum duration (days) of continuous surface or hyporheic connection between an adjacent wetland and a [jurisdictional] stream". Hydrological permanence can be grouped into three categories (USEPA 2015, 2-14, also Fritz et al. 2006) as: 1) perennial, flow areas which 
"maintain continuous surface flow throughout most years", 2) intermittent, those that "dry seasonally", and 3) ephemeral (or episodic) flows which are "usually dry except for several days immediately following precipitation". For this study, a fourth category was added, 4) none, which indicates that flows are not evident at any time during the year.

Another challenge for studying hydrologic connectivity is the sheer number of wetlands and their environments. For example, in Oregon alone, the statewide wetland database contains approximately 183,000 individual wetland polygons which have been categorized (Christy \& Bauer 2012). As emphasized by Leibowitz et al. (2008), it is impractical to evaluate non-navigable streams and adjacent wetlands individually.

Studies of wetland hydrology often rely on wetland type as a significant determinant of wetland function and as a method for describing wetland behavior. In 1979, Cowardin et al. proposed a hierarchical structure for classification of wetlands based on a series of systems, subsystems and classes. The main delineation or systems are marine, estuarine, lacustrine, riverine and palustrine. The Cowardin system was designed to assist with wetland inventory efforts and to provide consistent terminology and definition (Cowardin and Golet 1995) and is now considered the official classification method and federal standard used by the U.S. Fish \& Wildlife Service for the National Wetland Inventory or NWI (USFWS 2014). Brinson (1993) proposed an alternate method, the hydrogeomorphic classification system for wetlands or HGM, based on geomorphology, water source and hydrodynamics. In Oregon, the Oregon Rapid Wetland Assessment Protocol (ORWAP) was developed by the Oregon Department of State Lands (ODSL) and the USEPA as a "standardized protocol for rapidly assessing the functions and values of wetlands" (Adamus et al. 2010). Like many wetland classification efforts, ORWAP emphasizes wetland type as a significant determinant of 
wetland function, based on a modified version of Brinson's HGM classification system. Per the ODSL classification (Christie and Bauer 2012), Oregon wetlands are predominantly palustrine wetlands $(71 \%)$. Further evaluation shows that Oregon's wetlands occur in all five high-level systems according to the Cowardin et al. (1979) classification schema. Although widely used, common criticisms of the Cowardin and Brinson systems include the fact that spatial delineations do not coincide (Lang et al. 2012) and there is a lack of interchangeability between the two systems, especially for hydrogeomorphic characteristics (Tiner 2003, 2010). Tiner proposed a set of keys or attributes known as LLWW for landscape position, landform, water flow path, and waterbody type (Tiner 2003). Tiner proposed use of LLWW to "facilitate predicting wetland functions" for the National Wetland Inventory Plus (NWI Plus), an update to the NWI (Tiner, 2010, USFWS 2010). It is no surprise that the Connectivity Report (USEPA 2015) cites limited research when concluding that “...current science does not support evaluations of the degree of connectivity for specific groups or classes of wetlands" (USEPA 2015, 6-5). Based on this conclusion and the challenges in classifying wetlands by type, this research does not rely on wetland type for classifying wetland hydrology or connectivity.

A variety of studies suggest methods for modeling hydrologic flows at larger and larger scales, i.e., beyond the water body being studied. Indeed, studies describe a wide array of "hydroscapes" (Pringle 2001, 2003) which influence river interaction and connectivity, and the parameters which determine the extent of those hydroscapes: surface water, aquifers, riparian systems and geomorphic features (Ward et al. 2002); landform and landscape position (Tiner 2003), slope (Western et al. 1999); surface- and ground-water interactions (Freeman et al. 2007); flow path continuity between uplands, riparian zones, and 
stream channels (Jencso et al. 2009) and connectivity metrics from surface soil moisture measurements (Western et al. 2001). At the regional scale, Winter (2001) proposed the concept of "hydrologic landscape units", which Wolock et al. (2004) used to develop specific hydrologic landscape regions based on land-surface forms, geologic texture and climate characteristics. Based in part on Wolock's concept of hydrologic landscape regions, Wigington et al. (2013) proposed a landscape classification system at a river-cluster scale based on indices of annual climate, climate seasonality, aquifer permeability, terrain, and soil permeability. Wigington's system was described and mapped for the entire State of Oregon.

This research builds on the concept of landscape-scale analysis, in particular the connectivity of wetlands and nearby water features. Whatever the method, Leibowitz et al. (2008) emphasized that "any approach for evaluating hydrological permanence..., must be inexpensive and easily applied, with minimal data collection." 


\section{Study Area and Data}

Several wetland areas were selected for research and demonstration, all of which lie in the Tualatin River National Wildlife Refuge (TRNWR or the Refuge) near Sherwood, Oregon (Figure 3). Most data were acquired from publically-available sources with the exception of soil samples collected on site, as described in Chapter 4.

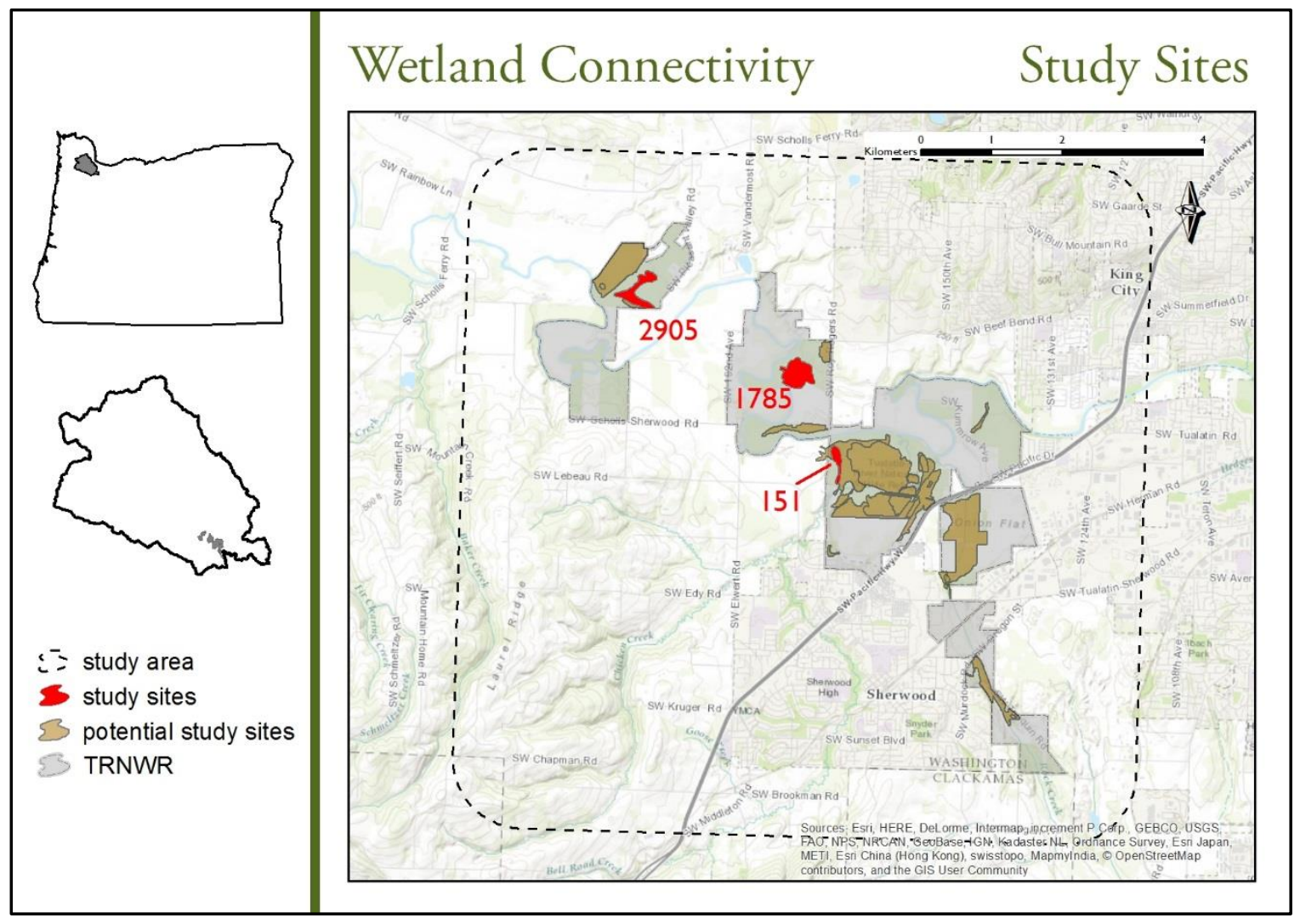

Figure 3. Study Sites in the Tualatin River National Wildlife Refuge.

\subsection{Tualatin River National Wildlife Refuge}

The Tualatin River National Wildlife Refuge (TRNWR or "the Refuge") is located in the southeastern portion of the Tualatin River subbasin, near Sherwood, Oregon. The Tualatin River subbasin consists of 712 square miles in northwest Oregon in the northern 
portion of the Willamette River basin (TRWC 2015). Most of the watershed is located in Washington County, where land use is a mix of $20 \%$ urban, $30 \%$ agriculture and $50 \%$ forestry. Population centers are denser in the valleys and in southeastern areas where approximately 500,000 people live in cities (TRWC 2015) including southwest portions of Portland and the nearby cities of Beaverton, Hillsboro, and Tigard. Land cover distribution is shown in Figure 4. Mountains ring the subbasin on the west (Coast Range), to the north (Tualatin Mountains) and along the south (Chehalem Mountains), with drainage patterns generally from the west to the south-southeast into the Tualatin River and eventually to the Willamette River in the southeastern portion of the subbasin (Figure 5). The subbasin's elevation range is approximately $600 \mathrm{~m}$ with very little elevation change in the lower reaches. The Tualatin River Watershed Council (2015) estimates that mean air temperatures in the valley floor in the winter range from $32^{\circ} \mathrm{F}$ to $63^{\circ} \mathrm{F}\left(0^{\circ} \mathrm{C}\right.$ to $\left.17^{\circ} \mathrm{C}\right)$; and in the summer from $41^{\circ} \mathrm{F}$ to $83^{\circ} \mathrm{F}\left(5^{\circ} \mathrm{C}\right.$ to $\left.28^{\circ} \mathrm{C}\right)$. The subbasin area experiences a Mediterranean climate with prolonged winter rainfall and summer drought, characterized by Wigington et al. (2013) as "wet" using the Feddema Average Annual Moisture Index. Westerly wind patterns from the Pacific Ocean help moderate temperatures year-round and provide moisture-laden air to the area which, along with low elevations, contributes to low snowfall averages (Wigington et al. 2013). As for rainfall, data of average annual precipitation from PRISM (Parameterelevation Relationships on Independent Slopes Model) over the 30-year period from 19812010 show values of 96-255mm (37.8-100.2 inches) across the watershed (PRISM n.d., Figure 6). Data more specific to the study area is available at multiple weather stations (Figure 7). Daily precipitation data is available from CoCoRaHS, the Community Collaborative Rain Hail \& Snow Network, for two weather stations which are each less than 
two (2) miles from the study area, specifically at station US1ORWS0060 Beaverton 5.6 SSW and station US1ORWS0096 Sherwood 2.0 NW (NOAA 2015, 2016). Extensive historical climate summaries are available at nearby Stations Beaverton 350595 and Newberg 357127 , which are part of the Global Historical Climatology Network (GHCN). Based on data at these GHCN sites (Menne et al. 2012), annual precipitation near the study area is approximately 100-109mm or about 40 inches (Figure 8). The months of July, August and September have historically experienced the lowest precipitation in the area, i.e., dry period, while the months of November, December and January represent the season of highest precipitation, i.e., wet period. 


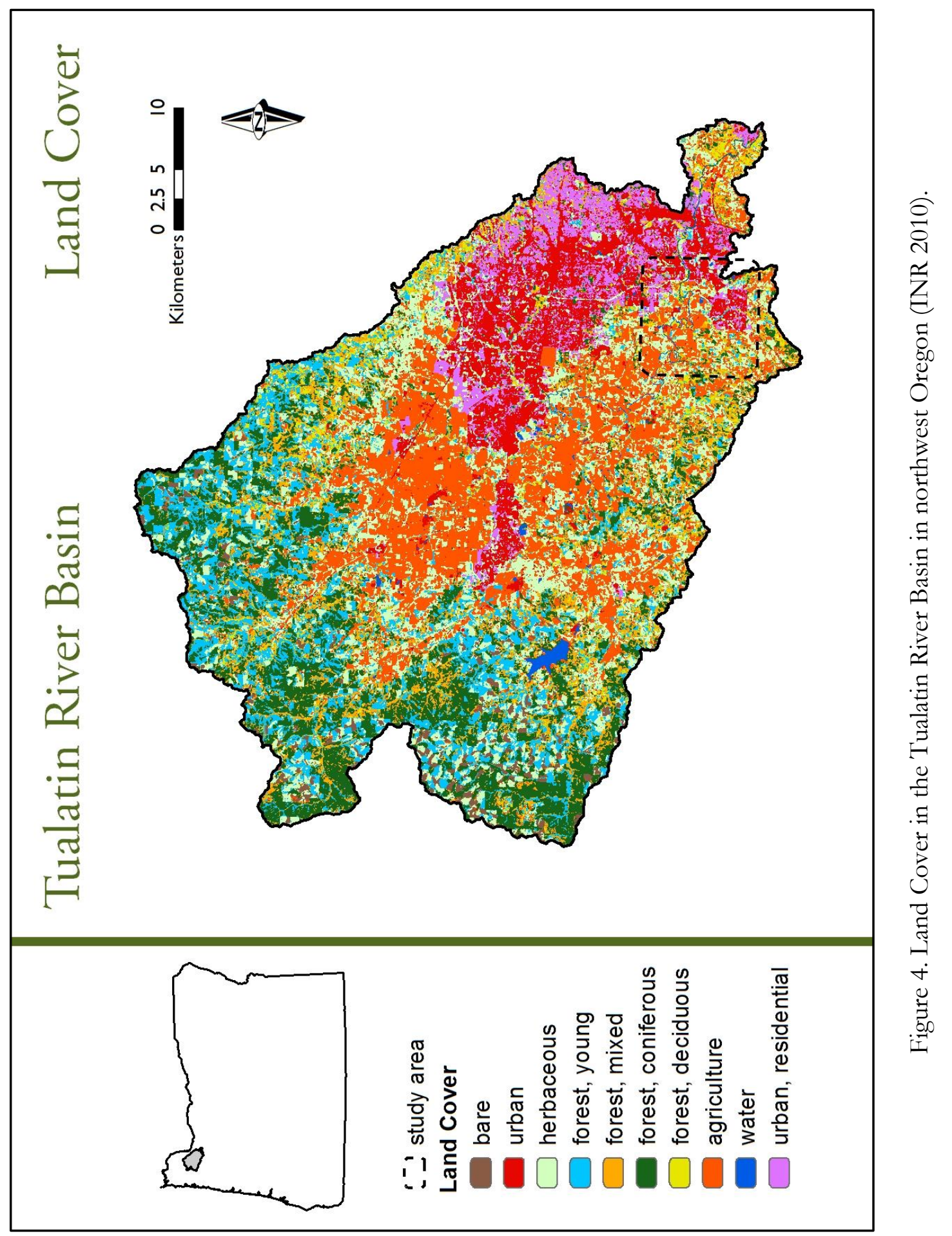




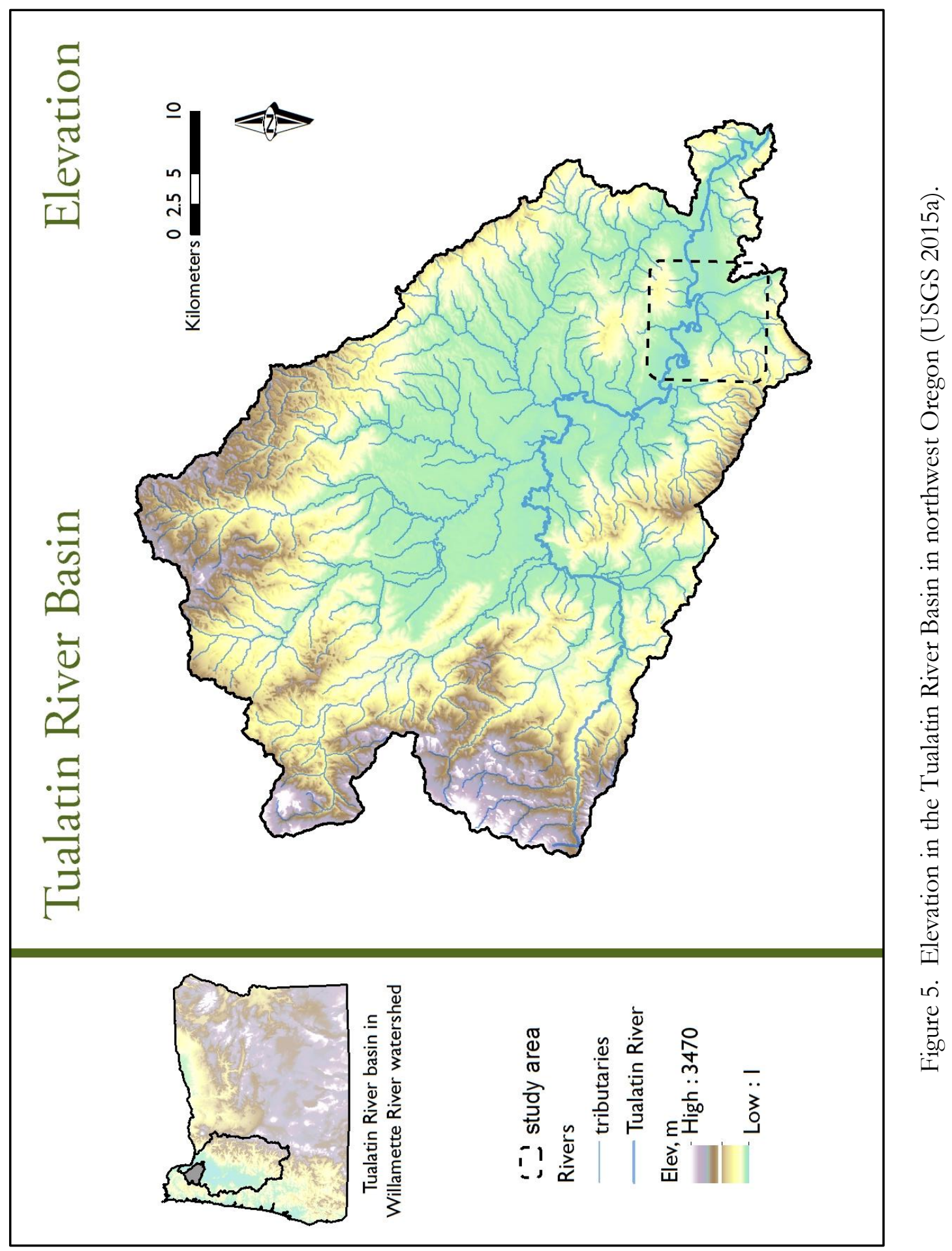




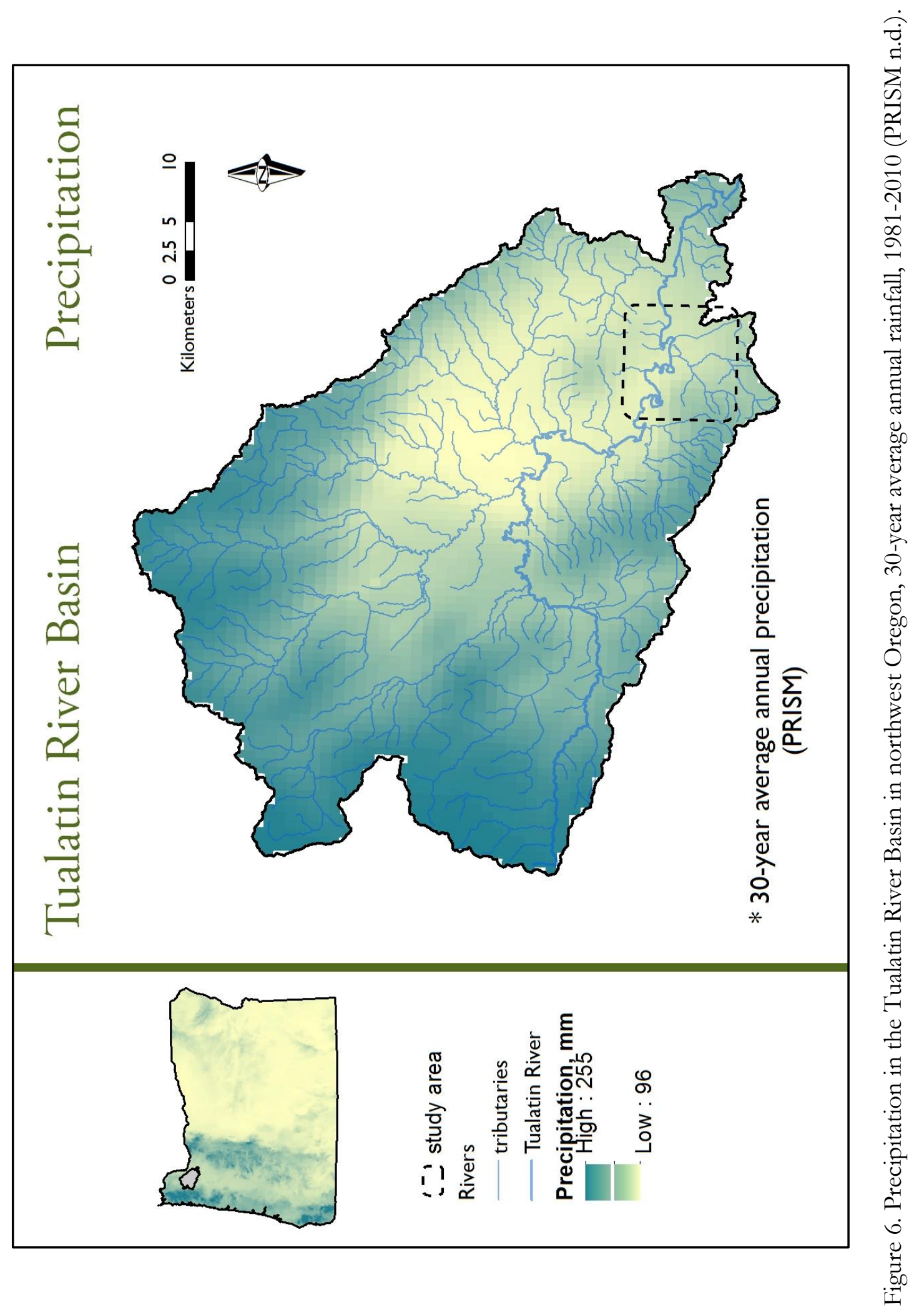




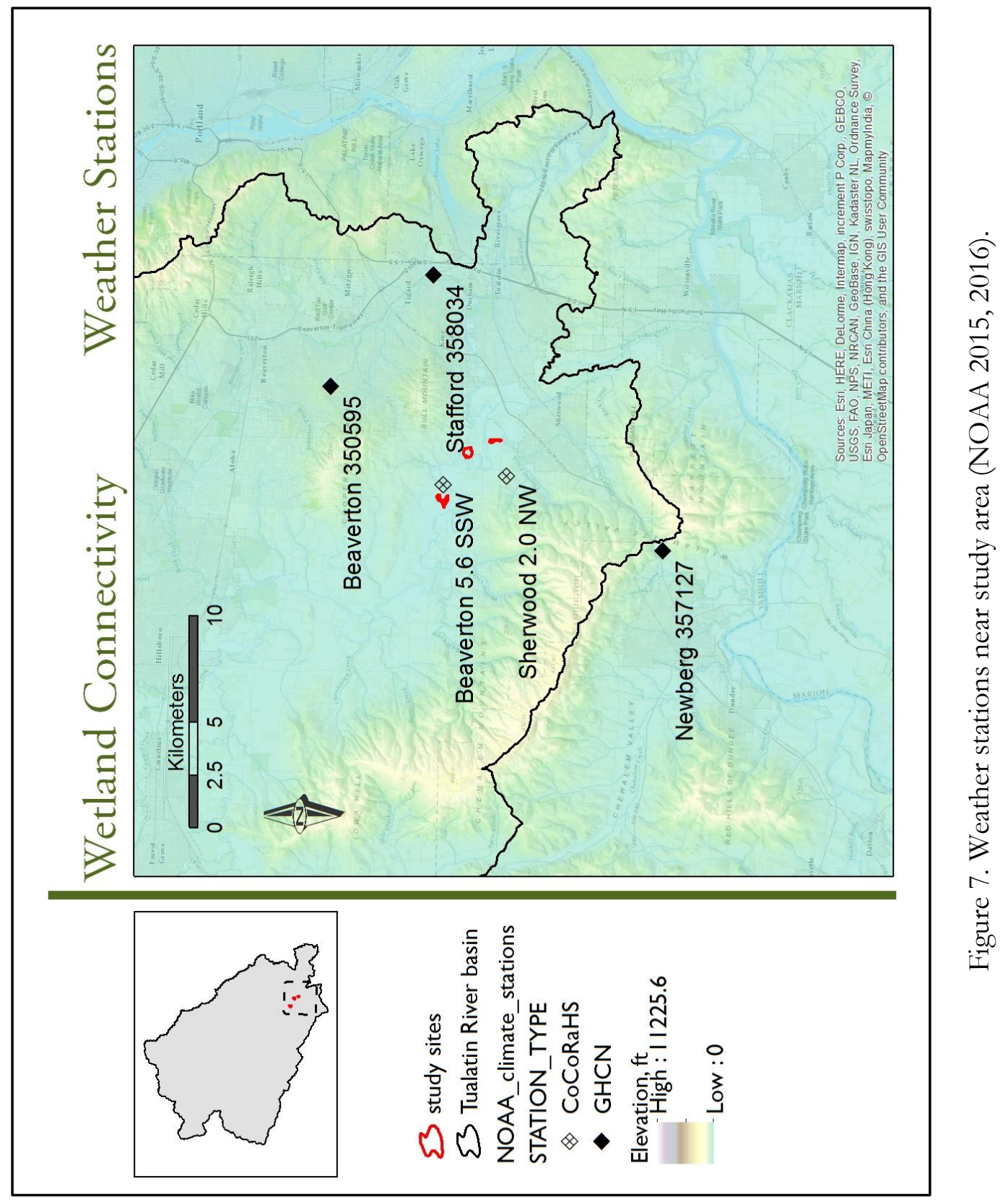




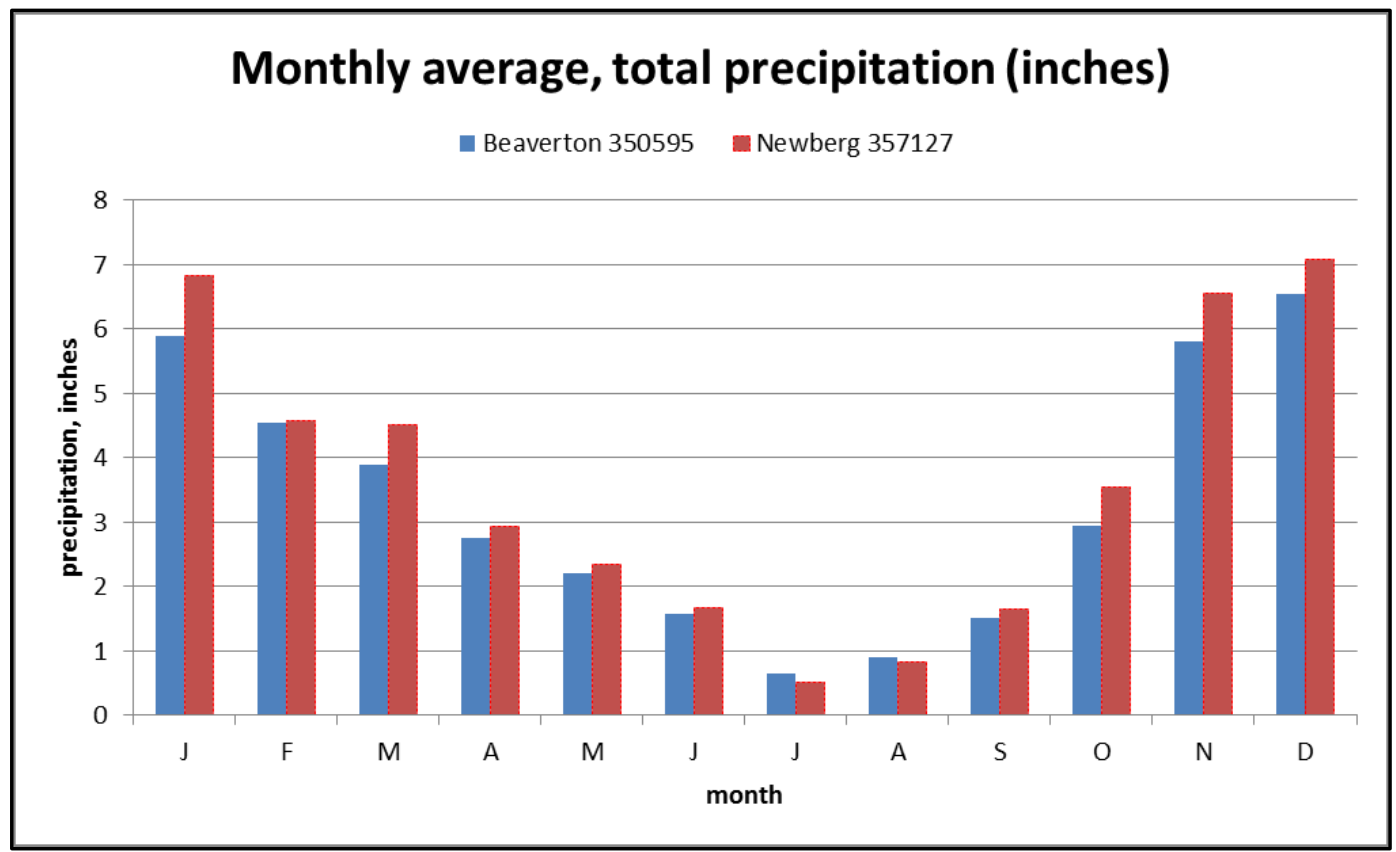

Figure 8. Monthly average precipitation near study area, in inches, at Global Historical Climatology Network (GHNC) weather stations (Menne et al. 2012, WRCC 2016).

The study area is contained within the Refuge, which lies in the relatively flat, lower reaches of the Tualatin River approximately sixteen (16) river miles upstream from the confluence with the Willamette River (Tualatin Riverkeepers 2007). The Tualatin River meanders through the Refuge, flowing generally from west to east. Topography in the Refuge is predominantly flat bottomland bordered by uplands, characterized by rivers and streams, wetlands, riparian woodlands, grasslands and forested uplands (USFWS 2013). Based on ArcMap analysis of digital elevation data within the Refuge boundaries, average elevation is 134 feet, ranging from a minimum 102 feet to a maximum of 305 feet, with a standard deviation of only 30 feet. Mountains shelter the Refuge to some degree. To the west and south of the Refuge are the Chehalem Mountains, which form part of the Southern border of the Tualatin subbasin and contain the highest point in the Willamette Valley, Bald 
Peak at 1,629 feet. A few miles to the north of the Refuge is Bull Mountain with a summit at 710 feet in elevation and slightly further north-northwest is Cooper Mountain at 774 feet high.

The Refuge is managed by the U.S. Fish \& Wildlife Service (USFWS). TRNWR lies in the Pacific Flyway and provides high-quality habitat for waterfowl during migration and beyond, especially in fall and winter when water features are flooded (USFWS 2016). Nearly 200 species of birds, over 50 species of mammals, 25 species of reptiles and amphibians and a wide variety of insects, fish and plants have been identified on-site, some of which take advantage of wetland environments to nest, breed, hunt, etc. USFWS management goals for the refuge include protection and restoration of habitats and populations of targeted fauna; providing high-quality opportunities for recreation and environmental education to enhance public appreciation, understanding and enjoyment of refuge resources; and protection and restoration of floodplains (USFWS 2013).

Established in 1992, TRNWR is one of a handful of urban national wildlife refuges in the country. The Refuge is near the town of Sherwood, Oregon, about 20 miles southwest of downtown Portland, Oregon. About 3,000 acres ( 4.8 square miles $)$ are "protected with resource use" (such as agricultural) or "protected as natural area". Based on GIS analysis, land use / land cover within the Refuge boundaries is approximately $60 \%$ pasture or crops, $20 \%$ wetlands, about $10 \%$ developed and $10 \%$ other (Homer et al. 2015, USGS 2014b). 


\subsection{Wetland Selection Criteria}

Two overriding factors influenced the selection of wetlands for this study. First, the work would require ground-truthing at the study sites. Second, the field study period would be relatively short, about one year. Therefore, preference was given to potential sites based on 1) proximity to Portland, allowing for short driving distances to the study sites to collect soil samples, 2) proximity of study sites to one another, close enough that sites should experience similar weather patterns and also so that soil samples can be gathered in a single day by a single researcher, 3) public access or public management of the area to increase the likelihood of obtaining permission for on-site research in an expedient manner, 4) availability of hydrologic studies of the area, which provided background for understanding the hydrology and climate of selected study site environments (e.g., Chang 2007, Hoyer and Chang 2014, Najafi et al. 2011), and 5) site-specific considerations described below.

To begin, an ArcMap analysis was performed of wetlands in the Tualatin River subbasin, which resulted in approximately 360 wetland polygons with "public access or management" (attribute MGMT=1 "protected with resource use" or attribute MGMT = 2 "protected as natural area"). A cluster of twenty-nine (29) wetlands was identified in the southeastern portion of the subbasin within the boundaries of the Refuge. After discussions with a Wildlife Biologist at TRNWR, a Special Use Permit for on-site research was negotiated (Appendix A). The Biologist helped finalize the site selection parameters, which included 1) clear accessibility by car and/or on foot, 2) limited distance to nearby river feature, under 100 feet preferred to match the definitions in the 2015 Clean Water Rule and to limit the number of sampling sites, 3) size, with a desire to evaluate similarly sized wetlands, and 4) limited overhead tree canopy to maximize visibility in satellite imagery. 
Based on the criteria described above, three (3) final locations were chosen, identified in the geodatabase extract with ID numbers 151, 1785 and 2905. Two of these wetlands (151 and 1785) were chosen to validate the approach and quantification methods. Both were expected to be wet, pooled or "connected" for much of the study period, based on field observations, discussions with the on-site biologist and comparisons of satellite imagery from wet and dry periods, e.g., January 2015 and July 2015 (Figure 9). To demonstrate the method, one additional wetland (2905) was selected which was expected to be dry, not pooled and "not connected" during the study period, using the same criteria.

Land use near the study sites reflects the overall land use within the Refuge, i.e., mostly pasture and crops (or land which is being or has been converted from these uses) with some wetlands and some limited development (Figure 10). All three study sites are situated on or near land which is classified as pasture/hay or cultivated crop, which result in man-made surfaces and soils. Additional man-made changes are implemented seasonally for management of the Refuge, including placement of flood up gates or barriers at the outflows of selected water features. Blocking outflows causes the wetlands and lowlands to fill and pool during the wet season, which helps to maximize aquatic habitat for wildlife, especially migrating birds. Land use and Refuge management practices alter the natural surface runoff patterns. However, these alterations were not expected to interfere with this research, since the focus is identifying the location of surface water without emphasis on the reason for the spatial or temporal distribution of the water. 


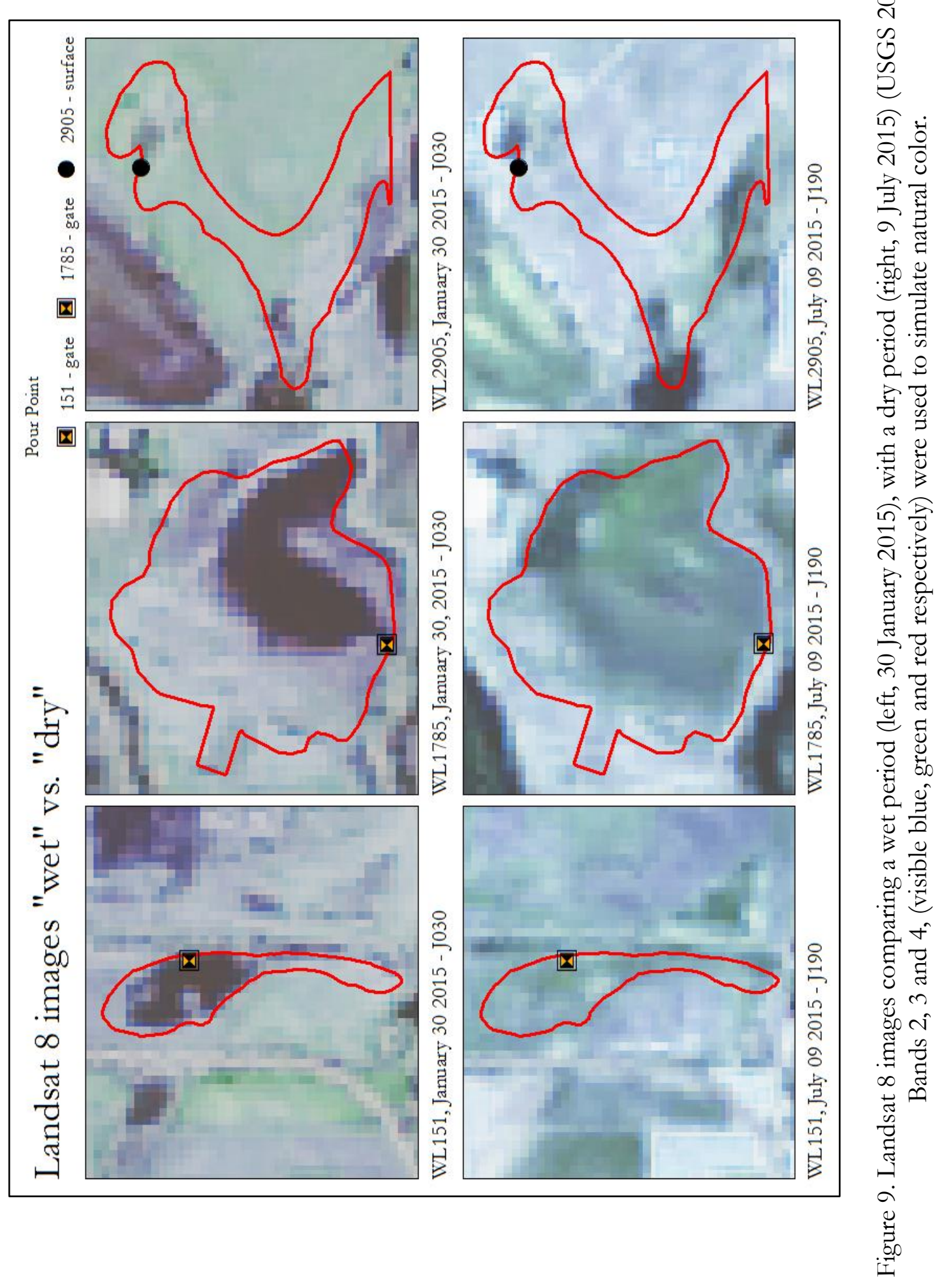




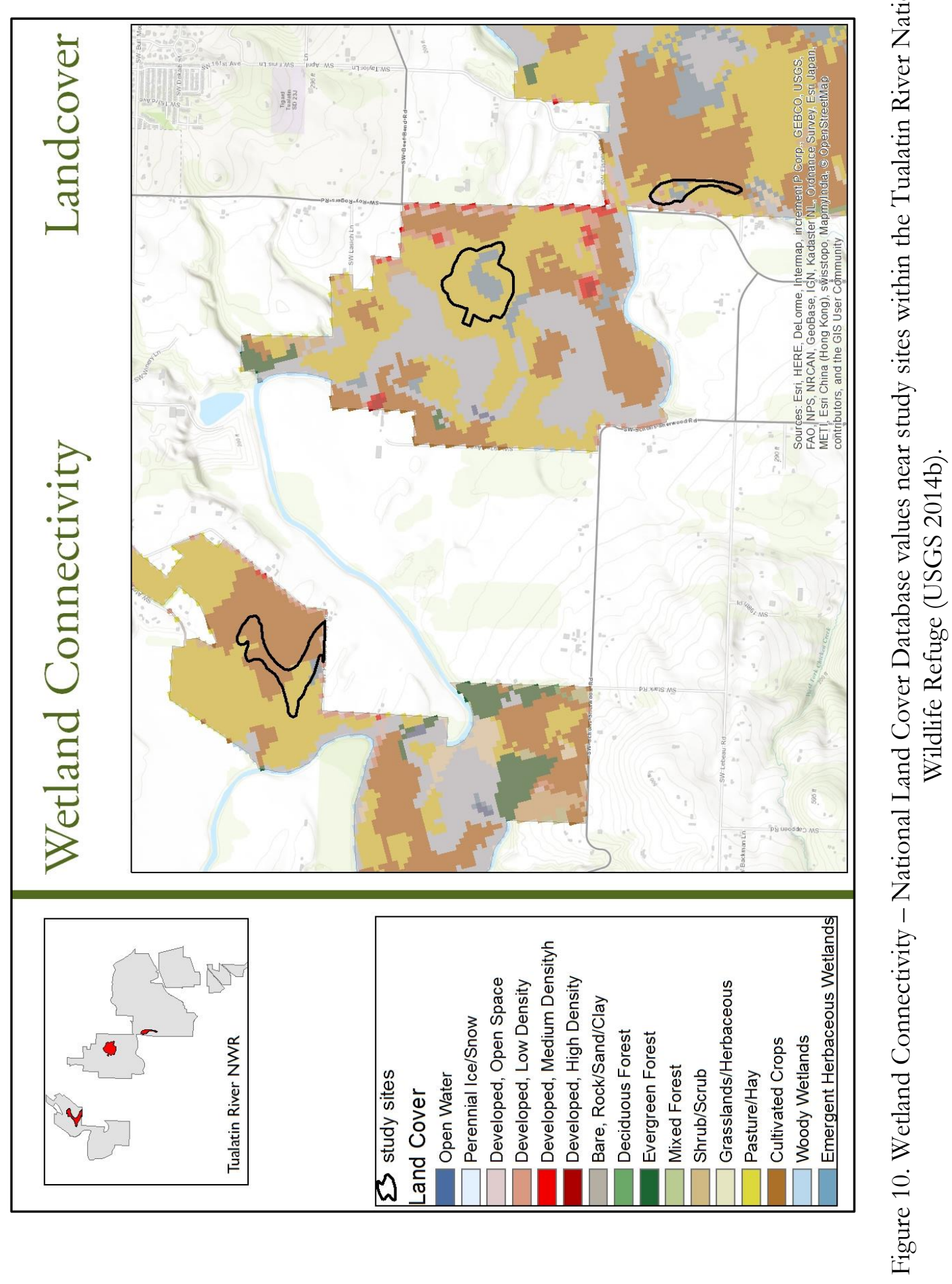




\subsection{Data and Software}

Data sources are shown in Table 1.

Wetland data and modified HUC8 subbasin boundaries were produced as part of the Wetland Prioritization Project in collaboration with the Institute for Natural Resources (INR-PSU 2013, Kagan et al. 2013) and The Wetlands Conservancy (2013a and 2013b). Oregon wetlands were organized into wetland complexes based partially on their proximity, i.e., wetlands within one hundred (100) meters of one another were combined into unique wetland complexes (Christy and Bauer 2012). Approximately 118,000 wetland complexes were created using this aggregation method. The wetland complex and HUC8 polygons were used in my research as-is, without modification.

Table 1. Data Sources

\begin{tabular}{|r|c|c|}
\hline Category & Source & Scale \\
\hline Wetland & TWC 2013a & to 0.008 acres (31 sq meters) \\
HUC8 (modified) & TWC 2013b & misc \\
\hline $\begin{array}{r}\text { Landscape } \\
\text { Tualatin River NWR boundaries }\end{array}$ & USFWS 2015 & misc \\
\hline DEM (3-meter) & USGS, Gesch et al. 2009 & 3-meter \\
Land Cover & USGS, Homer et al. 2015 & 30-meter \\
\hline Streams, Rivers & USGS / NHD 2013 & 1:24,000-1:100,000 \\
\hline Weather (precipitation) & NOAA 2015, 2016; Menne et & 30-year averages and daily \\
Imagery & ESRI et al., Google Maps & totals \\
\hline Latellite Imagery & misc \\
\hline Landsat 8 OLI & USGS 2015-2016 & 30-meter \\
\hline
\end{tabular}

Landscape data was acquired from publically-available sources: Refuge boundaries (cadastral data) from the U.S. Fish \& Wildlife Service (USFWS 2015); several categories of data from the U.S. Geological Services (USGS) including digital elevation model DEM files 
with a surface resolution of 3-meters (Gesch et al. 2009, USGS 2015a); land cover data (Homer et al. 2015, USGS 2014b); and stream and river features from the National Hydrography Geodatabase (USGS 2013). Weather data for stations near the study sites was provided by the National Oceanic and Atmospheric Administration (NOAA), specifically the 30-year average precipitation and daily precipitation totals for weather station US1ORWS0096 for selected dates in 2015 and 2016 (Menne et al. 2012; NOAA 2015, 2016). A few background images were provided in the World Imagery option of the Basemap feature in ESRI's ArcMap software (ESRI 2013) and via Google Maps for the area in and around the Refuge (Google Maps n.d.).

Satellite imagery for this study are the multispectral images from the Operational Land Imager (OLI) sensors on Landsat 8 (USGS 2015b), specifically in the visible green (Band 3, 0.53 - 0.59 micrometers), near-infrared (Band 5, 0.85-0.88 micrometers) and shortwave-infrared spectrum (Band 6, 1.57-1.65 micrometers, a.k.a. SWIR 1) used to calculate indices for NDWI and MNDWI (USGS 2014a). Note: The range of SWIR 1 on Landsat 8 is similar to the range of mid-infrared or MIR on Landsat 7, i.e., Band 5, 1.55-1.75 micrometers.

In addition, primary field observations and soil samples were collected for this study to estimate surface moisture content, as described in Chapter 4.

Geospatial analysis and mapping was performed in ESRI's ArcMap 10.2 (2013), especially tools provided in the Spatial Analyst extension. The least cost path was determined with Python 2.7.5 (Python Software Foundation 2013). Statistical analysis was performed using IBM’s SPSS ${ }$, Version 23 (2012) with additional calculations completed using Microsoft Excel® (2010). 


\section{Methods}

\subsection{Approach}

Although the main research goal is to investigate remote sensing in quantifying soil moisture, the research design was guided by the applications of remote sensing in wetland connectivity characterization.

This study estimates surface moisture between wetlands and adjacent water bodies, measured at a landscape scale, using indices generated from remote sensing imagery; then compares the results to soil samples taken in the field. To demonstrate the technique, wetlands are characterized by their hydrologic connectivity into categories of hydrological permanence. Evaluation occurred in five steps (Figure 11). First, in order to determine the location of soil sample sites, a flow path was identified between a wetland and the closest water body. Second, surface moisture was estimated based on satellite images collected during the study period. Water indices were calculated in ArcMap, i.e., the Normalized Difference Water Index (NDWI - Equation 1) and the Modified Normalized Difference Water Index (MNDWI - Equation 2). The third step was to collect soil samples in the flow path on dates coinciding with satellite image capture, and then to analyze each sample for water content. The fourth step was to validate the ability of remote sensing water indices to predict the location of surface moisture compared to the water content estimated using soil samples from the field. The fifth and final step was to demonstrate the use of water indices in a wetland environment, specifically to estimate hydrologic connectivity and hydrological permanence.

Methods are informed by research and metrics described in Chapter 2, e.g., use of topology and landscape position in determining flow path; use of remote sensing to predict 
surface moisture; specifically the Normalized Difference Water Index (NDWI - Equation 1) and the Modified Normalized Difference Water Index (MNDWI - Equation 2); the comparison of representative wet and dry periods; validation of the indices compared to the soil samples; and classification for water index values using threshold values suggested by insitu soil surveys. 


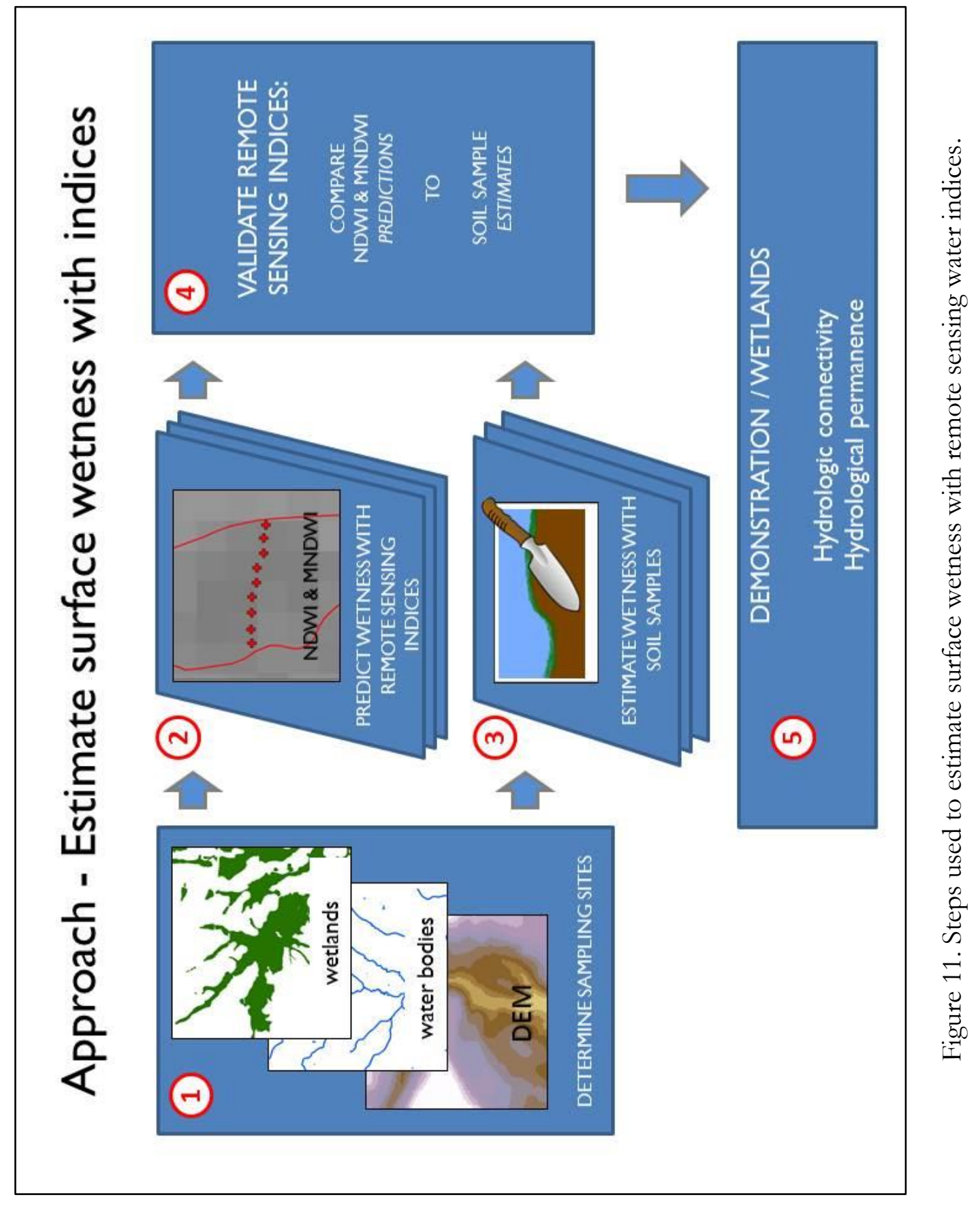




\subsection{Evaluate the Indices}

\section{Step 1 - Determine sampling sites}

The goal of step 1 was to identify locations for sampling sites at each wetland by estimating a flow path between each wetland and the nearest water body (also used to identify the location for analysis of remote sensing imagery).

Topology is a key factor in predicting hydrologic response and connectivity (e.g., Jencso et al. 2009). Topology can be represented by a digital elevation model (DEM), a height-map representation of the terrain's surface. For this study, elevation data from the USGS was used for topology analysis, specifically raster files with 3-meter resolution or 1/9arc-second resolution (Gesch et al. 2009, USGS 2015a). The flow path was estimated as follows (Figure 12). A rasterized version of the NHD river and water body features was created. Next, each wetland polygon was converted to a raster. Using the elevation raster files, ArcMap Fill was used to condition the DEM, smoothing depressions or sinks in the surface raster in preparation for further hydrologic processing. ArcMap Flow Direction and Flow Accumulation were executed to determine the likely surface pooling patterns expected for each wetland. Another ArcMap tool (Zonal Statistics) was used to identify the maximum flow accumulation within each wetland polygon. Using Raster Calculator, the flow accumulation value for each pixel within the wetland was compared to the maximum flow accumulation for the entire wetland. If the values were equal, i.e., if the flow accumulation at the pixel was equal to the maximum flow accumulation for the wetland, the pixel was considered the pour point for that wetland. If the DEM is fairly flat, which is the case for many wetlands, more than one pixel in a wetland polygon might be identified as the pour point, in which case a manual override was necessary to handle the exception. Next, the 
rasterized stream feature (NHD) was "burned" into the conditioned DEM. Finally, the flow path was estimated using Python script that incorporated the ArcMap Least Cost Path tool. The starting point of each flow path was the pixel representing the pour point. The end point was the pixel representing the intersection of the flow path with the nearest stream segment (ESRI 2013).

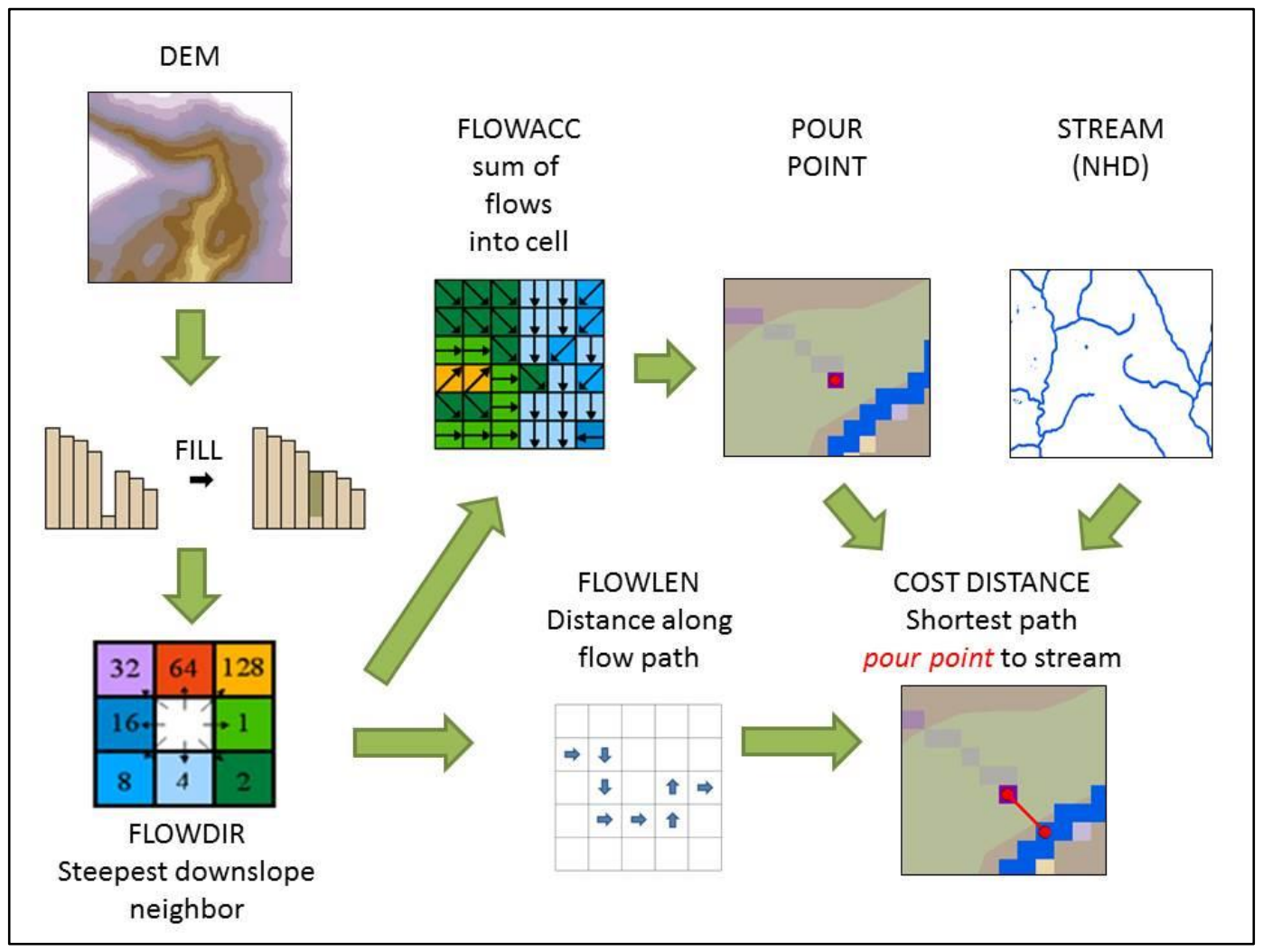

Figure 12. Method for calculating flow path from a wetland (polygon) to the nearest stream segment (polyline).

\section{Step 2 - Predict surface wetness with remote sensing indices}

The goal of step 2 was to predict surface wetness in the flow path based on remotely sensed data. 
The hydroperiod is the "seasonal pattern of the water level of a wetland and is the wetland's hydrologic signature" (Mitsch \& Gosselink 2007). Estimates of the hydroperiod are sometimes made using recorded field data (e.g., National Wetland Inventory) and this can be used to suggest a wetland's inundation profile (Adamus et al. 2010). To characterize the hydroperiod of wetlands in this study, a different approach was which relied on multispectral remote sensing data in addition to field observations and sampling. Readilyavailable remotely sensed imagery was extracted for the study area over the course of the study period, specifically Landsat 8 data from OLI sensors, captured every sixteen (16) days and made available for download within 1-3 days after each data capture (USGS 2014a). Resolution for Landsat 8 multispectral imagery is 30 meters.

NDWI and MNDWI indices were calculated for each capture date within the study period where the images were of high enough quality to be usable. All eleven bands of each Landsat 8 scene were downloaded, for path 46, row 28, which completely covered the study area (Figure 13). Using the ArcMap Composite Bands tool, the visible bands were stacked (blue, green and red or bands 2, 3 and 4, respectively), and pan-sharpened (15-meter resolution) to enable a visual comparison with the water index layers. Separate bands were used for NDWI and MNDWI calculations, specifically near-infrared or NIR (Landsat 8 band 5, 0.85-0.88 micrometers) and short-wave infrared or SWIR (Landsat 8 band 6, 1.571.65 micrometers, a.k.a., SWIR 1). Using raster algebra, a raster layer representing each moisture index was created for each usable image date. Wetness on the surface was predicted using NDWI and MNDWI, as described in Chapter 2.1:

$$
\begin{aligned}
\text { Equation 1: NDWI } & =[(\text { Green }- \text { NIR }) /(\text { Green }+ \text { NIR })] \\
\text { Equation 2: MNDWI } & =[(\text { Green }- \text { SWIR }) /(\text { Green }+ \text { SWIR })]
\end{aligned}
$$




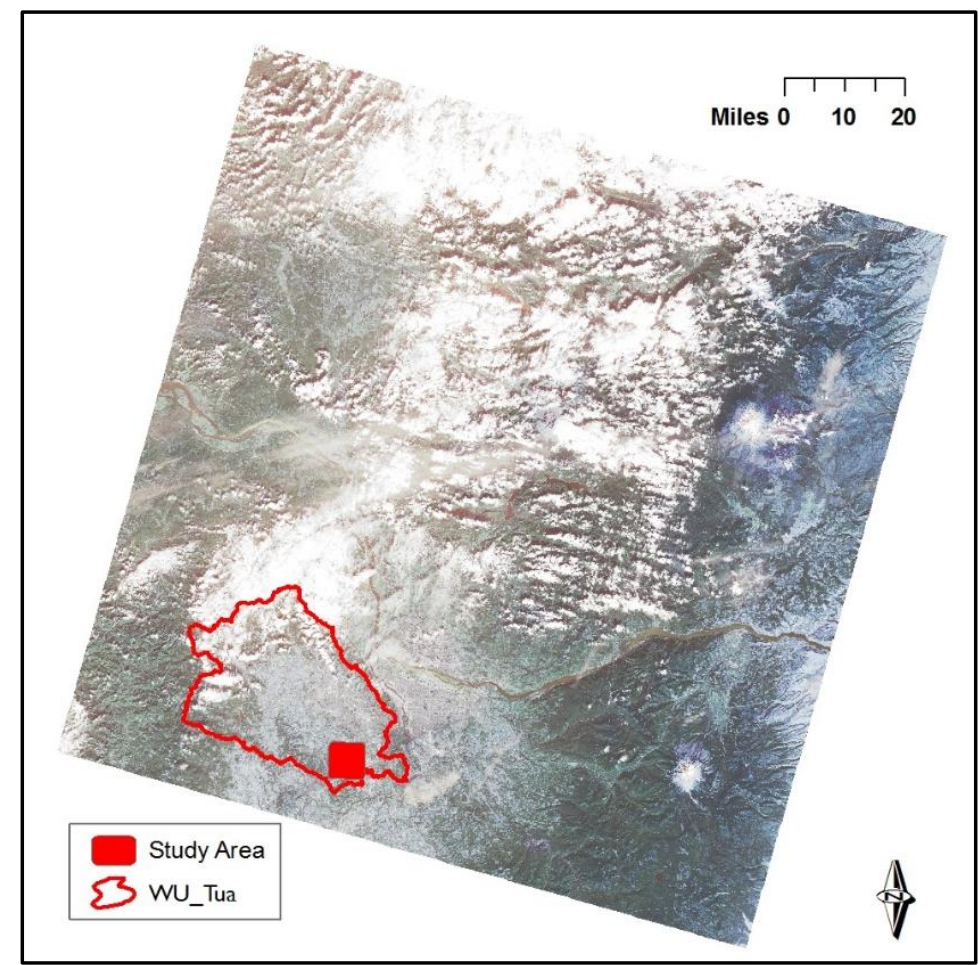

Figure 13. Landsat 8 imagery on 13 October 2015 (path 46 , row 28) showing relative position of study area and Tualatin River subbasin. (USGS 2015b).

Using ArcMap, soil moisture estimates from remote sensing water indices (NDWI and MNDWI) were extracted from the raster and attributed to the point representing each sampling site. Pixels with a higher water index value are areas predicted to have higher moisture content on the surface compared to other pixels in the raster (Soti et al. 2009). These were symbolized with dark pixels in the maps, with areas of lower index value were represented with lighter-colored pixels. Boxplots showing the highs, lows, averages and outliers for NDWI and MNDWI values were generated based on the water index values at sampling sites for each wetland (performed with the ArcMap tool Extract Values to Points). This extraction was performed for each combination of sampling site, wetland, index, and usable satellite image. Based on literature review, values were expected to range from -1 for 
dry surfaces to +1 for open water features. For example, in the original NDWI study by McFeeters (1996), NDWI values ranged from -1.0 to 1.0 with zero or negative values indicating soil or terrestrial vegetation and positive values indicating open water features. MNDWI values were presented by Xu (2006), and later by Soti et al. (2009) and Ho et al. (2010) with non-water pixels (i.e., dry soil, urban features, etc.) exhibiting negative MNDWI values from -1.0 to 0 and pixels containing water (i.e., moist soil or open water) resulting in positive MNDWI values up to 1.0. Moist soil values ranged from 0 to 0.3 and open water varied between 0.3 and 1.0 .

Step 3 - Estimate surface wetness with in-situ soil surveys

The goal of step 3 was to estimate surface wetness in the flow path based on soil samples collected in the field.

First, the sampling schedule was determined based on weather data outlined in Chapter 3.1. The target dry period was July-August-September and the target wet period was November-December-January. Sampling took place on the date of each Landsat 8 satellite fly-over, i.e., every sixteen (16) days, plus or minus one day, so that conditions captured in the satellite image would be similar to those on the ground.

Next, the sampling sites were selected. Three wetlands were identified as described in Chapter 3.2. Within each of three wetlands, the initial sampling sites were identified using the method described in Step 1 (above). Final placements were adjusted according to on-site observations such as a change in elevation, vegetation and/or soil which indicated pooling, channeling, or erosion.

Once the Refuge biologist approved the sampling plan, sampling sites were marked in the field. On the initial visit, twine and a measuring tape were used to place flags made of 
a 2" x 4" piece of orange plastic on a thin metal stake about two (2) feet tall. Sampling sites were placed approximately fifteen (15) meters apart, which represents half the width of the land area represented by one 30-meter Landsat 8 pixel. As a result, each pixel in the satellite image should coincide with at least one sampling site. Overall, a total of twenty-five (25) sites at three wetlands were flagged for sampling.

Based on discussions with the Refuge biologist and review of satellite images from typically wet and dry periods (Figure 9), the potential behavior of surface hydrology was characterized for each wetland. Wetland 151 was expected to pool and therefore to be inundated during the study period. At wetland 151, sampling sites were stationed upstream from the weir in the area which appeared to be a channel (Figure 14). Sampling sites continued westward on an area slightly upland from the channel. It was expected that the channel area would flood first (sites 99, 8, 7, 6 and 5), followed by the upland areas (sites 4, 3, 2 and 1). Wetland 1785 was expected to pool and therefore to be inundated during the study period. At wetland 1785, sampling sites were placed at the weir and to the northeast in the area which appeared to be a channel based on on-site observations (Figure 15). A crosssection into the upland area was positioned perpendicular to site 1, numbered as if facing the drain, e.g., 2-L furthest from the channel, 1-L nearer to site 1 in the channel, 1-R near site 1 on the right of the channel and 2-R furthest from the channel on the right. Wetland 2905 was not expected to pool during the study period and therefore no surface inundation was anticipated during the study period. The land in and around the wetland polygon had been modified prior to the study by agricultural use and by the addition of a pond approximately 200 feet to the east of the estimated pour point. It seems that much of the surface runoff in the immediate vicinity is diverted into this pond, perhaps to help drain the area when crops 
were present. Initially, five (5) sample sites were placed relative to the pond, with site 4 at the elevated road west of the pond and site 5 at the western edge of the pond. It was expected that site 4 would not be inundated during the study period, while site 5 was expected to be inundated if or when water levels in the pond were higher than in the initial flag placement, i.e., in October. After further analysis, five (5) new sampling sites numbered A1-A5 (a.k.a. 11 - 55) were placed to the southwest of the pond, from the estimated pour point along the downstream path indicated in ArcMap analysis (Figure 16). It was expected that all five sites 11-55 would not be inundated during the study period.

On sampling days, field equipment included a notepad to record observations, a five (5) gallon bucket, a hand shovel for taking samples, quart-sized zipped-closure baggies, a marking pen to identify each sample site, a camera to document findings, and an insulated cooler in which to store samples for transit to the soils lab at Portland State University (PSU). An e'Trex handheld Global Positioning System (GPS) was used on two occasions to record surface locations. On each sampling day, general notes were recorded regarding weather conditions on-site, including rough estimates of temperature (based on my vehicle's temperature gauge), cloud cover and precipitation. A soil sample was taken at each sampling site if feasible. If the site was under water, the site was documented as inundated, i.e., open water, and no further sampling was required. If the site was not inundated, about 3"- 4" of the top soil was removed with a hand shovel (Figure 17). An attempt was made to avoid taking vegetation. The hole for each sample did not overlap the hole for any previous sample so that soil moisture could be more accurately estimated. At each sampling site, about 50-100 grams of soil was removed and placed in a zipped-closure plastic baggie and marked with the sample's date, wetland number and sampling site number. Baggies were 
placed in a bucket under a loose cloth to limit the effects of atmosphere, especially sunlight. After sampling was complete for all sites at a wetland, the baggies were placed in an insulated container. Once sampling was complete at all wetlands for that day, samples were transported to PSU for processing, often on the same day that samples were collected.

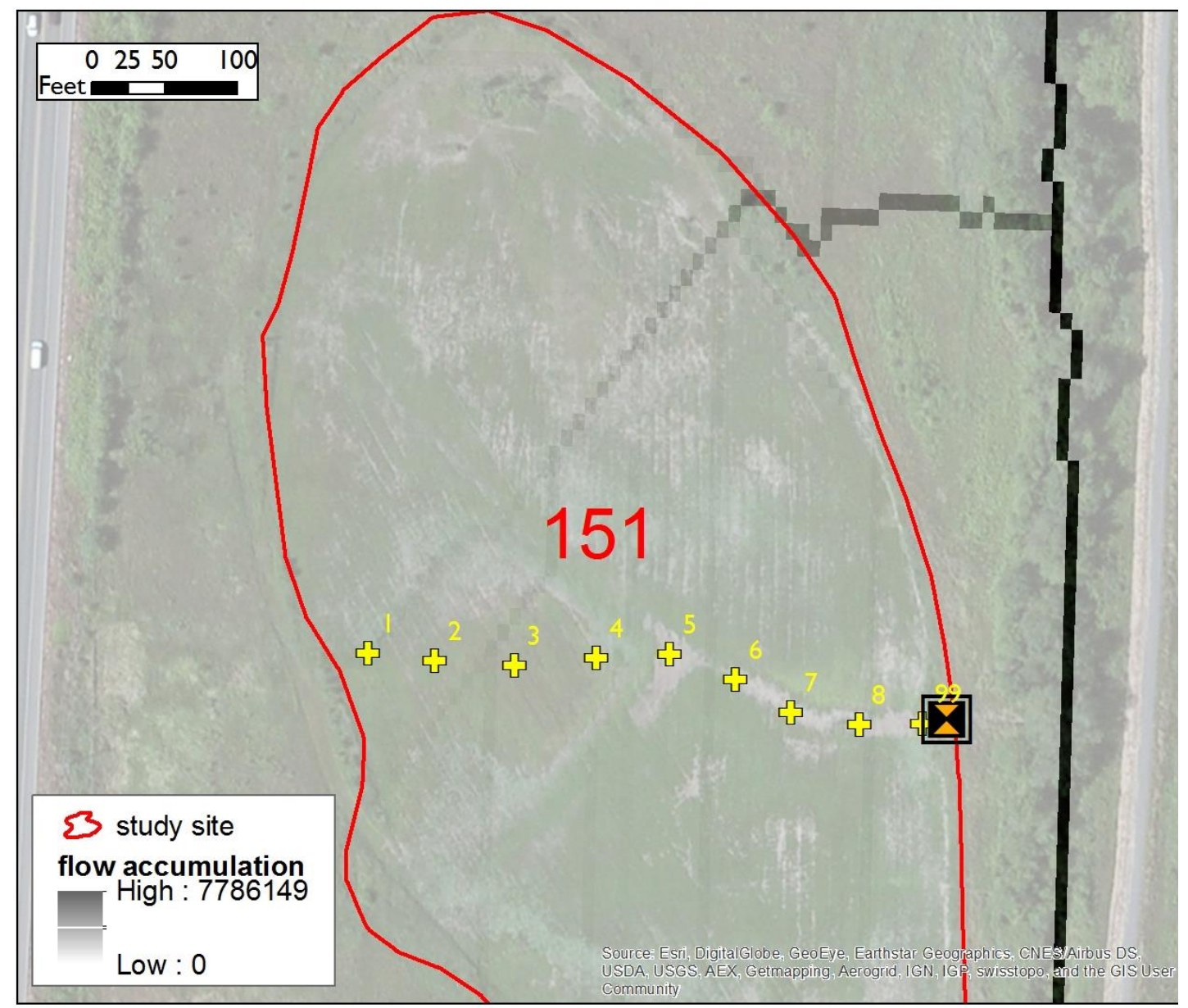

Figure 14. Wetland 151, flow accumulation pattern calculated using terrain analysis showing aerial imagery and location of gate. 


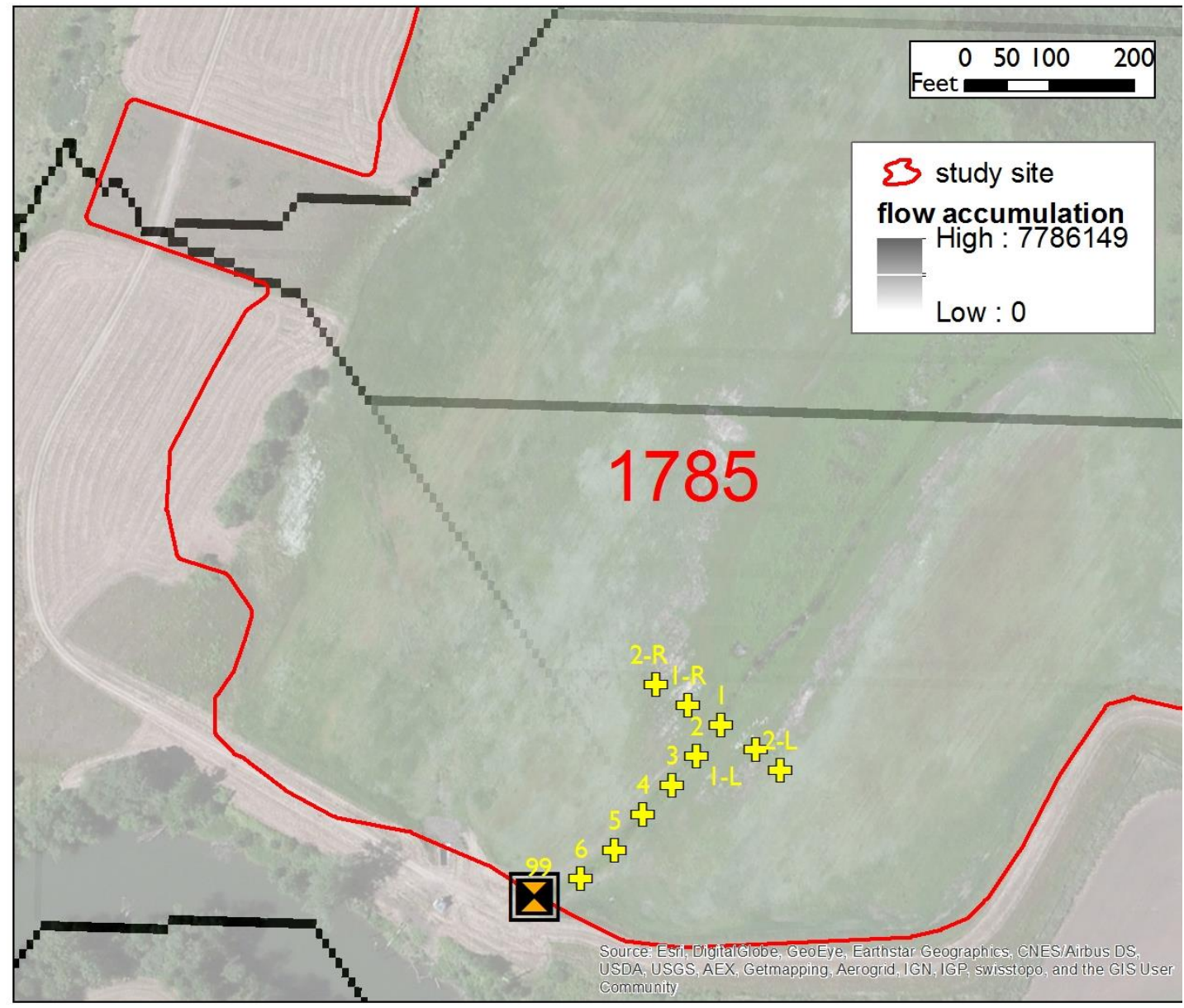

Figure 15. Wetland 1785, flow accumulation pattern calculated using terrain analysis showing aerial imagery and location of gate. 


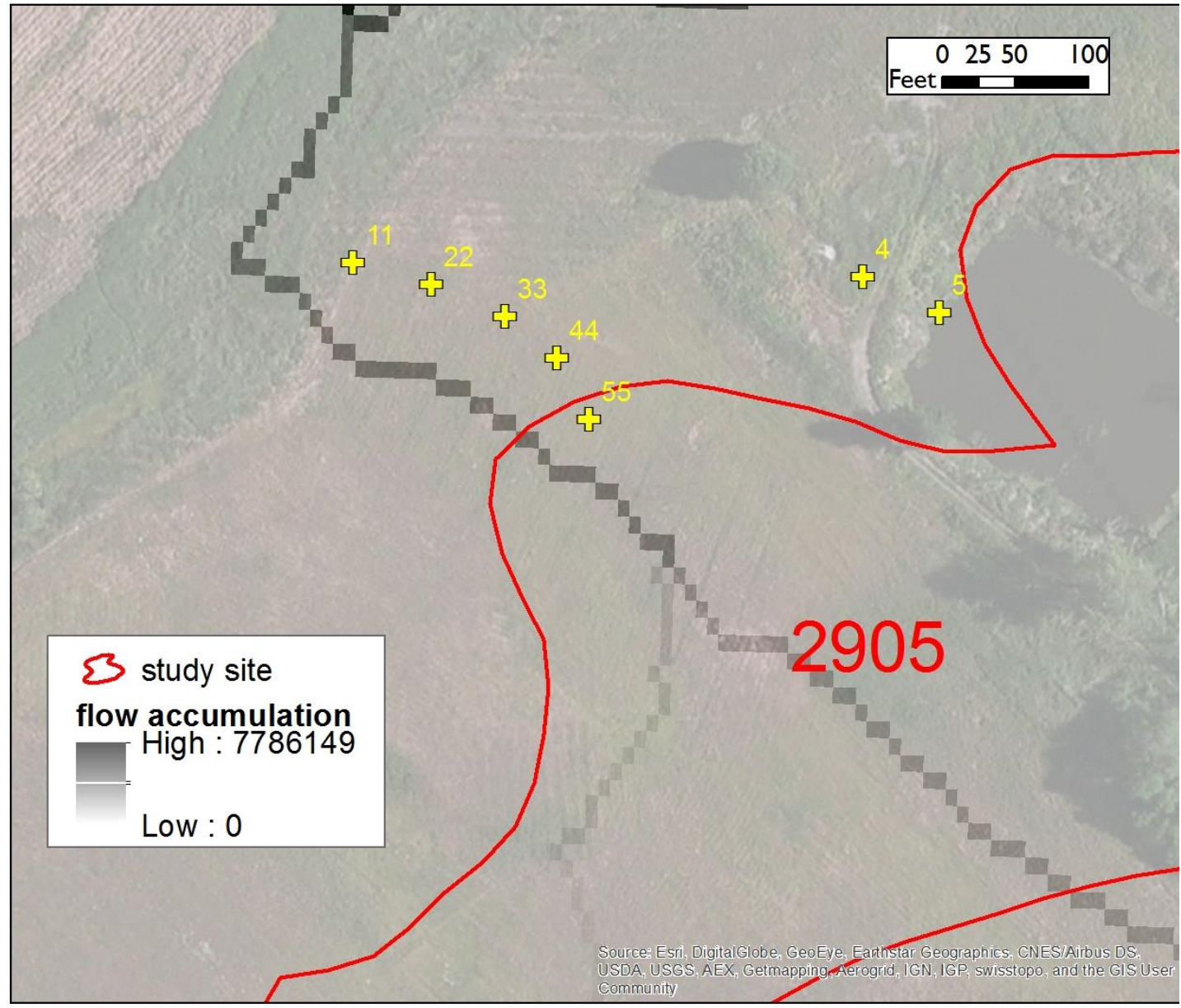

Figure 16. Wetland 2905, flow accumulation pattern calculated using terrain analysis showing aerial imagery. 


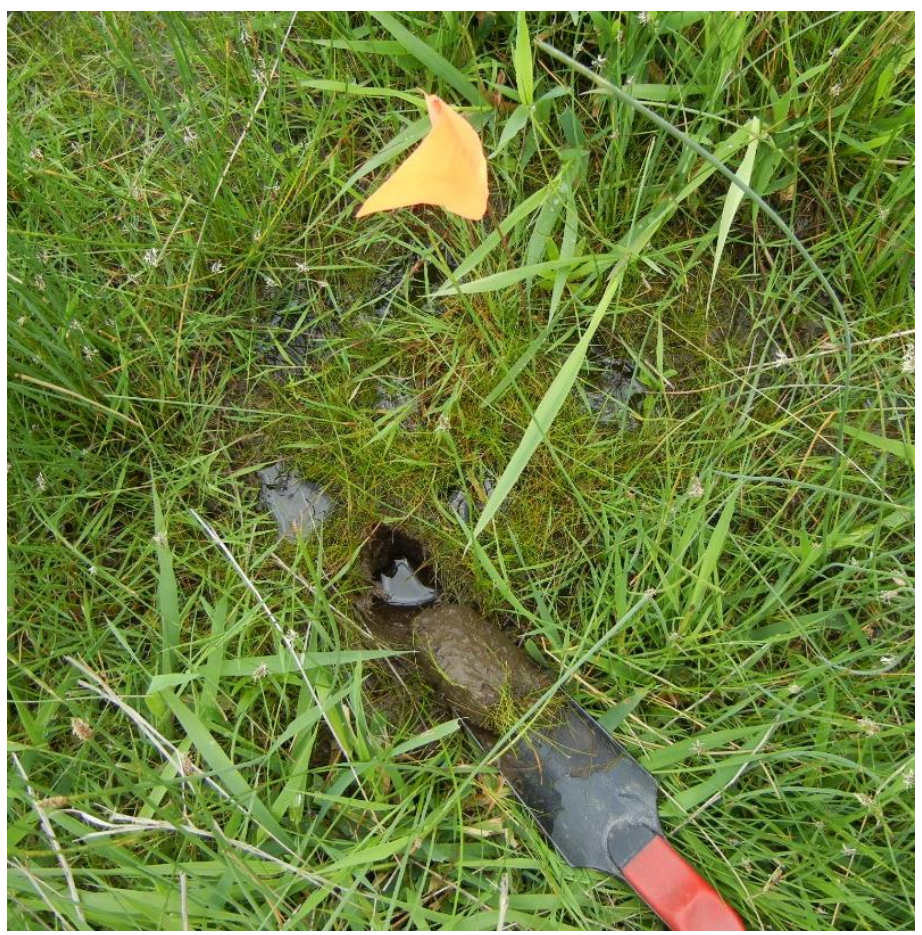

Figure 17. Example of soil sampling technique, showing sampling hole, space, sample site flag. Note water table near surface. Wetland 151 on 22 April 2016.

For each sampling date, soil samples were processed to estimate soil moisture based on the gravimetric method of soil moisture determination (Reynolds 1970). This study relied on the dry weight basis which expresses the moisture content as the ratio of the weight of water in a soil to the overall weight of the soil (Davie 2008), calculated using Reynolds' (1970) methods:

1. Weigh the soil sample while wet.

2. Dry the sample for 24 hours at approximately $100^{\circ}$.

3. Weigh the soil sample after drying.

4. Compare the difference between wet and dry samples to estimate soil moisture: 


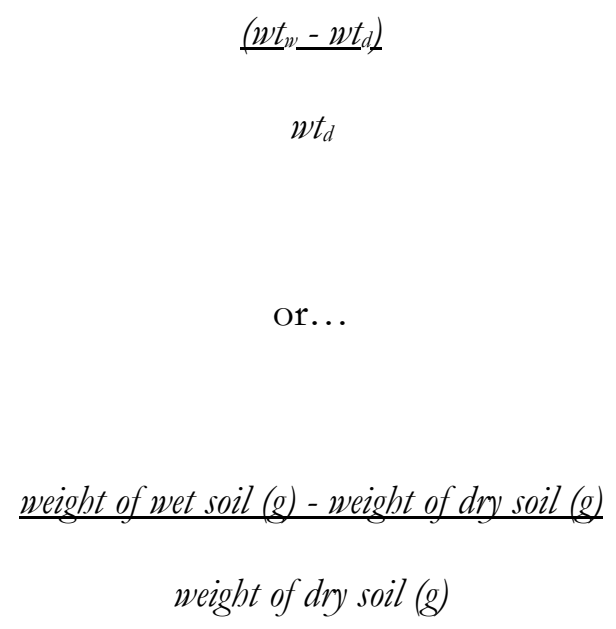

Samples were processed in the soil lab in the Department of Geography at PSU and on one occasion, in ovens at the Science Research \& Training Center at PSU. First, the weight of a small aluminum tray was determined (tare). Then a subset of each sample was placed in a tray and weighed wet. The entire batch of samples was dried for 24 hours. After determining the tare, each sample was weighed dry. All weights were recorded and the dry weight ratio calculated to provide an estimate of soil moisture. Using ArcMap, soil moisture estimates from field observations were attributed to the point representing each sampling site.

Step 4 - Validate surface moisture indices with in-situ soil surveys

The goal of step 4 was to validate surface moisture predictions based on remotelysensed data by comparing them to surface moisture estimates based on soil samples from the field.

Scatterplots allow for a visual inspection of two sets of data using the Cartesian coordinate system. If the distribution of points is not random and a pattern is visible, it indicates a relationship between the sets of data. To find a correlation between the remote 
sensing predictions and soil sample estimates, scatterplots were created in Microsoft Excel showing the soil moisture estimates from soil sampling on the X-axis and the NDWI values which had for each soil sample point on the Y-axis, which had also been attributed to each soil sample point. An equation of best fit was generated, the fit line, describing the relationship between the soil sample estimates and NDWI predictions. A similar scatterplot and best fit equation were created with soil sample values on the $\mathrm{X}$-axis and MNDWI values on the Y-axis.

Correlation tests between each water index and the dry-weight estimates were also performed using IBM's SPSS. These show the strength of association between the two variables. Pearson's $r$ is a measure of how close or far away the data is from a line of best fit.

Finally, regression analysis was performed using IBM's SPSS. Overall, regression evaluates the goodness of fit, i.e., the ability of the dependent variable (the water index) to predict the independent variable (moisture, dry-weight).

\subsection{Demonstrate the Indices}

\section{Step 5 - Categorize bydrologic connectivity and bydrological permanence}

The goal of step 5 was to use the water indices in wetland environments to answer two questions: Is a wetland hydrologically connected to a nearby water feature on a specific day and what is the hydrological permanence of the hydrologic connectivity between a wetland and a nearby water feature over the course of a year (ephemeral, intermittent or perennial)?

To address the question of hydrologic connectivity, it was desirable to analyze usable satellite imagery for dates which were not part of the original analysis. A search was 
performed for appropriate Landsat 8 imagery from any date in 2015 prior to October with usable scenes, each of which was processed using the method described in Chapter 4.2. Boxplots showing the highs, lows, averages and outliers for NDWI and MNDWI values were generated based on the water index values at sampling sites for each wetland (Extract Values to Points). This extraction was performed for each combination of sampling site, wetland, index, and usable satellite image. Resulting water index values indicated the relative dryness or wetness of surfaces. To simplify the demonstration, the index predictions of surface moisture were placed into three categories: dry, moist, and wet-or-inundated. Thresholds were set for the soil samples to determine which values for NDWI and MNDWI corresponded to each of the three categories, using the fit lines generated in Step 4 (above).

Threshold values for soil moisture samples taken in the field were informed by relevant literature. According to the Soil Survey Manual, evaluations of water state classes, e.g., wet or dry soils, are often performed using visual and tactile observations in the field (Soil Survey Staff 2015, p 25-30). For this study, initial classifications were based on the descriptions and indicators in the Soil Survey Manual. If the surface at a sample site was covered with water, the condition at the site was recorded as inundated to indicate that open water was observed. As samples were collected, if free water was observed in the sample hole (i.e., the water filled or partially filled the hole), the sample was considered wet. Also, if the sample was muddy to the point of flowing, i.e., could not hold its shape, it was considered wet. If not wet, the sample was deemed moist if the soil surface exhibited a water film or was glistening, and the sample could retain its shape (ball, rod or ribbon test) or the color was similar before and after the drying process (color value test). If the sample lacked these wetness properties, the surface was dull, or the sample was hard and crumbled 
easily, it was considered dry. For all dates in the study (fourteen cycles), moisture values after drying were compared to the properties observed in the field, and to photographs taken in the field, to identify a pattern or correlation. Generally, values above 0.6 represented wet or saturated samples. Below around 0.3 , the samples were dry or very dry. Therefore, for this study, threshold values for classifying surface moisture based on soil samples are: dryweight basis moisture estimate of $(0-0.3)=$ dry, from $(0.301-0.6)=$ moist, and $(0.601-1.0)=$ wet-to-inundated, a.k.a., wet.

Once threshold values were determined based on the research data, two suites of images were mapped to demonstrate the use of water indices. Based on precipitation data shown in Figure 8, one suite of three images was selected to represent a relatively wet period, from January to April, while the second suite of three images represented the dry period, from July to September. Visual comparisons were made using the stacked visual satellite bands (blue, green and red). In addition, where the months overlapped similar months from the study period, e.g., October through April, photos from field observations were referenced, assuming general vegetation patterns were similar from year-to-year.

Using the correlation equations for the NDWI and MNDWI line of best fit generated in Step 4 (above), the soil sample threshold values for dry, moist and wet-toinundated were entered for the " $x$ " value. Resulting " $y$ " values represent the thresholds for NDWI and MNDWI water index values (for this study). Using these index thresholds, hydrologic connectivity was categorized for each wetland for each image capture date based on water indices. For NDWI and MNDWI analysis, hydrologic connectivity was indicated if pixels were categorized as wet-to-inundated in a contiguous pattern from the pour point along the flow path to the intersection point with a nearby water body, indicating that 
surface flows were likely present along the flow path. If this was the case, the wetland was considered hydrologically connected on that day. If not, the wetland was considered hydrologically not connected on that day. The hydrologic connectivity indicator (yes/no) was attributed to each wetland on each image date (Table 2).

To address the question of hydrological permanence, recall that hydrological permanence represents the number of consecutive days of open water or moist soil in the flow path (Leibowitz et al. 2008), based on the frequency and timing of hydrologic connectivity (Figure 18). Ideally, sequential images taken with regular and high frequency might illustrate the presence or absence of connectivity over time. As previously stated, Landsat 8 imagery is captured at a regular interval but at a fairly low frequency, every sixteen (16) days. Therefore, it was expected that ephemeral connectivity events could not be identified using Landsat 8 data, given their short duration, i.e., a few days. It was also expected that cloud cover would render some images unusable, creating holes in the sequential pattern and therefore gaps in the evidence to support a classification of perennial or intermittent.

Based on the time series suites, wet and dry, hydrological permanence was categorized for each wetland as perennial, intermittent or none as described in Chapter 2.2. For reference, the assignment to a category also took into account the usable images from the original research period from October 2015 to May 2016, assigned to a dry and a wet period as appropriate. If the wetland was connected in all images, it was classified as perennial. If connectivity was observed in one series, but not the other, permanence was classified as intermittent or seasonal. If no connectivity was evident in any of the images, hydrological permanence was classified as none. Resulting classifications were attributed to 
each wetland (Table 2), where HC = hydrologically connectivity; $\mathrm{Y}=$ yes or $\mathrm{N}=$ no; and where $\mathrm{HP}=$ hydrological permanence; $\mathrm{P}=$ perennial, $\mathrm{I}=$ intermittent, or $\mathrm{N}=$ none.

Table 2. Sample attribute table showing hydrologic connectivity $(\mathrm{HC})$ and hydrological permanence (HP) for study wetlands. For HC, $\mathrm{Y}=y$ es, $\mathrm{N}=$ no. For HP, $\mathrm{P}=$ perennial, $\mathrm{I}=$ intermittent/seasonal, $\mathrm{N}=$ none.

\begin{tabular}{|c|c|c|}
\hline wetland-ID & HC & HP \\
\hline 151 & $\mathrm{Y} / \mathrm{N}$ & $\mathrm{P} / \mathrm{I} / \mathrm{N}$ \\
\hline 1785 & $\mathrm{Y} / \mathrm{N}$ & $\mathrm{P} / \mathrm{I} / \mathrm{N}$ \\
\hline 2905 & $\mathrm{Y} / \mathrm{N}$ & $\mathrm{P} / \mathrm{I} / \mathrm{N}$ \\
\hline
\end{tabular}

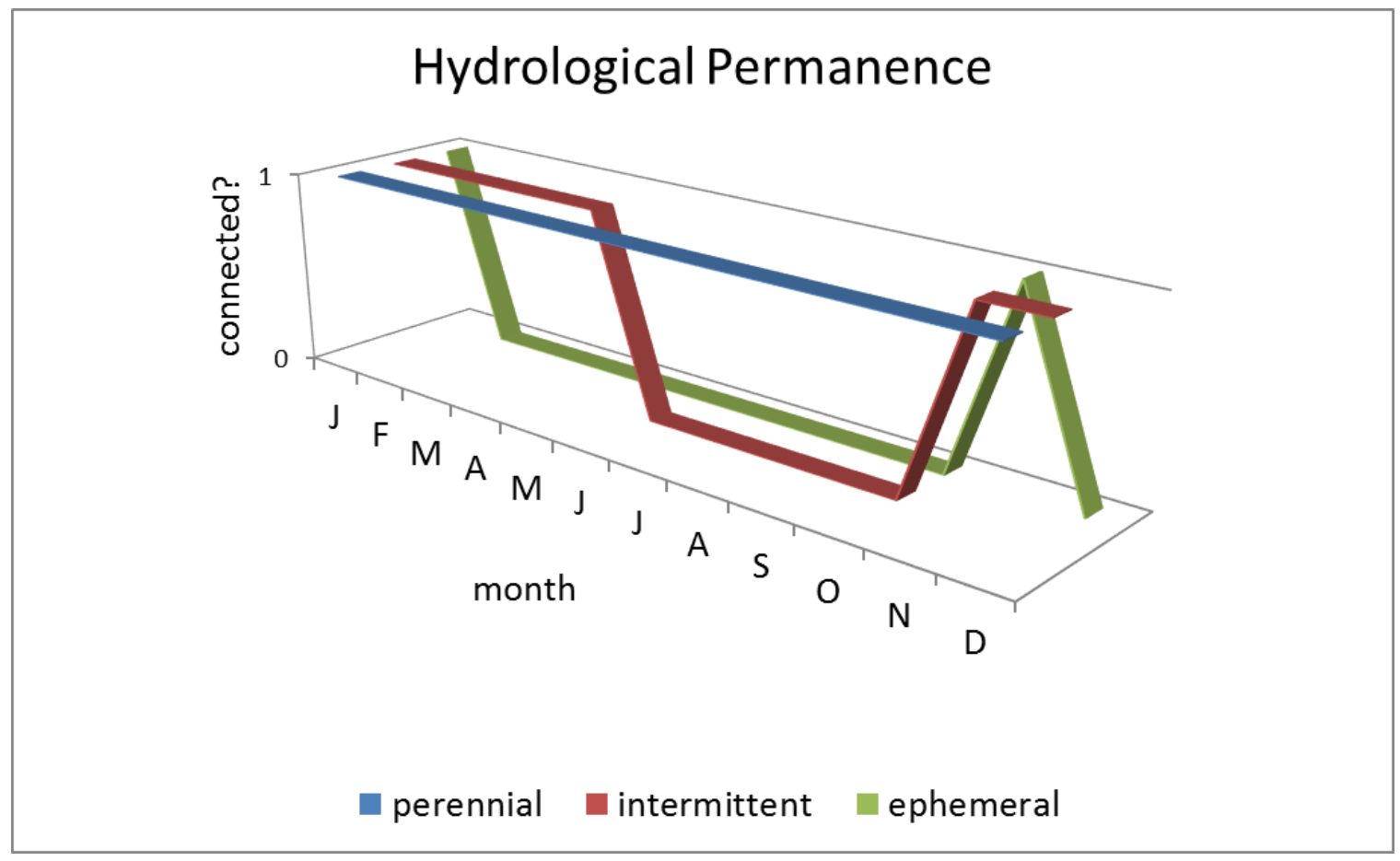

Figure 18. Hydrological Permanence based on whether a wetland is connected and for what duration, i.e., perennial, intermittent or ephemeral (Fritz et al. 2006, Leibowitz et al. 2008). 


\section{Results}

\section{Step 1 - Determine sampling sites}

Flow path estimates from ArcMap were consistent with on-site observations at Wetland 2905 but not at Wetland 151 or Wetland 1785. First, a review at the site with consistent estimates (Figure 16). Flows from the southeast to the northwest of the image were predicted. There is a gently sloping depression leading to the northwest toward areas of higher expected flow accumulation (darker black pixels). The main sampling sites were eventually placed in this downward-sloping area. Sample site 5 (near the pond) and site 4 (over the roadway) were retained from the original station placements. As it turns out, during the flood event in December, the wetland in the northwest filled this depression, following the path of the sample site locations with deeper water at site 11 and shallower water at site 55. Next, a review of the flow path estimates at Wetland 151 (Figure 14). ArcMap analysis predicted flows to the northeast of the image, ending in the channelized ditch which runs north-south to the east of the wetland. However, on-site observations revealed an elevated dirt roadway running north-south, somewhat parallel to the ditch to the east of the wetland. Outflows from the wetland were directed through the weir (flood up gate) directly to the east of the wetland, then under the roadway. In addition, there were obvious signs of erosion in a pattern of channeling which converged as it approached the weir. Vegetation patterns delineate the areas where water might have ponded or channeled while bare soil was evident in the slightly lower elevations in the channeled areas. Sampling sites were eventually placed to follow the elevation difference, which was subtle, perhaps only one or two feet from the highest points (near sampling sites 1-4) and the deepest point (near sites 5, 7 and 8 and site 99 near the weir / outflow drain). Last, an evaluation of the 
flow path anticipated for Wetland 1785 (Figure 15). Flows were predicted by ArcMap analysis in a westward direction. In reality, there is a weir / drain protected by a 6-foot retaining wall at the southern end of the wetland. The wall blends left and right into an elevated berm upon which a dirt roadway was built. Refuge management closed the flood up gates at this outflow which helped create a large lake feature beginning about November and still very evident in May. Only during the extreme flood event in December did water flow across the roadway as predicted by ArcMap calculations. At that time, water flowed into the wetland from the nearby Tualatin River.

\section{Step 2 - Predict surface wetness with remote sensing indices}

Landsat imagery was downloaded for a total of fourteen (14) dates from 13 October 2015 to 8 May 2016. Included were all eleven bands of the Level 1 terrain-corrected product. There is extensive cloud cover in twelve (12) of the images (Figures 19, 20 and 21). As a result, the only usable images were from 13 October 2015 (which represents a dry period) and 1 January 2016 (which represents a relatively wet period). For each usable date, for each pixel near each sampling site, NDWI and MNDWI values were extracted and attributed to the point representing the sampling site. These values represent surface moisture predictions based on remote sensing data. 


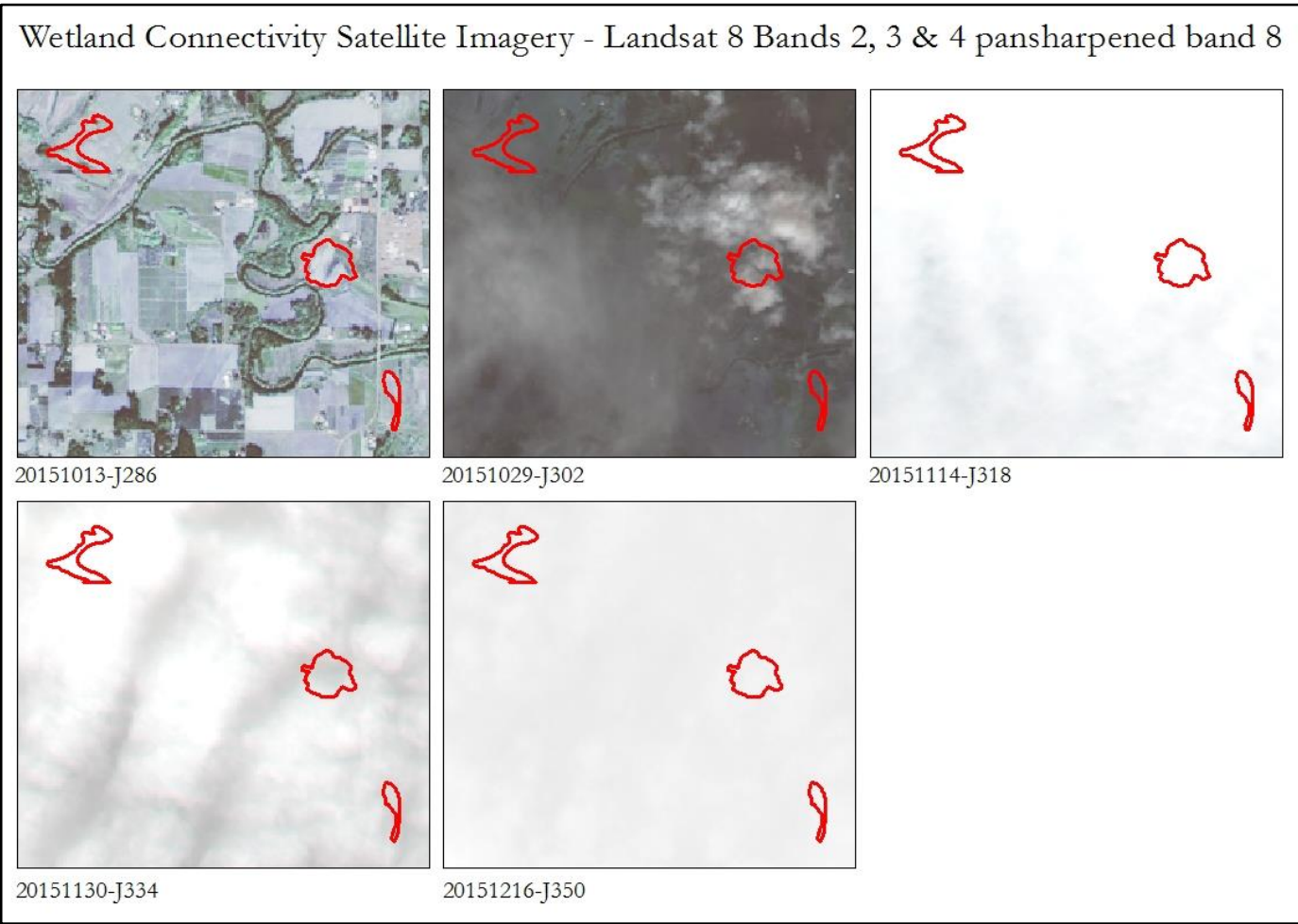

Figure 19. Satellite imagery 1. Landsat 8 imagery (path 46, row 28) showing study sites for dates in 2015 (format: yyyymmdd-julian date) (USGS 2015b). 


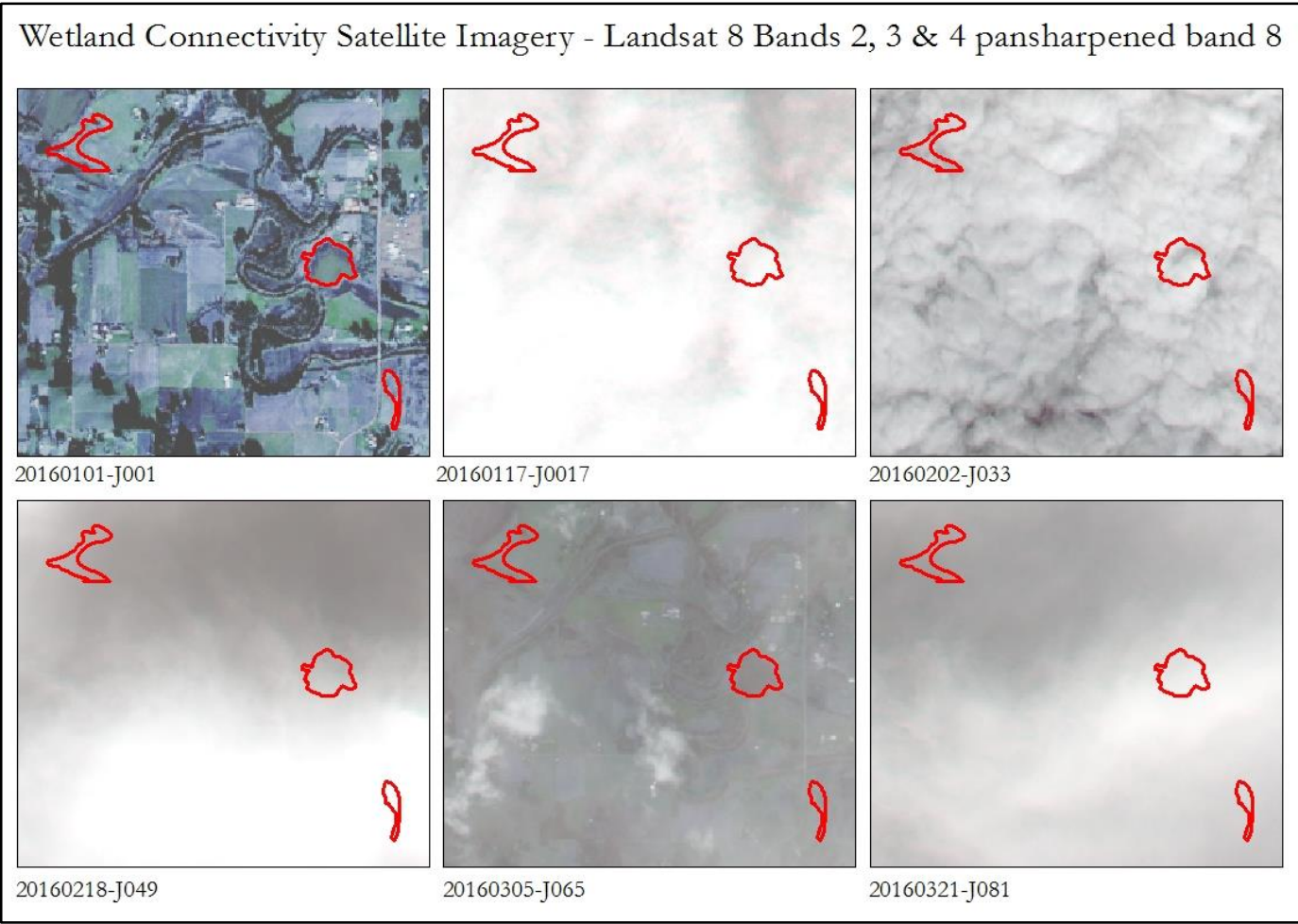

Figure 20. Satellite imagery 2. Landsat 8 imagery (path 46, row 28) showing study sites for dates from January to March 2016 (format: yyyymmdd-julian date) (USGS 2015b). 
Wetland Connectivity Satellite Imagery - Landsat 8 Bands 2, 3 \& 4 pansharpened band 8
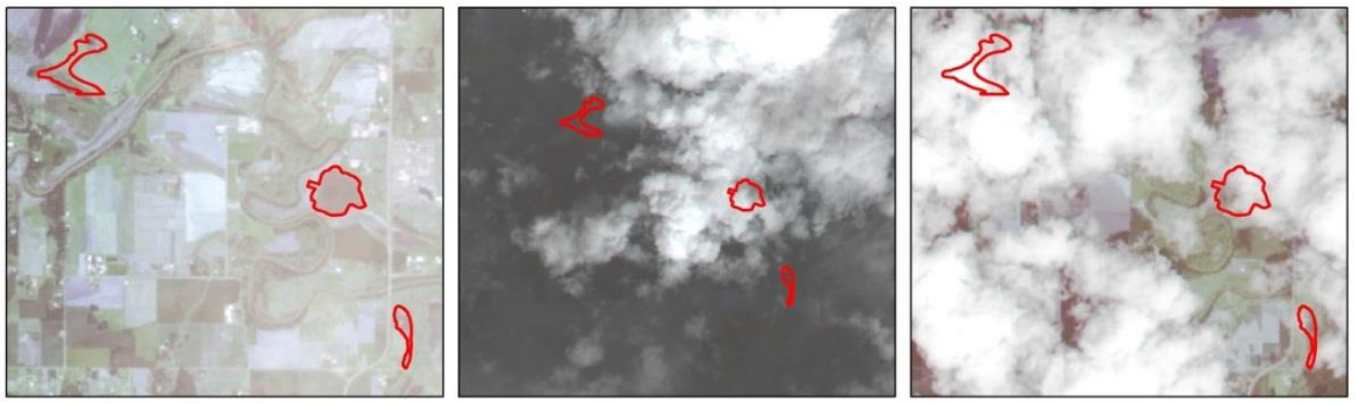

20160406-J097

$20160422-\mathrm{J} 113$

20160508-J129

Figure 21. Satellite imagery 3. Landsat 8 imagery (path 46, row 28) showing study sites for dates from March to May in 2016 (format: yyyymmdd-julian date) (USGS 2015b).

Maps of NDWI and MNDWI raster values in relation to soil sample sites are shown for each wetland in Figures 22, 23 and 24. High values (dark pixels) represent areas predicted to be wetter using water index ratios while low values (light pixels) represent areas predicted to be drier. Overall, the range of values for both NDWI and MNDWI are lower in dry conditions (images on the left) than in wet conditions (images on the right). This relationship is easier to visualize in boxplots which show the distribution of values with highs, lows, averages and outliers (Figure 25).

Given the raw NDWI and MNDWI values, only the relative dryness or wetness of the surface was predicted. Categories of surface moisture were developed for this research 
later, in Step 4. There, wetness predictions based on remote sensing data were compared and validated against the wetness estimated based on soil sampling in the field.

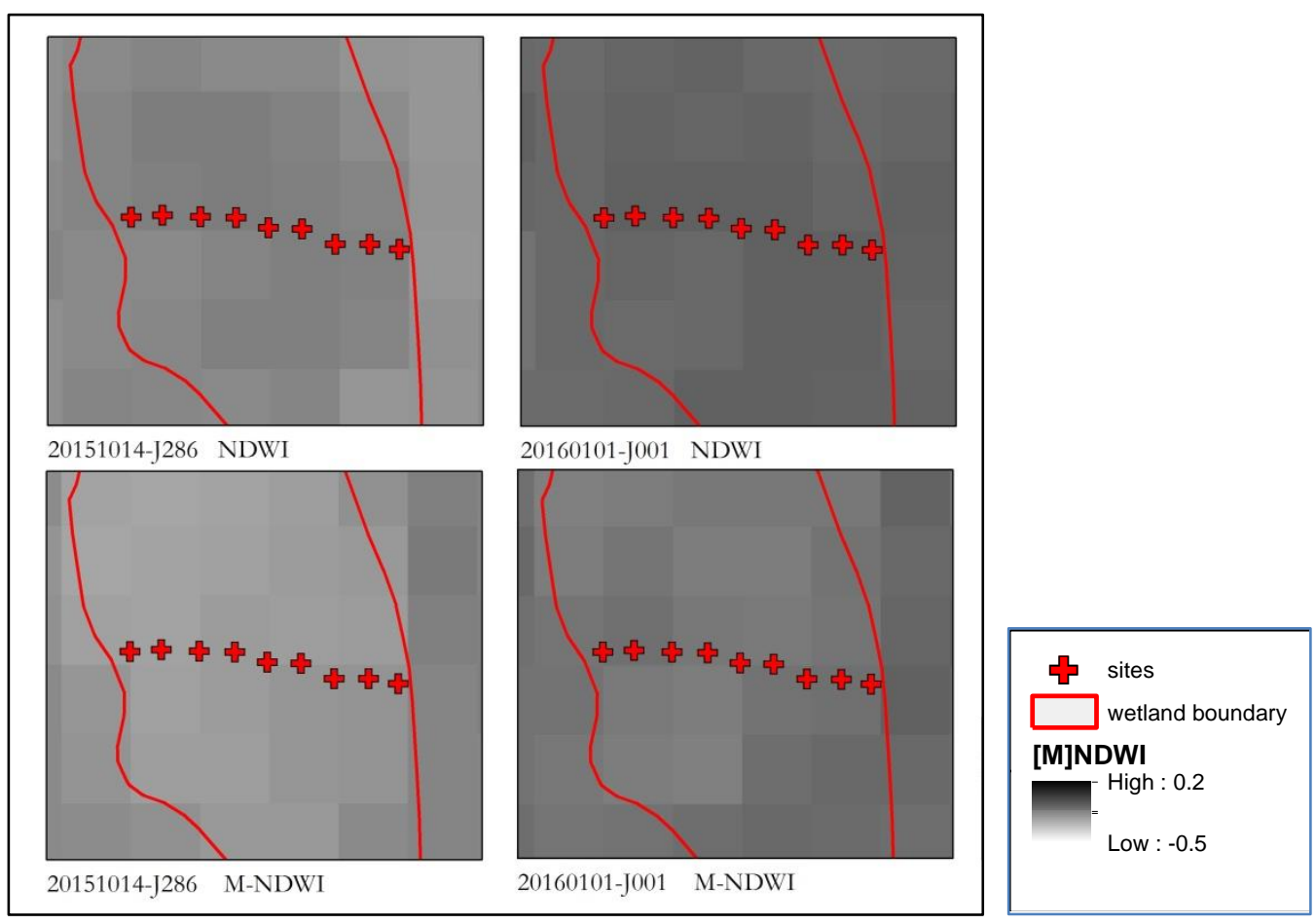

Figure 22. Soil moisture predictions based on NDWI \& MNDWI for Wetland 151 in dry (left) and wet conditions (right). Date format is yyyymmdd-julian. 


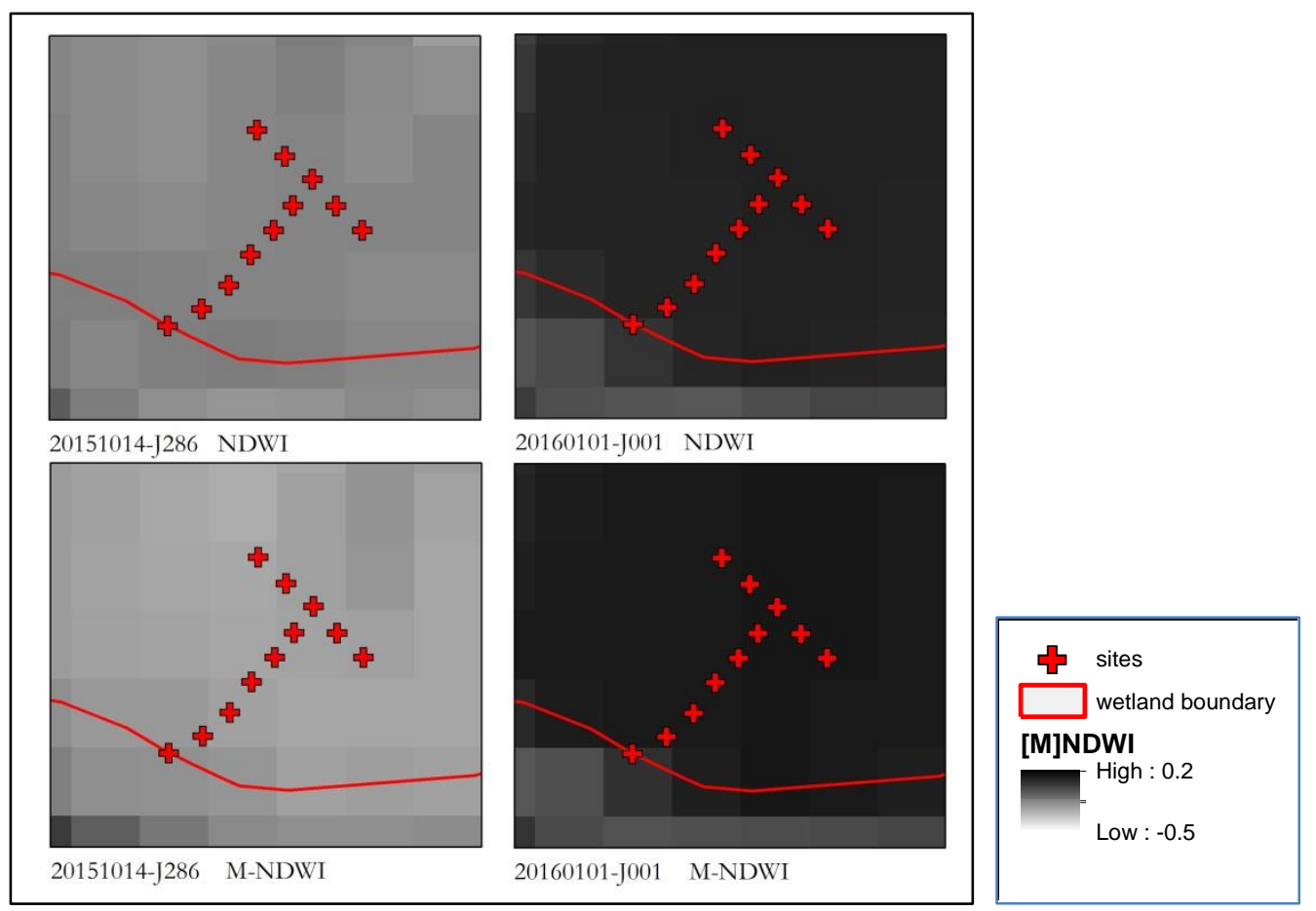

Figure 23. Soil moisture predictions based on NDWI \& MNDWI for Wetland 1785 in dry (left) and wet conditions (right). Date format is yyyymmdd-julian.

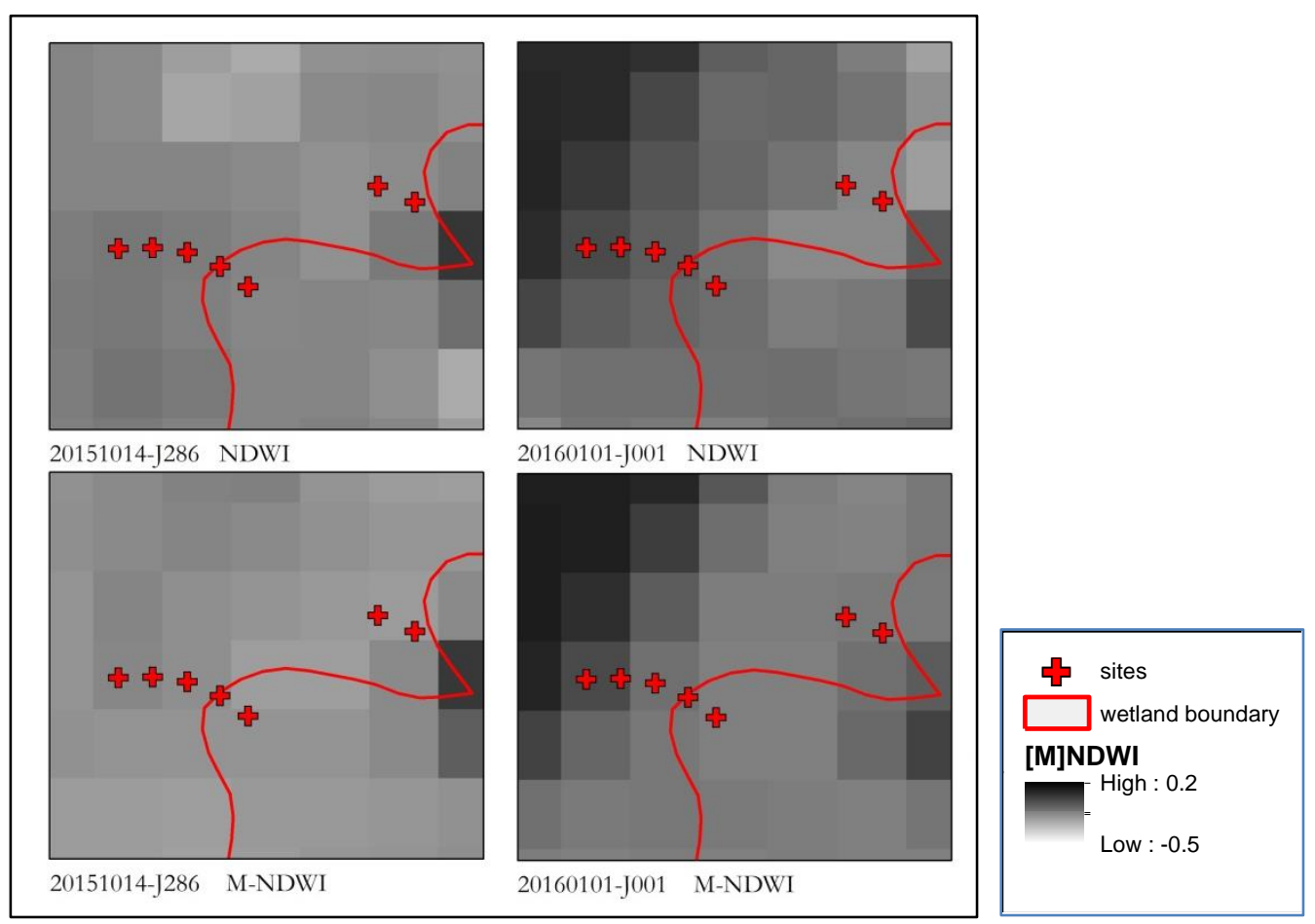

Figure 24. Soil moisture predictions based on NDWI \& MNDWI for Wetland 2905 in dry (left) and wet conditions (right). Date format is yyyymmdd-julian. 


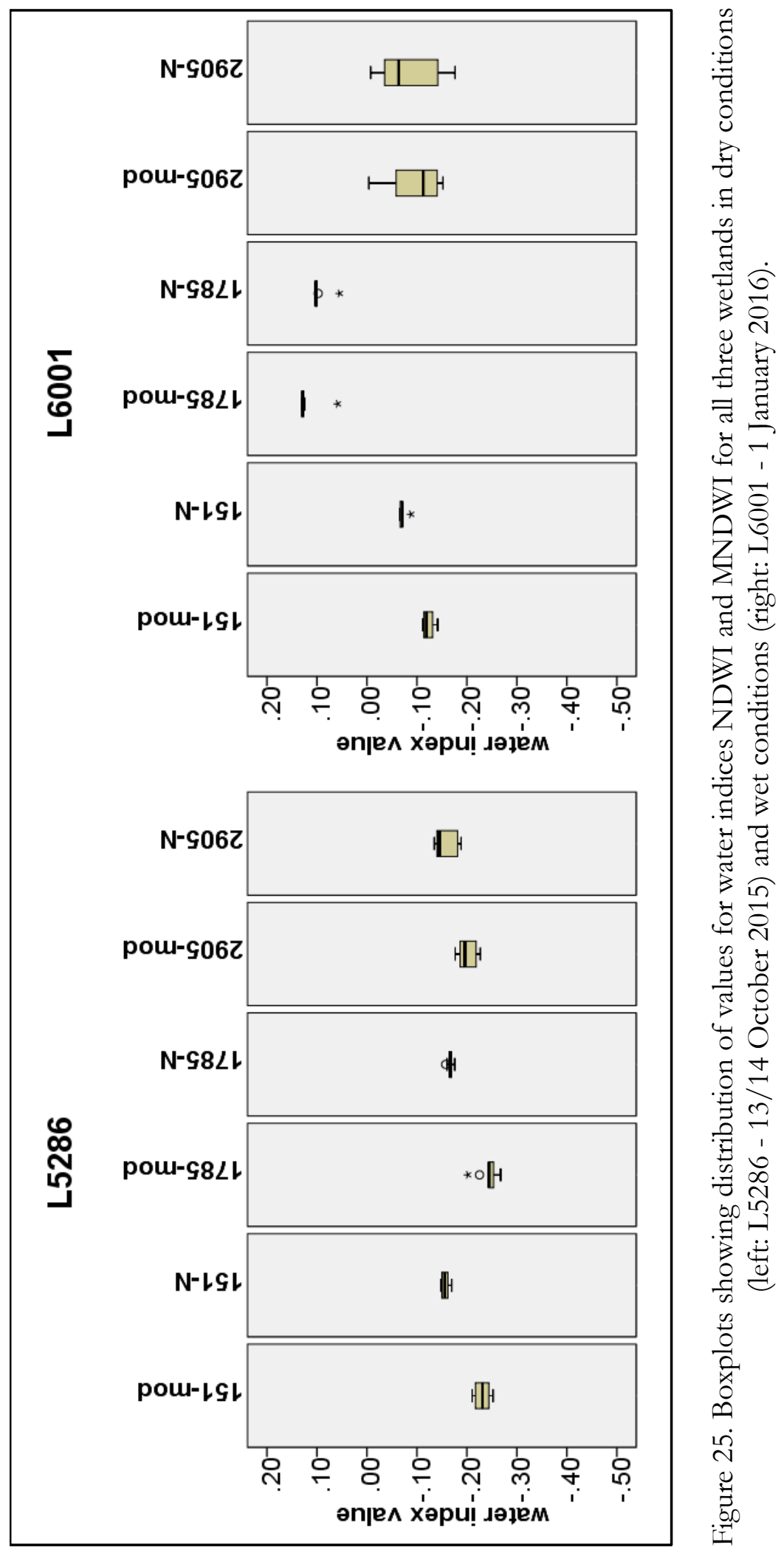




\section{Step 3 - Estimate surface wetness with in-situ soil surveys}

Permission to access the Refuge was obtained in early October and soil sampling commenced shortly thereafter. Sampling occurred on the same date as each Landsat satellite fly-over, plus or minus one day. Soil samples were collected for each and every 16-day satellite cycle from mid-October 2015 through 9 May 2016, a total of fourteen (14) cycles (Table 3).

Table 3. Site Log showing Landsat satellite fly-over dates (L8) and on-site sample dates.

\section{Blackmore Thesis - site log}

\begin{tabular}{|r|r|r|r|r|l|}
\hline $\begin{array}{c}\text { date-L8 } \\
\text { image }\end{array}$ & $\begin{array}{c}\text { date-L8- } \\
\text { julian }\end{array}$ & $\begin{array}{c}\text { days-til- } \\
\text { sample }\end{array}$ & \multicolumn{1}{c|}{$\begin{array}{c}\text { date- } \\
\text { sample }\end{array}$} & $\begin{array}{c}\text { date- } \\
\text { sample- } \\
\text { julian }\end{array}$ & \multicolumn{1}{|c|}{ activity } \\
\hline & & & $9 / 4 / 2015$ & & meet Curt, discuss project \\
\hline $10 / 13 / 2015$ & 286 & 1 & $10 / 14 / 2015$ & 287 & "Day 1", set flags \& sample 3 sites) \\
\hline $10 / 29 / 2015$ & 302 & 0 & $10 / 29 / 2015$ & 302 & "Day 2", check flags, try GPS \& sample \\
\hline $11 / 14 / 2015$ & 318 & $(1)$ & $11 / 13 / 2015$ & 317 & "Day 3", check flags \& sample \\
\hline $11 / 30 / 2015$ & 334 & 0 & $11 / 30 / 2015$ & 334 & "Day 4", check flags \& sample \\
\hline $12 / 16 / 2015$ & 350 & 0 & $12 / 16 / 2015$ & 350 & "Day 5", check flags \& sample \\
\hline $1 / 1 / 2016$ & 1 & 0 & $1 / 1 / 2016$ & 1 & "Day 6", check flags \& sample \\
\hline $1 / 17 / 2016$ & 17 & 1 & $1 / 18 / 2016$ & 18 & "Day 7", check flags \& sample \\
\hline $2 / 2 / 2016$ & 33 & 0 & $2 / 2 / 2016$ & 33 & "Day 8", check flags \& sample \\
\hline $2 / 18 / 2016$ & 49 & 0 & $2 / 18 / 2016$ & 49 & "Day 9", sample \& pole mapping \\
\hline $3 / 5 / 2016$ & 65 & $(1)$ & $3 / 4 / 2016$ & 64 & "Day 10", sample \& newts \\
\hline $3 / 21 / 2016$ & 81 & 0 & $3 / 21 / 2016$ & 81 & "Day 11", sample \& sad rain \\
\hline $4 / 6 / 2016$ & 97 & 0 & $4 / 6 / 2016$ & 97 & "Day 12", sample, warm \& sunny \\
\hline $4 / 22 / 2016$ & 113 & 0 & $4 / 22 / 2016$ & 113 & "Day 13", sample, GPS 2 \\
\hline $5 / 8 / 2016$ & 129 & 1 & $5 / 9 / 2016$ & 130 "Day 14", sample, nutria \\
\hline & & & $5 / 9 / 2016$ & & meet Curt, discuss wrap-up \\
\hline
\end{tabular}

A note about flags: Location flags were placed at all sampling sites on 14 October 2015, Day 1 of sampling. On Day 2 of sampling, 29 October 2015, quite a few flags at WL1785 had been relocated or were missing altogether. A few were located nearby but in some cases the plastic flag material was shredded. After discussions with the Refuge biologist, it was hypothesized that animals, possibly nutria, had been disturbing the markers. 
On future sampling dates, other flags at Wetland 1785 went missing and were replaced, using the original measurement techniques and placement locations. As it turned out, a beaver dam was constructed during the study period at the outflow gate of WL1785. Three beavers were observed nearby on 18 February 2015 and a nutria was observed in the vicinity on 9 May 2015 (Appendix B).

During the initial visits to the study wetlands, conditions which were very dry (Appendix C). Notable was the empty channel at WL1785. This is to be expected, given that Oregon was in a severe drought in 2015 and that Oregon recorded its warmest year ever in 2015 (CIRC 2016a). As for precipitation, by the end of October, Oregon was tracking its driest year ever, according to the National Oceanic and Atmospheric Administration or NOAA (CIRC 2016a); however, the hydrologic environment changed drastically before yearend (Figure 26). The region experienced the "Wettest Winter" during the period December 2015 through February 2016, with “impressive” amounts of rain, 26.57 inches or 10 inches above normal (CIRC 2016b). The intense pattern of precipitation, especially around midDecember, caused flooding in the low-lying areas near the study wetlands, especially near the Tualatin River. An example of this flooding occurred at WL1785, where the water levels in the Tualatin River had risen so high that the river was flowing over the riverbanks, into the wetland (Appendix D). As of the 16 December sampling visit, WL151 waters had extended across most lower elevations (expected), much of the area at WL1785 was inundated, creating a large area of open water (expected), and waters from the wetland near WL2905 had encroached into the flagged channel, inundating all sampling sites (not expected). In December, temperatures were below freezing as evidenced by ice formations at all three sites on 1 January, especially in areas of shallow water and saturated, wet soil. By 1 January 2016, 
flood waters had receded at WL1785 and WL2905. Unfortunately, the flood up barriers at WL151 had been compromised during the December flood event, which caused the gates to be dislodged and ponded water to flow out of the wetland, leaving only channeled waterways and exposed mud across the wetland on 1 January (Appendix E). On subsequent sampling dates, the flood up barriers at WL151 had been restored. Water levels followed precipitation patterns, generally lowering over the period from January to May, although the extent of the large open water area at WL1785 was substantial through early May, still measuring 4-5 feet deep at the outflow gate.

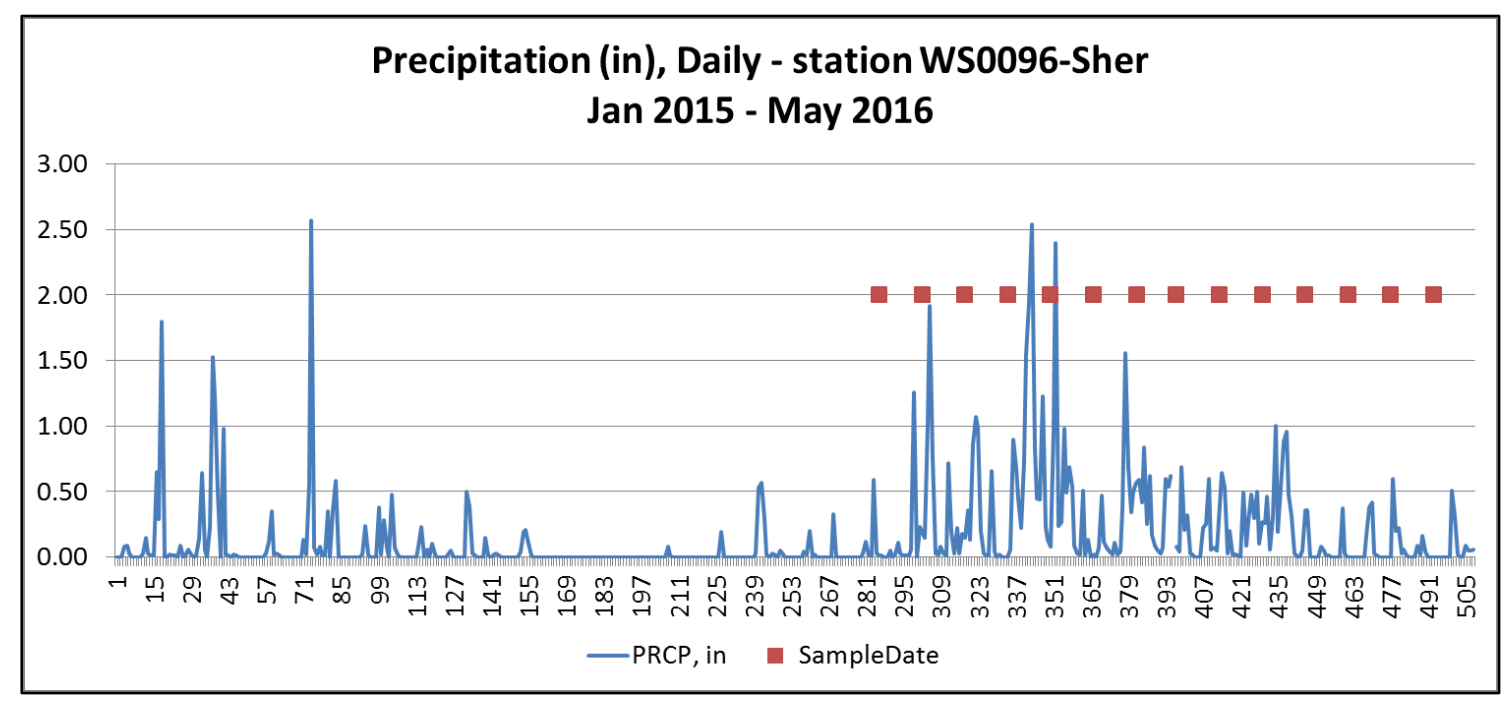

Figure 26. Daily precipitation in mm at NOAA weather station WS0096 Sherwood 2.0 NW showing dates when soil samples were taken from October 2015 to May 2016 (NOAA 2015, 2016). Note: Julian dates across the x-axis are extended beyond 2015 (J365) into 2016 for sake of visual continuity.

Estimates of soil moisture with in-situ soil surveys were based on the weight-by-drymethod as described in Chapter 4.2, with examples of soil processing shown in Appendix F. Soil moisture estimates for dates corresponding to the usable satellite images are shown in 
Table 4 and Table 5. Note: In cases where the water table was higher than the bottom of the sampling hole, the amount of water in the sample was sometimes greater than the dry soil content of the sample. In these cases, the calculation for dry weight ratio was greater than 1.00 , which was interpreted to indicate complete saturation.

Given the raw estimates of soil moisture from in-situ soil samples, only the relative dryness or wetness of the surface was estimated. Categories of surface moisture were developed for this research later, in Step 4. There, wetness predictions based on remote sensing data were compared and validated against the wetness estimated based on soil sampling in the field. 
Table 4. Sample data on 14 October 2015 with calculations for dry-weight analysis of soil samples, shown as (wet-dry)/dry.

\begin{tabular}{|c|c|c|c|c|c|c|c|}
\hline sample_date & weight_start & weight_end & weight_diff & $\begin{array}{c}\text { (wet-dry) } \\
\text { / dry }\end{array}$ & sample_site & wc_site & tray_ID \\
\hline $10 / 14 / 2015$ & 15.3827 & 14.2488 & 1.1339 & 0.08 & 1 (upland, W) & 151-1 & 6 \\
\hline $10 / 14 / 2015$ & 30.5901 & 26.1624 & 4.4277 & 0.17 & 2 (upland) & $151-2$ & 90 \\
\hline $10 / 14 / 2015$ & 21.4183 & 18.7181 & 2.7002 & 0.14 & 3 (upland) & $151-3$ & $47 B$ \\
\hline $10 / 14 / 2015$ & 20.1160 & 16.9048 & 3.2112 & 0.19 & 4 (upland) & $151-4$ & 88 \\
\hline $10 / 14 / 2015$ & 20.5683 & 17.4658 & 3.1025 & 0.18 & 5 (channel) & $151-5$ & $11 \mathrm{~B}$ \\
\hline $10 / 14 / 2015$ & 19.1777 & 16.8497 & 2.3280 & 0.14 & 6 (channel) & $151-6$ & 34 \\
\hline $10 / 14 / 2015$ & 29.0955 & 23.5523 & 5.5432 & 0.24 & 7 (channel) & $151-7$ & 9 \\
\hline $10 / 14 / 2015$ & 25.8392 & 20.9936 & 4.8456 & 0.23 & 8 (channel) & $151-8$ & 50 \\
\hline $10 / 14 / 2015$ & 33.1982 & 27.0205 & 6.1777 & 0.23 & 99 (drain, E) & 151-99 & 7 \\
\hline $10 / 14 / 2015$ & 25.0630 & 17.8150 & 7.2480 & 0.41 & $1.1=2-\mathrm{L}$ (upland) & 1785-1-1 & 94 \\
\hline $10 / 14 / 2015$ & 28.1858 & 20.1725 & 8.0133 & 0.40 & $1.2=1-\mathrm{L}$ (upland) & $1785-1-2$ & 93 \\
\hline $10 / 14 / 2015$ & 15.2880 & 8.7904 & 6.4976 & 0.74 & $1.3=1$ (channel) & 1785-1-3 & 10 \\
\hline $10 / 14 / 2015$ & 26.8133 & 18.8848 & 7.9285 & 0.42 & $1.4=1-\mathrm{R}$ (upland & $1785-1-4$ & 73 \\
\hline $10 / 14 / 2015$ & 28.3284 & 20.0723 & 8.2561 & 0.41 & $1.5=2-\mathrm{R}$ (upland) & $1785-1-5$ & 62 \\
\hline $10 / 14 / 2015$ & 24.7895 & 15.9086 & 8.8809 & 0.56 & 2 (channel) & $1785-2$ & 61 \\
\hline $10 / 14 / 2015$ & 11.6145 & 6.7085 & 4.9060 & 0.73 & 3 (channel) & $1785-3$ & $17 \mathrm{~N}$ \\
\hline $10 / 14 / 2015$ & 15.3974 & 10.1650 & 5.2324 & 0.51 & 4 (channel) & $1785-4$ & 28 \\
\hline $10 / 14 / 2015$ & 21.5069 & 17.9946 & 3.5123 & 0.20 & 5 (channel) & $1785-5$ & 16 \\
\hline $10 / 14 / 2015$ & 22.5578 & 19.3500 & 3.2078 & 0.17 & 6 (channel) & $1785-6$ & 14 \\
\hline $10 / 14 / 2015$ & 20.7843 & 13.8581 & 6.9262 & 0.50 & 99 (drain) & 1785-99 & 3 \\
\hline $10 / 14 / 2015$ & 16.4295 & 13.4287 & 3.0008 & 0.22 & 1 (upland) & 2905-1 & 1 \\
\hline $10 / 14 / 2015$ & 35.7651 & 29.1075 & 6.6576 & 0.23 & 2 (upland) & 2905-2 & 2 \\
\hline $10 / 14 / 2015$ & 18.6254 & 16.0936 & 2.5318 & 0.16 & 3 (upland) & $2905-3$ & 3 \\
\hline $10 / 14 / 2015$ & 16.3384 & 12.0004 & 4.3380 & 0.36 & 4 (road) & $2905-4$ & 4 \\
\hline $10 / 14 / 2015$ & 35.6087 & 24.6317 & 10.9770 & 0.45 & 5 (drain @ pond) & 2905-5 & 5 \\
\hline
\end{tabular}

Table 5. . Sample data on 1 January 2016 with calculations for dry-weight analysis of soil samples, shown as (wet-dry)/dry.

\begin{tabular}{|c|c|c|c|c|c|c|c|}
\hline sample_date & weight_start & weight_end & weight_diff & $\begin{array}{c}\text { (wet-dry) / } \\
\text { dry }\end{array}$ & sample_site & wc_site & tray_ID \\
\hline $1 / 1 / 2016$ & 33.8959 & 22.8421 & 11.0538 & 0.48 & 1 (upland, W) & 151-1 & 2 \\
\hline $1 / 1 / 2016$ & 30.7974 & 19.8916 & 10.9058 & 0.55 & 2 (upland) & $151-2$ & 3 \\
\hline $1 / 1 / 2016$ & 28.7115 & 19.8225 & 8.8890 & 0.45 & 3 (upland) & $151-3$ & 4 \\
\hline $1 / 1 / 2016$ & 25.7588 & 16.7600 & 8.9988 & 0.54 & 4 (upland) & $151-4$ & 5 \\
\hline $1 / 1 / 2016$ & & & & $\mathrm{~N} / \mathrm{A}$ & 5 (channel) & $151-5$ & inundated \\
\hline $1 / 1 / 2016$ & & & & N/A & 8 (channel) & $151-8$ & inundated \\
\hline $1 / 1 / 2016$ & & & & N/A & 99 (drain, E) & $151-99$ & inundated \\
\hline $1 / 1 / 2016$ & & & & $\mathrm{~N} / \mathrm{A}$ & $1.1=2-\mathrm{L}$ (upland) & 1785-1-1 & inundated \\
\hline $1 / 1 / 2016$ & & & & $\mathrm{~N} / \mathrm{A}$ & $1.2=1-\mathrm{L}$ (upland) & 1785-1-2 & inundated \\
\hline $1 / 1 / 2016$ & & & & $\mathrm{~N} / \mathrm{A}$ & $1.3=1$ (channel) & 1785-1-3 & inundated \\
\hline $1 / 1 / 2016$ & & & & $\mathrm{~N} / \mathrm{A}$ & $1.4=1-\mathrm{R}$ (upland) & 1785-1-4 & inundated \\
\hline $1 / 1 / 2016$ & & & & $\mathrm{~N} / \mathrm{A}$ & 4 (channel) & $1785-4$ & inundated \\
\hline $1 / 1 / 2016$ & & & & N/A & 5 (channel) & $1785-5$ & inundated \\
\hline $1 / 1 / 2016$ & & & & N/A & 6 (channel) & $1785-6$ & inundated \\
\hline $1 / 1 / 2016$ & & & & $\mathrm{~N} / \mathrm{A}$ & 99 (drain) & 1785-99 & inundated \\
\hline $1 / 1 / 2016$ & 25.3681 & 16.7421 & 8.6260 & 0.52 & 11 (lowest, NW) & 2905-11 & 7 \\
\hline $1 / 1 / 2016$ & 33.2697 & 24.3486 & 8.9211 & 0.37 & 22 & 2905-22 & 8 \\
\hline $1 / 1 / 2016$ & 34.6125 & 24.4740 & 10.1385 & 0.41 & 33 & 2905-33 & 9 \\
\hline $1 / 1 / 2016$ & 25.9529 & 18.8060 & 7.1469 & 0.38 & 44 & 2905-44 & 11 \\
\hline $1 / 1 / 2016$ & 23.8664 & 16.7072 & 7.1592 & 0.43 & 55 (highest, SE) & 2905-55 & 12 \\
\hline $1 / 1 / 2016$ & 14.1324 & 9.4201 & 4.7123 & 0.50 & 4 (road) & $2905-4$ & 0 \\
\hline $1 / 1 / 2016$ & & & 0.0000 & $\mathrm{~N} / \mathrm{A}$ & 5 (drain @ pond) & $2905-5$ & inundated \\
\hline
\end{tabular}




\section{Step 4 - Validate surface moisture indices with in-situ soil surveys}

Scatterplots were created with combinations of soil sample moisture estimates as the $\mathrm{X}$-axis and on the Y-axis, NDWI and MNDWI values which were extracted to the points representing each sample site on the same date (Figure 27). All usable data is represented, i.e., all sample sites tied to water index values from usable satellite imagery on 13/14 October 2015 (dry) and 1 January 2016 (wet). As shown in the diagram, equations representing the best-fit relationship between the soil moisture from the dry-weight measurements $(\mathrm{x})$ and the water index values $(\mathrm{y})$ are:

$$
\text { NDWI: } \quad y=0.24 x-0.22
$$

MNDWI: $\quad y=0.34 x-0.31$

Correlation tests were performed. For NDWI, Pearson's r was a fairly high .732 with a significance of .000 (2-tailed). Pearson's $r$ for MNDWI was even better at .758 with a significance of .000 (2-tailed).

Using IBM SPSS, bivariate (two-variable) linear regressions were performed of values for the dry-weight moisture estimates based on in-situ soil surveys vs. each water index. Results are shown in Table 6. 


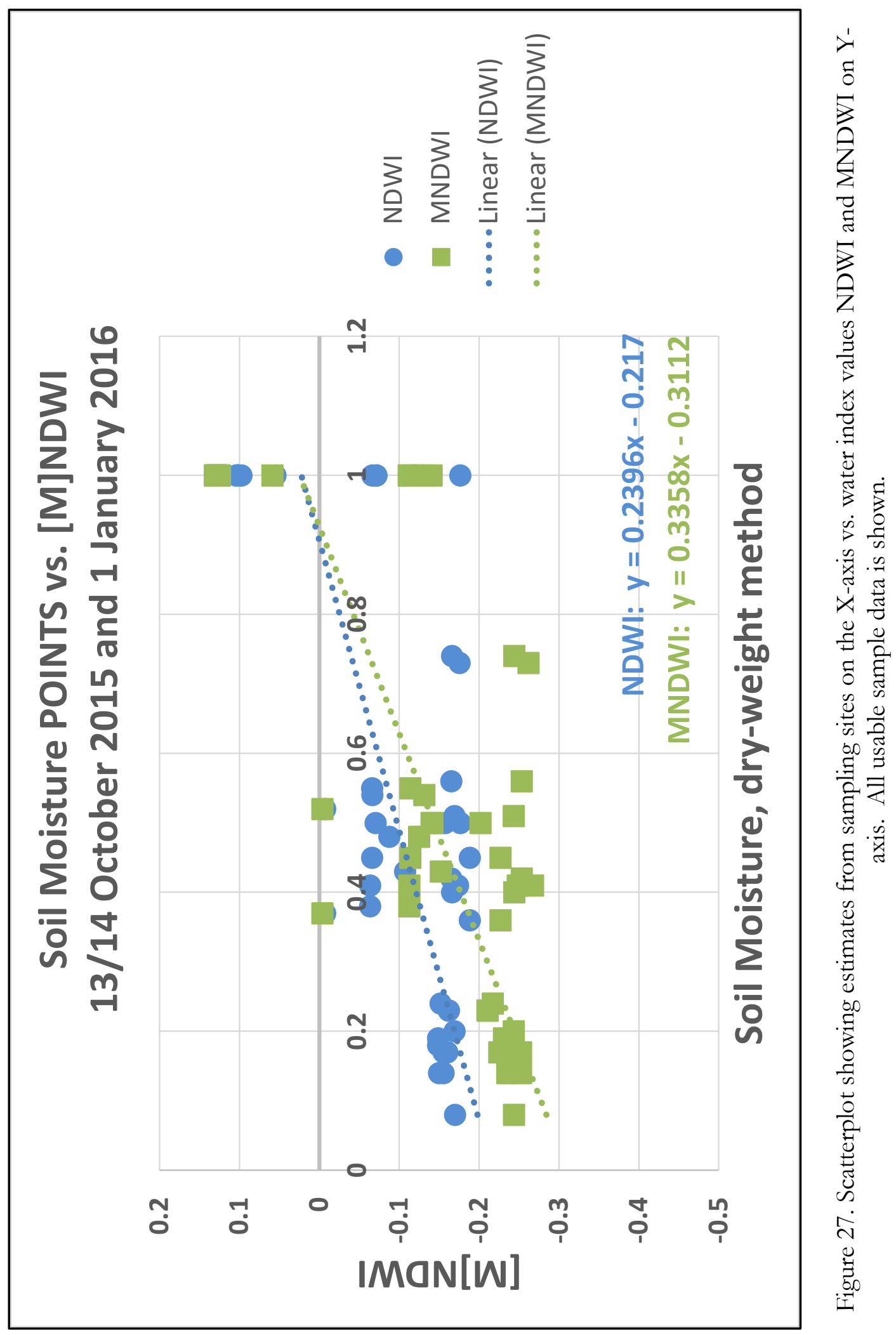


Table 6. Regression results for dry-weight estimates vs. NDWI (top) and MNDWI (bottom) soil moisture predictions.

Model Summary

\begin{tabular}{|l|r|r|r|r|}
\hline Model & $\mathrm{R}$ & R Square & \multicolumn{1}{c|}{$\begin{array}{c}\text { Adjusted R } \\
\text { Square }\end{array}$} & $\begin{array}{l}\text { Std. Error of the } \\
\text { Estimate }\end{array}$ \\
\hline 1 & $.732^{\mathrm{a}}$ & .536 & .526 & .22294 \\
\hline
\end{tabular}

a. Predictors: (Constant), NDWI

Model Summary

\begin{tabular}{|l|r|r|r|r|}
\hline Model & \multicolumn{1}{|c|}{$\mathrm{R}$} & R Square & \multicolumn{1}{c|}{$\begin{array}{c}\text { Adjusted R } \\
\text { Square }\end{array}$} & $\begin{array}{l}\text { Std. Error of the } \\
\text { Estimate }\end{array}$ \\
\hline 1 & $.758^{\mathrm{a}}$ & .574 & .565 & .21359 \\
\hline
\end{tabular}

a. Predictors: (Constant), MNDWI

Step 5 - Categorize bydrologic connectivity and bydrological permanence

Of the seventeen (17) satellite fly-overs after 1 January 2015 and prior to the start of the research field work on 13 October 2015, there were seven (7) usable images. Six (6) of these were chosen to represent a dry period (images from 9 July, 26 August and 27 September) and a relatively wet period (images from 30 January, 3 March and 20 April). Figure 26 shows the precipitation for all of 2015 and through May of 2016. To prepare for analysis of the time series images, daily precipitation data was extracted (Table 7) to 
emphasize total precipitation in the previous 3- and 7-days immediately before each image was captured.

Statistics for water index values in the dry and wet time series are summarized in Figure 28 and Figure 29.

Table 7. Precipitation totals (inches) at weather station WS0096 Sherwood 2.0 NW near the study area (NOAA 2015, 2016).

\begin{tabular}{|r|r|c|c|}
\hline date & julian date & $\begin{array}{c}\text { precip } \\
\text { (in) prev3 }\end{array}$ & $\begin{array}{c}\text { precip } \\
\text { (in) prev7 }\end{array}$ \\
\hline 2016 & & & \\
\hline 2015 & 1 & 0.16 & 0.81 \\
\hline 20160101 & & & \\
\hline 20151013 & 286 & 0.64 & 0.80 \\
\hline 20150927 & 270 & 0.33 & 0.33 \\
\hline 20150826 & 238 & 0.00 & 0.00 \\
\hline 20150420 & 190 & 0.00 & 0.00 \\
\hline 20150303 & 110 & 0.00 & 0.57 \\
\hline 20150130 & 62 & 0.41 & 0.56 \\
\hline & 30 & 0.09 & 0.19 \\
\hline
\end{tabular}




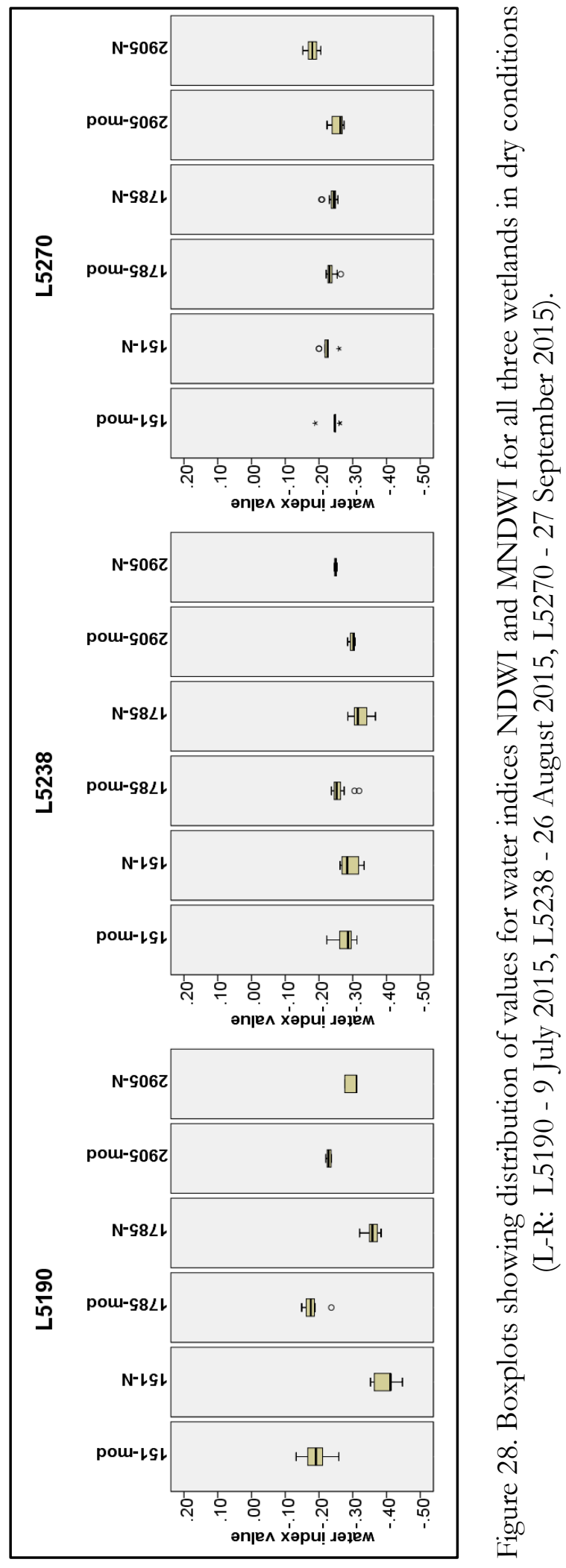




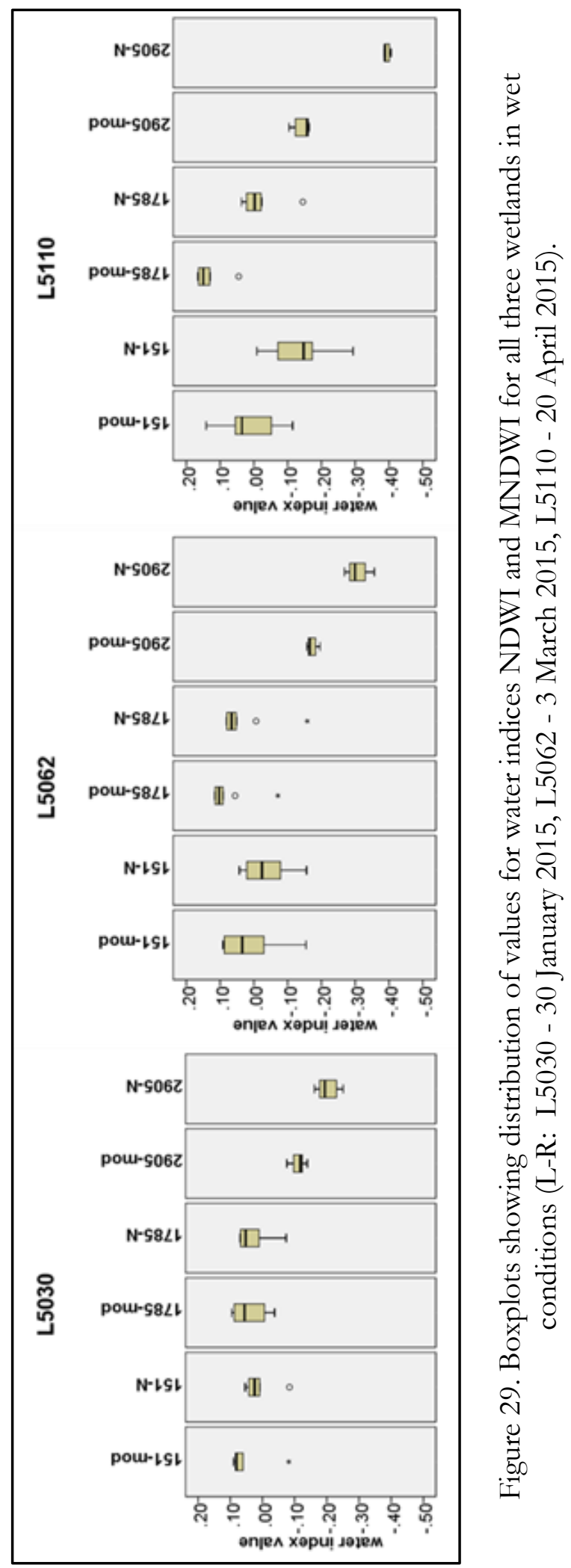


Substituting soil moisture threshold values for " $\mathrm{x}$ " in the correlation equations from Step 4 - Validate, the resulting water index threshold values for dry, moist and wet-toinundated were:

$\begin{array}{lll}\text { NDWI: } & (-1.00 \text { to }-0.1501) & \text { dry } \\ & (-0.15 \text { to }-0.0701) & \text { moist } \\ & (-0.07 \text { to } 1.00) & \text { wet-to-inundated } \\ \text { MNDWI: } & (-1.00 \text { to }-0.2101) & \text { dry } \\ & (-0.21 \text { to }-0.1101) & \text { moist } \\ & (-0.11 \text { to } 1.00) & \text { wet-to-inundated }\end{array}$

Images for the research dates were mapped again (13 October 2015 and 1 January 2016), this time using classifications for remote sensing indices and for soil sample data (Figures 30, 31 and 32) rather than the continuous, light-dark pixel data. Color coding on water indices is based on the classifications and threshold values described above: brown for dry, green for moist, and blue for wet-to-inundated. Color coding on symbols at sample sites indicates the category of soil moisture based on threshold values above: browns to yellow for dry, greens for moist and blues for wet-to-inundated.

Next, water index predictions for the two suites of demonstration images (dry and wet) were mapped using classifications to demonstrate their spatial distribution and relationships. Paired figures represent soil moisture classifications for time series - dry and wet - for WL 151 (Figures 33 and 34), WL1785 (Figures 35 and 36), and WL2905 (Figures 37 and 38). 


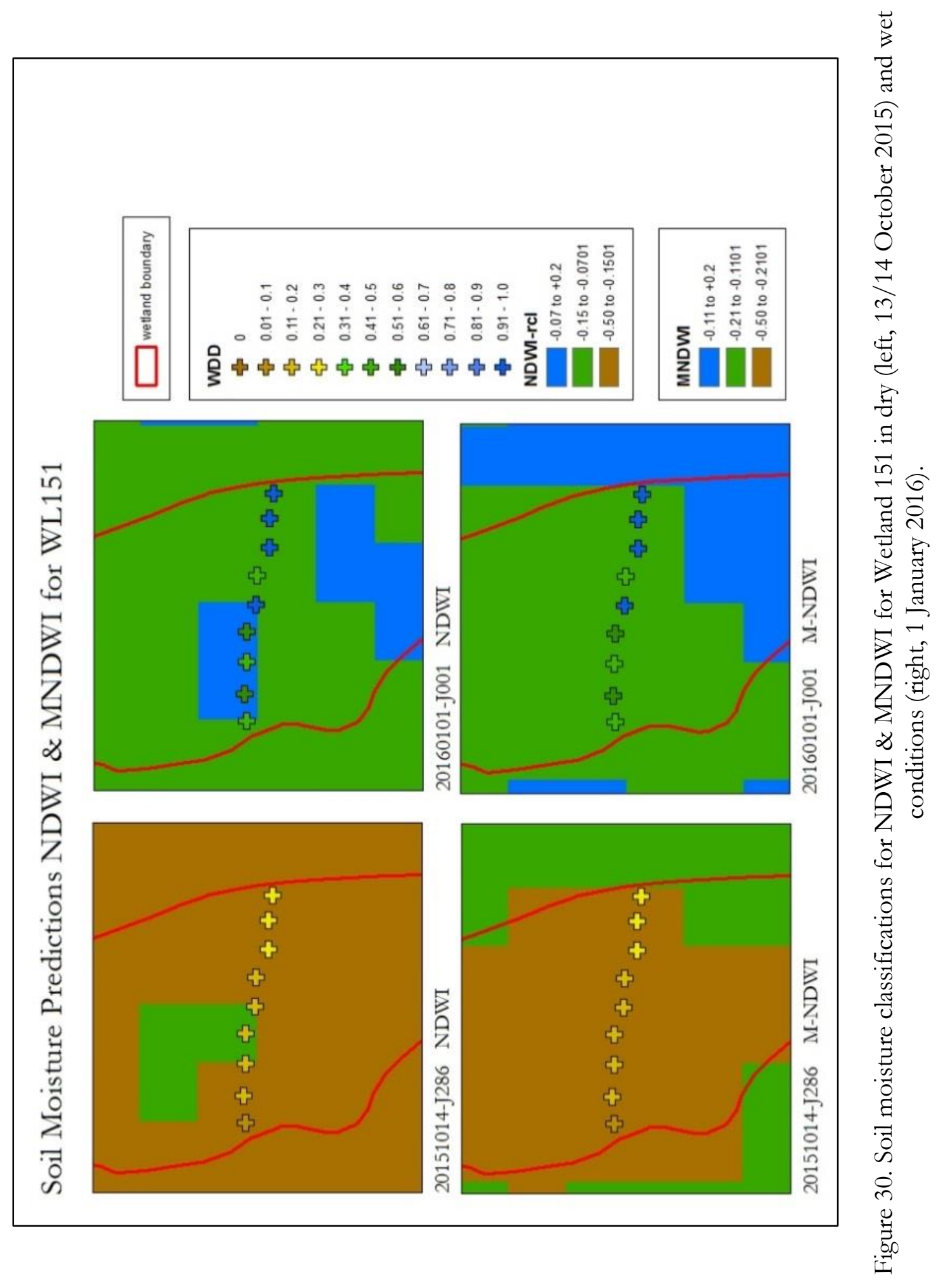




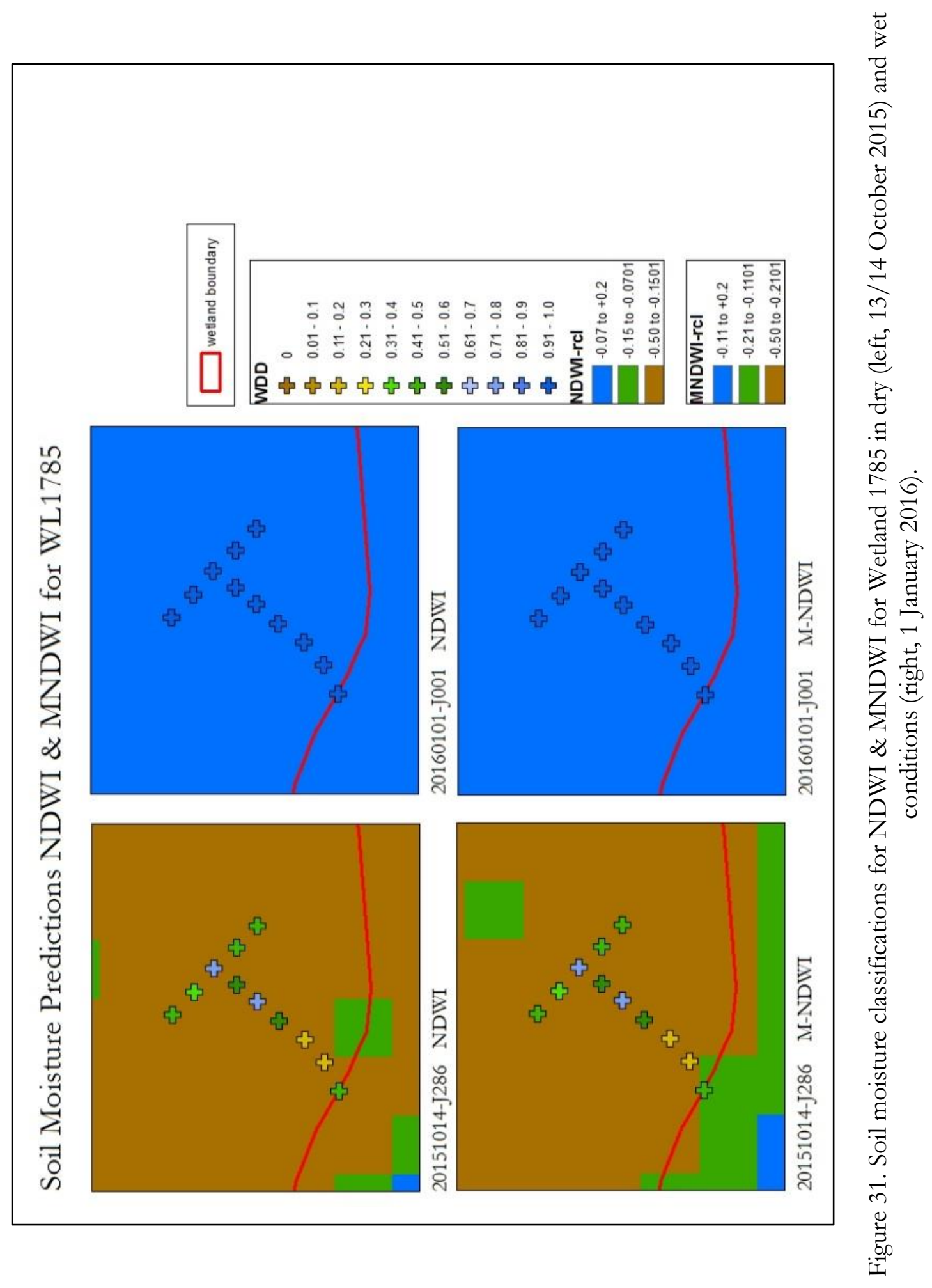




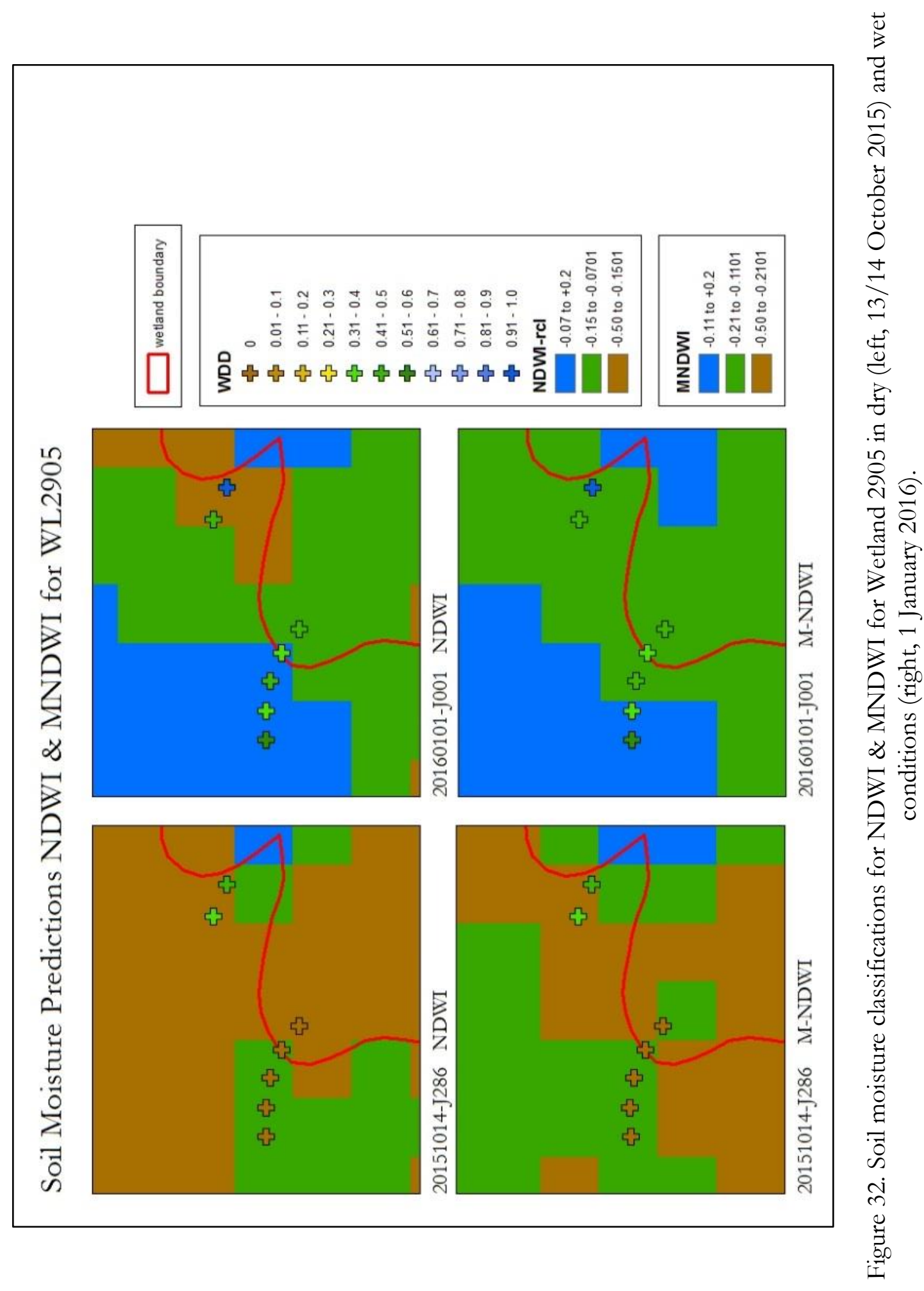




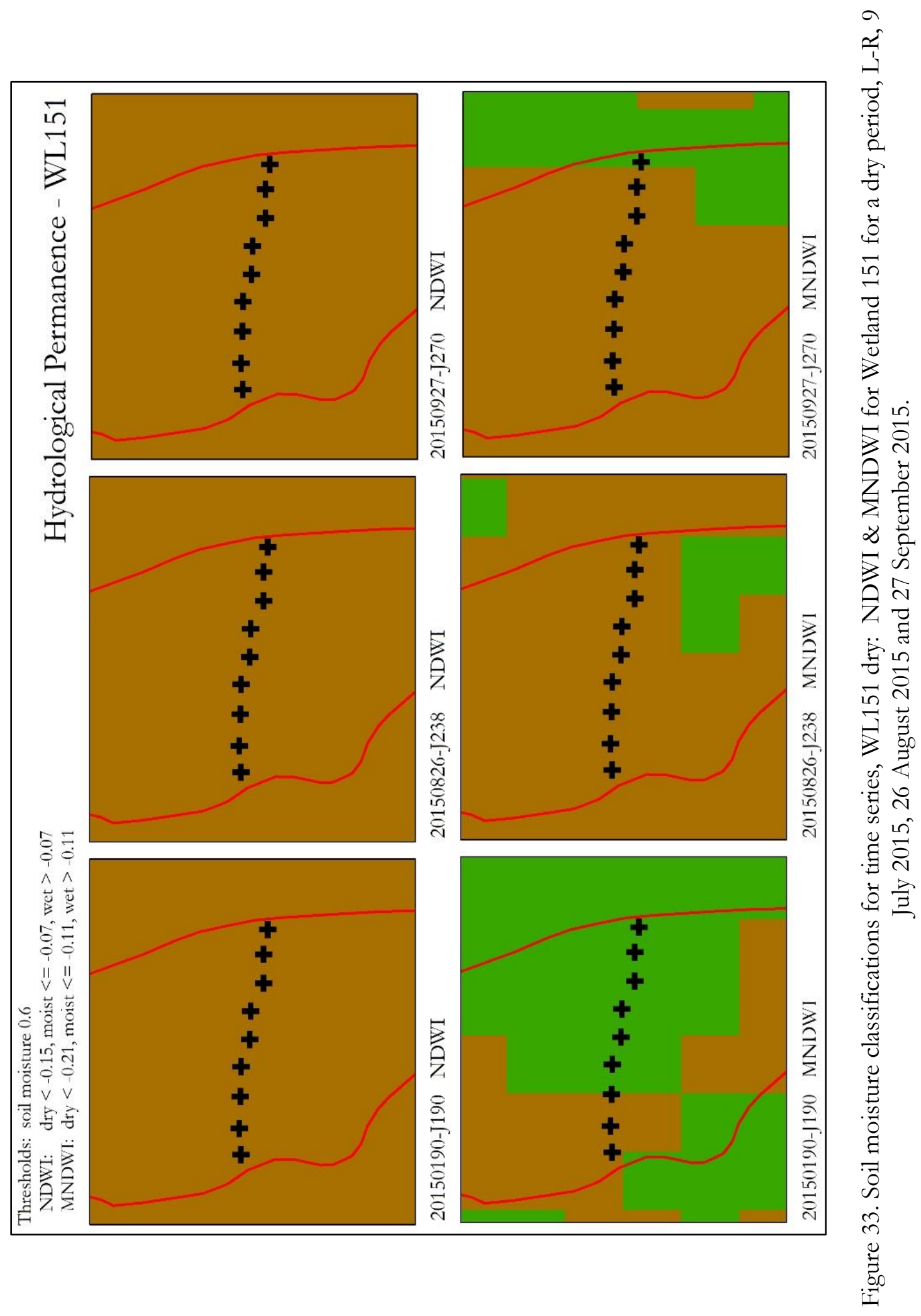




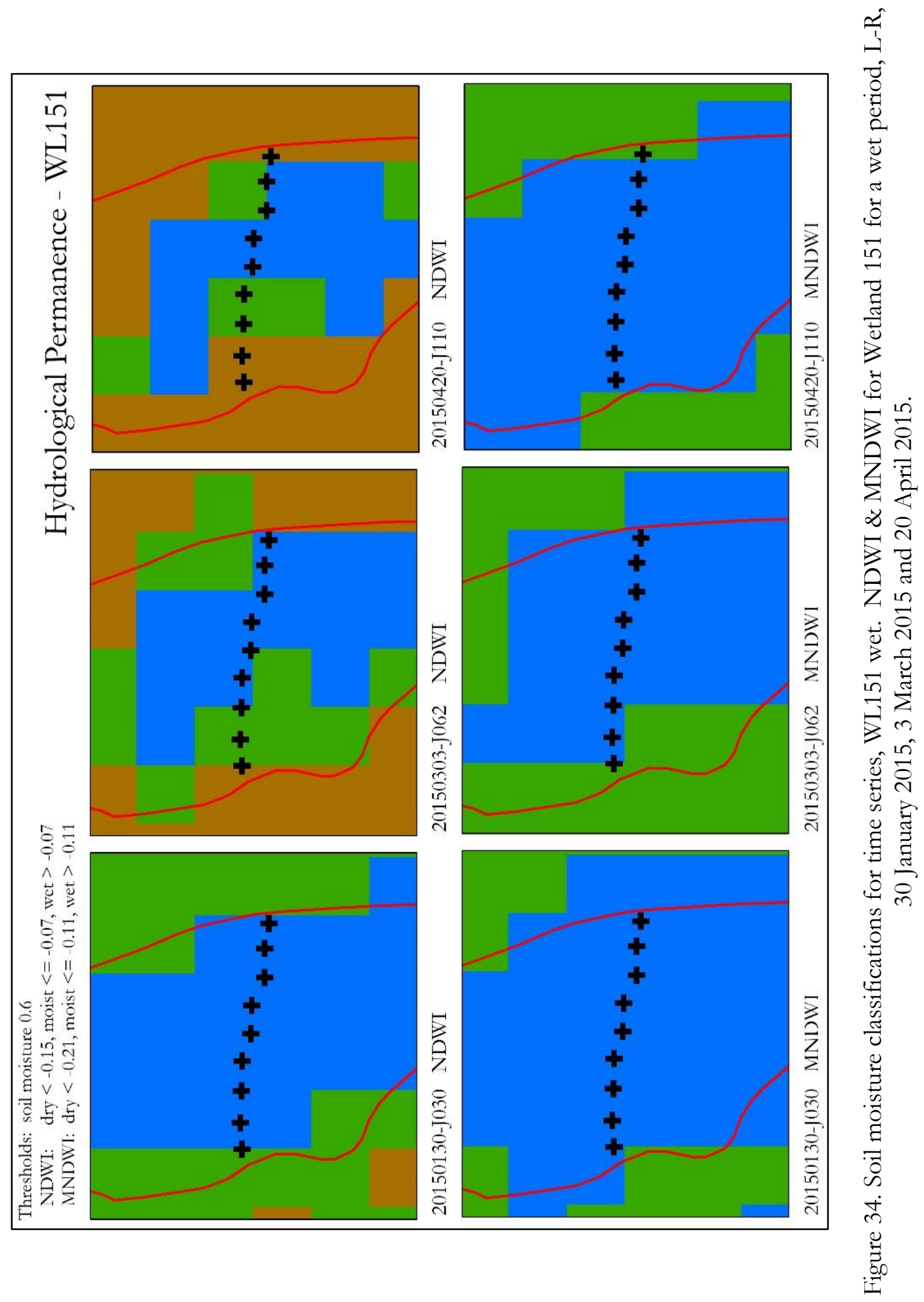




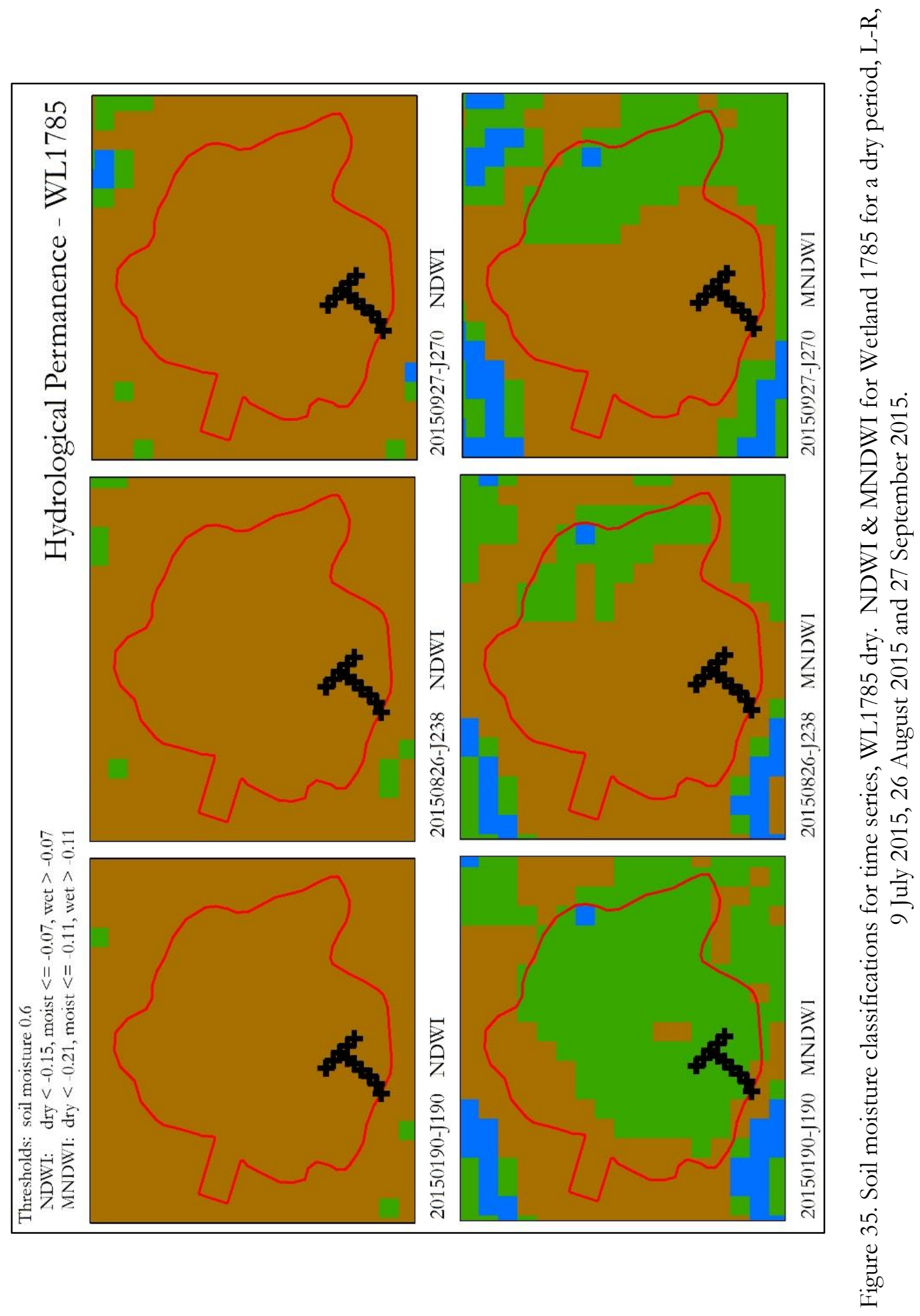




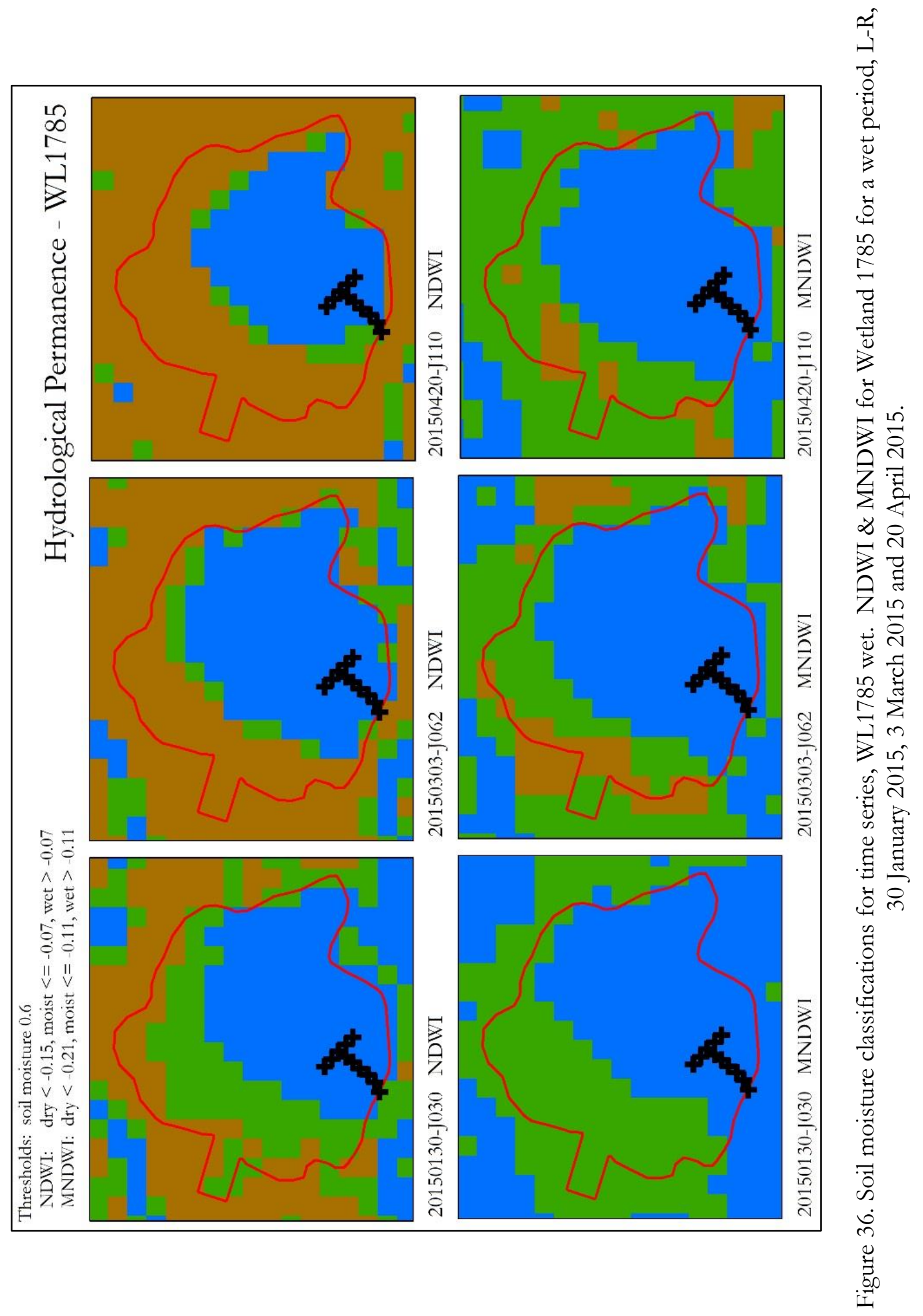




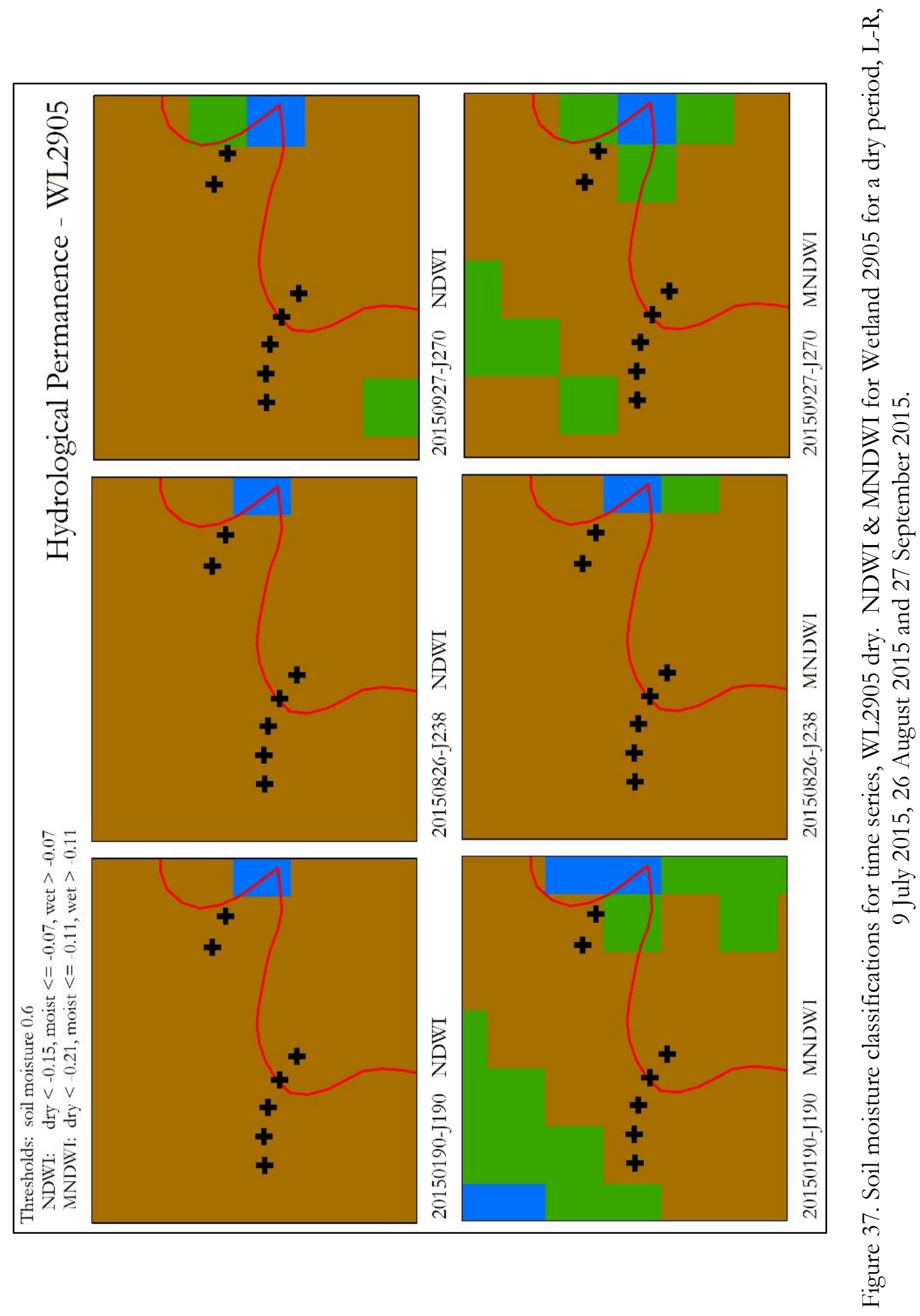




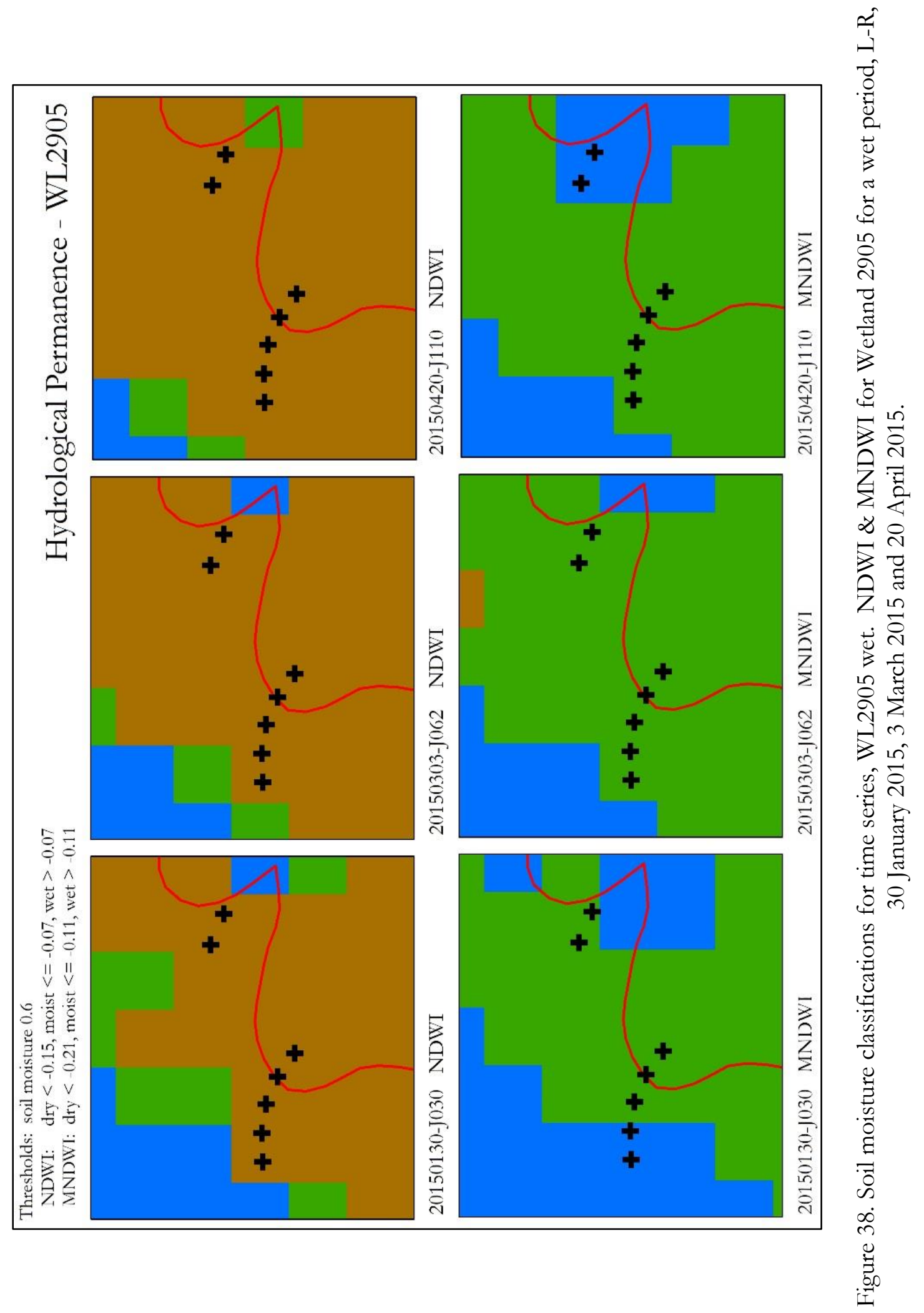




\section{Analysis and Discussion}

6.1 Challenges using ArcMap to determine sampling sites

Flow path estimates exhibited several inconsistencies with conditions observed onsite. Several factors may have contributed to this outcome. Because the land around the study wetlands is fairly flat, use of the Fill function to recondition the DEM may have created surfaces which do not match actual conditions. Second, the elevations in The National Dataset are based on historical measurements. On-site conditions and surfaces may have been modified since the elevation dataset was created and information published in 2009. Third, man-made drainage systems and weirs (gates) are in place at all three wetlands, as described in Chapter 5. It is not clear when these structures were installed and therefore whether the elevation database accounted for their presence. As noted, final placement of sampling sites took into account the flow path analysis, discussions with the Refuge Biologist, and on-site observations.

6.2 The pros and cons of using NDWI \& MNDWI in detecting surface moisture

When the surface conditions covered a large enough area, i.e., the area of homogeneous surface wetness was equal to or larger than the resolution of the sensor, satellite indices appear to accurately detect the surface moisture. At 30-meter resolution, this detectable area is about 900 square meters or about 0.22 acres. If a sensor captures the reflectance of more than one land cover type or feature in a single pixel, the resulting value represents an average of those responses, and results in a mixed pixel (Lillesand et al. 2008, p 574), sometimes called a "mixel". Water and moisture covering small areas on the surface, i.e., less than about 900 square meters, were less likely to be accurately detected. 
For example, where large areas of open water were observed in the field, the wet areas were correctly identified by both NDWI and MNDWI. A good example is the large open water area for WL1785 on 1 January 2016, which was accurately classified as wet-toinundated (Figure 31). Another example is the pond near WL2905 sampling sites (e.g., Figure 37). This pond shows up consistently as a dark-pixel, high-value prediction of wetness for both NDWI and MNDWI, at least for the pixels which represent the larger extent of the pond (in Figure 37, the pond is indicated by blue pixels, representing wet-toinundated conditions).

Large areas of dry surface conditions were also accurately predicted to be dry; however, it seems that rainfall in the days preceding the satellite image capture may have caused MNDWI and NDWI to respond differently. To illustrate, each of the four dry dates in this study are considered (J190, J238, J270 and J286). The summer of 2015 was an exceptionally hot and dry period around Portland, Oregon (Wiltgen 2015). When the soil and vegetation were likely both dry (J238 and J270), both NDWI and MNDWI calculations resulted in fairly consistent negative values, indicating a relative lack of water. After a period of hot days and no rainfall in the 7-days before satellite image capture on J190, NDWI predicted drier conditions (lower index values) than MNDWI at WL151 (Figure 28 and Figure 33). On the other hand, when it had rained a significant amount prior to the satellite image capture on J286, even though the vegetation was observed to be dry, MNDWI predicted drier conditions than NDWI at WL151 (Figure 25 and Figure 30). Perhaps this difference was caused by reflectance from surface moisture remaining after the recent rain. Note that on none of the four dry days analyzed was the surface sufficiently moist to predict open water (wet-or-inundated), except of course at the pond near WL2905. 
Where vegetation was present, the predictions of the near-infrared based NDWI could be indicative of the moisture content of the plant material rather than surface water. During my study, the most likely evidence of different NDWI and MNDWI responses to vegetation might be shown in the time series for WL151 wet and WL1785 wet (Figure 34 and Figure 36). During on-site visits in the spring of 2016, grasses were observed growing in the shallows of the inundated areas in both of these wetlands. The grasses grew progressively denser as spring advanced, leaving patches of open water in the deeper, channeled areas of the wetland. If the seasonal vegetation patterns observed in 2016 were similar in 2015, the grasses may have caused NDWI to predict moisture rather than wet-toinundated conditions in the inundated-and-grassy areas while MNDWI was continuing to predict open water. As shown in the time series for these two wetlands, the net effect is that NDWI predicts a smaller, shrinking wet-to-inundated area but MNDWI continues to predict larger, less-rapidly-shrinking area of wet-to-inundated conditions in later spring.

Certain surface features may have caused erroneously high NDWI responses. In calculations of indices which use near-infrared bands (like NDWI), there can be confusion between bare soil and "free water" features (e.g., Soti et al. 2009, Xu 2006). This was evident in my research in areas beyond the ground-truthing zones of the wetlands (not diagrammed). In a visual review near the study wetlands, many buildings and empty fields (bare soil) were predicted by high NDWI values to be wet; however, some of these areas did not appear to be wet in the visible-band imagery. These pixels could represent errors of commission; however, my research did not extend beyond the wetland features.

Examples of features which might be too small to identify with 30-meter Landsat resolution include sampling site 5 at the edge of the pond in WL2905 (most dates) and the 
channeled water at WL1785 on J286 (Figure 31). These cases likely resulted in mixed pixel values because the water feature would be not spatially distributed enough to fill the pixel; therefore, the pixel value would represent an average of the reflections from the target feature (surface water) and other land cover in the immediate vicinity. As a result, the spatial resolution of the satellite image might be too coarse (covering too large an area) to detect wetness at these spots. Even when site 5 was completely underwater (e.g., 1 January 2016), water indices do not predict inundation. At WL1785 on J286, water indices predicted dry conditions, however, two sample sites in WL1785 on that date were wet-to-inundated (blue symbols) based on in-situ surveys. Significant rainfall was recorded in the days preceding this analysis date (Table 7). However, on-site observations indicated very dry conditions (Appendix C). It is possible that the antecedent conditions were so dry, so drought-affected, that the vegetation dried quickly in the two days before the satellite image was captured, leaving only pockets of moisture along the channel surface and near-surface. These spots of moisture were probably too small to be detected by the water indices because of the coarse, 30-meter resolution of the satellite image.

Statistical computations and graphs reveal additional relationships between the water index predictions and the in-situ soil survey data (Figure 27). The dataset is admittedly small, with only 50 points total for the two data gathering cycles on 13/14 October 2015 and 1 January 2016. As expected, dry and moist samples were plotting against water index predictions in the lower left (dry) and lower-center (moist) of the graph. Many wet samples plotted in the upper-right of the graph, as expected, indicating high moisture from estimates of samples taken in the field and also high water index predictions. However, a number of on-the-ground samples were inundated (right on x-axis, soil moisture value of 1.0 ) but the 
index values at the same site were low (below zero), indicating drier surfaces. These errors may have been due to the moisture being subsurface and not visible to satellite measures of surface reflection, due to reflection from vegetation rather than the underlying soil, or due to the moisture pattern being too small in physical extent to register in the water indices, i.e., the resolution of the satellite imagery was too low to detect the moisture at these spots. In further statistical analysis, correlation test results are fairly high, with a Pearson's r of .732 and .758 for NDWI and MNDWI, respectively. This is to be expected since both the water indices and the soil samples are attempts to measure the same phenomenon, surface moisture. On the other hand, the regression fit is fairly low, with r-squared (goodness-of-fit) at .536 and .574 for NDWI and MNDWI, respectively. The small sample size and/or the handful of errors noted above may have reduced the predictive ability of the regression.

To further test the sensitivity of the water index extractions, each sample site was buffered, then water index values were extracted using the average value within the buffer (Zonal Statistics). In this way, if a sampling site was near the edge of a water index pixel in the Landsat image, the average value of any pixels within the zone of the buffered point would be extracted and might result in a prediction closer to the soil sample estimates. The size of the buffer was determined by the metadata from the Landsat metadata, i.e., the Geometric_RMSE_Model_X and Geometric_RMSE_Model_Y of the Data Format Control Block for Level 1 data (USGS 2014a). These values represent the positional accuracy of the Landsat image, specifically the post-fit root mean square error of the geometric residuals in the across-track $(\mathrm{X})$ and along-track $(\mathrm{Y})$ directions, in meters. For the 13 October image, these values were $(4.267,5.245)$ and on 1 January they were $(5.954,7.203)$. Between 13 October 2015 and 5 March 2016, the maximum values were $(6.924,9.654)$. Therefore, to 
include the maximum variation in positional accuracy, i.e., 9.654 meters, a 10-meter buffer was selected. A scatterplot was produced with the buffered values representing the predicted wetness values (Figure 39). Results extracted using the average value within a 10meter buffer were essentially the same as those produced using extracts at the sample point locations, i.e., the linear equations are the same to two decimal places. 


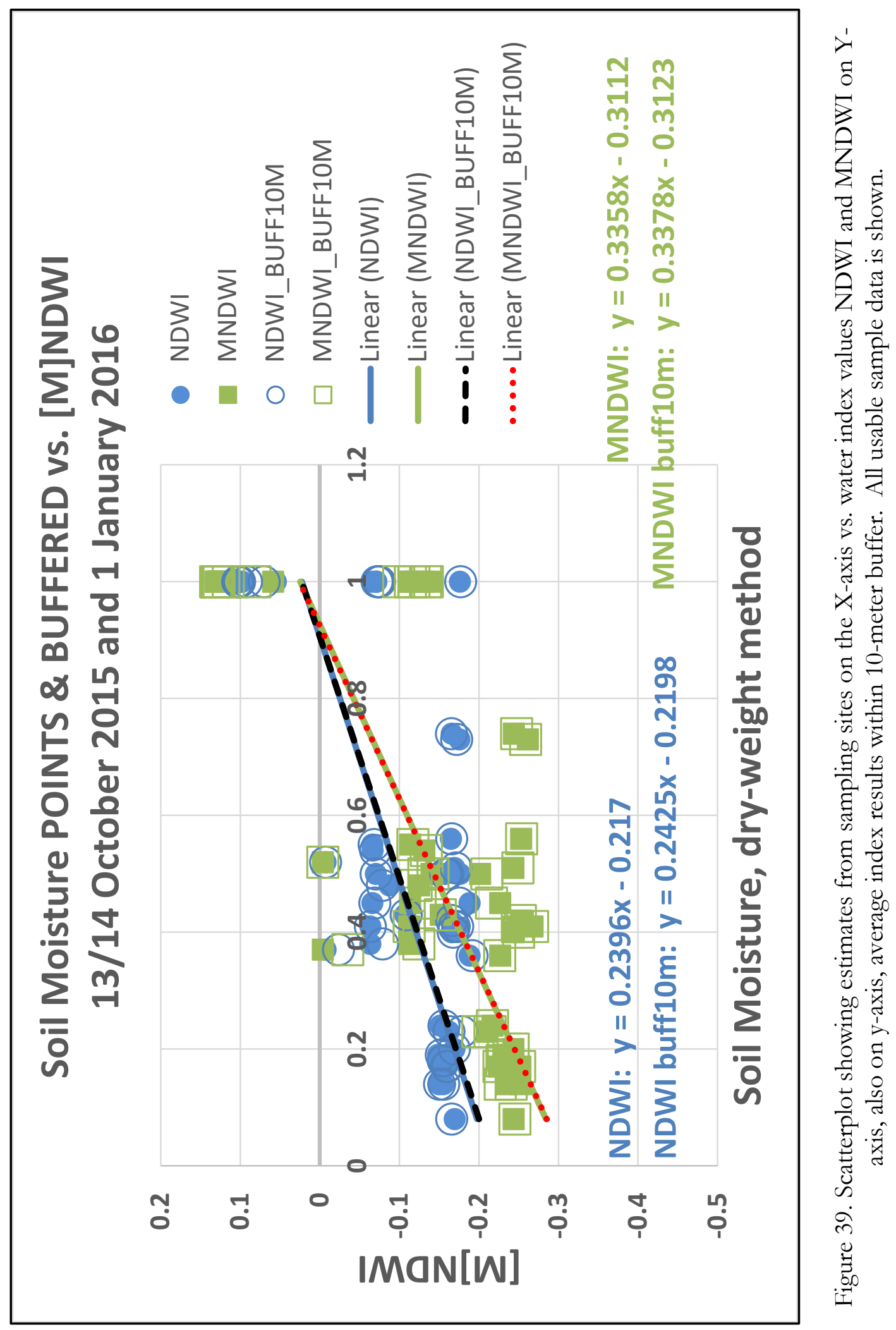




\subsection{Hydrologic connectivity and hydrological permanence}

One of two demonstration goals for this study was to determine whether a wetland was hydrologically connected to a nearby water feature on a particular day, i.e., an individual study date. For WL2905, this was straightforward. This wetland appeared not connected in dry conditions on 14 October, based on predictions by water indices, analysis of soil samples and on-site observations. In wet conditions on 1 January 2015, WL2905 was again deemed to be not connected, based on the fact that open water was not predicted by the water indices nor was it estimated in soil sampling (or observed) along the 11-55 track. The only place which was deemed wet at WL2905 on 1 January 2015 was at sampling site 5, at the edge of the pond. On the other hand, determining connectivity to the nearby water features for the remaining two wetlands, WL151 and WL1785, was not straightforward. In fact, it was not technically possible. Outflows from the weir / gates have been routed under roadways, so satellite images would not be able to determine the surface moisture immediately adjacent and downstream from the pour points. However, pixels within WL1785 were predicted to be wet-to-inundated in a contiguous pattern, as confirmed by observations and sampling data. Therefore, WL1785 was deemed to be internally connected on 1 January 2016. Based on field-validated mapping on 1 January 2016 (Figure 30) and the satellite-based time series (Figure 34), WL151 showed indications of being internally connected as well during wet periods. As a result, this research seems to demonstrate not whether hydrologic connectivity between wetlands and nearby water features can be estimated but rather, whether hydrologic connectivity between specific geographic locations can be estimated. In other words, water indices appear able to predict surface wetness or inundation between point $\mathrm{A}$ and point $\mathrm{B}$. In the context of my research, internally connected points are those which 
lie within pixels identified as wet-to-inundated in a contiguous path in any one satellite image, i.e., on a single date.

Based on the analysis of data for demonstration dates, and informed by results for Steps $1-4$ of the original evaluation of the water indices, estimates of hydrologic connectivity and hydrological permanence were generated for each wetland (Figure 40 and Figure 41). After all the analysis, sampling and validation, the conclusions are fairly straightforward. Wetland 151 was considered internally connected for an intermittent / seasonal duration. Wetland 1785 was also considered internally connected for an intermittent / seasonal duration. Wetland 2905 was deemed to have no hydrologic connectivity based on satellite data and the hydrologic connectivity was therefore summarized as none. In fact, this wetland was observed to be connected to the nearby water feature (the nearby wetland) on an ephemeral, short-term basis during the flooding event in mid-December. 


\section{Hydrologically connected?}

\begin{tabular}{|c|c|c|c|}
\hline feature-ID & $\mathrm{HC}$ & date & surface conditions \\
\hline 151 & internal & 20150130 & wet \\
\hline 151 & internal & 20150303 & wet \\
\hline 151 & internal & 20150420 & wet \\
\hline 151 & $\mathrm{~N}$ & 20150709 & dry \\
\hline 151 & $\mathrm{~N}$ & 20150826 & dry \\
\hline 151 & $\mathrm{~N}$ & 20150927 & dry \\
\hline 151 & $\mathrm{~N}$ & 20151013 & dry \\
\hline 151 & internal? & 20160101 & wet \\
\hline 1785 & internal & 20150130 & wet \\
\hline 1785 & internal & 20150303 & wet \\
\hline 1785 & internal & 20150420 & wet \\
\hline 1785 & $\mathrm{~N}$ & 20150709 & dry \\
\hline 1785 & $\mathrm{~N}$ & 20150826 & dry \\
\hline 1785 & $\mathrm{~N}$ & 20150927 & dry \\
\hline 1785 & $\mathrm{~N}$ & 20151013 & dry \\
\hline 1785 & internal & 20160101 & wet \\
\hline 2905 & $\mathrm{~N}$ & 2050130 & wet \\
\hline 2905 & $\mathrm{~N}$ & 20150303 & wet \\
\hline 2905 & $\mathrm{~N}$ & 20150420 & wet \\
\hline 2905 & $\mathrm{~N}$ & 20150709 & dry \\
\hline 2905 & $\mathrm{~N}$ & 20150826 & dry \\
\hline 2905 & $\mathrm{~N}$ & 20150927 & dry \\
\hline 2905 & $\mathrm{~N}$ & 20151013 & dry \\
\hline 2905 & $\mathrm{~N}$ & 20160101 & wet \\
\hline
\end{tabular}

Figure 40. Hydrologic connectivity. Demonstration of water indices, specifically estimates of hydrologic connectivity $(\mathrm{HC})$ by wetland for study sites at the Tualatin River National Wildlife Refuge from January 2015 to May 2016. 


\begin{tabular}{|c|c|c|}
\hline \multicolumn{3}{|l|}{ Hydrological permanence } \\
\hline & & \\
\hline feature-ID & HC & HP \\
\hline 151 & internal & $\mathrm{I}$ \\
\hline 1785 & internal & $\mathrm{I}$ \\
\hline 2905 & $\mathrm{~N}$ & $\mathrm{~N}$ \\
\hline & & \\
\hline
\end{tabular}

Figure 41. Results - Hydrological permanence. Demonstration of water indices, specifically the summary of hydrologic connectivity (HC) and hydrological permanence (HP) by wetland for study sites at the Tualatin River National Wildlife Refuge from January 2015 to May 2016. Note: For HC, internal $=$ intermittent $/$ seasonal connectivity, $\mathrm{N}=$ none. For $\mathrm{HP}, \mathrm{I}=$ intermittent/seasonal permanence, $\mathrm{N}=$ none. 


\section{Conclusions}

The goal of this research was to demonstrate the use of water indices to identify water features on the Earth's surface. The research question was whether water indices derived from Landsat 8 OLI satellite imagery, specifically the Normalized Difference Water Index (NDWI) and the Modified NDWI (MNDWI), are effective in identifying open water and surface moisture. These two water indices have been studied in a variety of settings, including wetlands. On the other hand, there is a well-documented lack of metrics for estimating connectivity in wetlands (or other hydrologic environments). Therefore, this research proposed the use of familiar ratios (NDWI and MNDWI) to a new and unfamiliar area of scientific study: hydrologic connectivity and hydrologic permanence.

Based on this study, both NDWI and MNDWI were responsive to changes in surface moisture in wetlands, including open water features and soil moisture. NDWI and MNDWI were both able to accurately identify large open water features across the landscape. In dry conditions, NDWI and MNDVI were shown to respond in a different but somewhat predictable manner, based on precipitation events prior to the satellite image capture. MNDWI appears to be more able to locate surface moisture in dry conditions than NDWI. On the other hand, NDWI appeared to more able to predict variations in dry conditions when recent rainfall was significant, perhaps responding to vegetation moisture rather than surface moisture. While some NDWI responses in this study appeared to be erroneous values (e.g., buildings or bare soil), NDWI's predictive responses to vegetation might be a proxy indicator for soil moisture at or just below the surface.

To demonstrate the use of water indices, estimates were generated for hydrologic connectivity and hydrological permanence for each wetland. Results for soil sample 
moisture estimates were categorized as dry, moist or wet-to-inundated, based on characteristics of the soil as observed in the field. Thresholds were established for soil samples then threshold values for NDWI and MNDWI were derived using the equation of best fit between soil survey values and water index predictions identified in this research. One objective of the demonstration was to identify contiguous paths of wet-to-inundated surfaces to identify areas which might be hydrologically connected on any one date. A second objective was to predict hydrologic permanence over time, indicating whether any hydrologic connections persist. The study determined that ephemeral connectivity events might not be captured using Landsat imagery, but that intermittent and perennial connections are clearly identifiable.

Studies of hydrologic connectivity and hydrological permanence stand to benefit most from the research described here. It is relatively easy to generate water indices from a satellite image and estimate whether the contiguous path between point $\mathrm{A}$ and point $\mathrm{B}$ appears wet-to-inundated, as predicted by high-pixel values in that path. As a sample application, a historical study could be conducted which estimates surface moisture using NDWI and MNDWI to indicate the patterns of inundation for a particular wetland, including the time of year with the highest and lowest probability of connectivity. For studies of climate change, the historical patterns could be evaluated to determine whether there has been an increase or decrease in the frequency or duration of connectivity patterns. Also, while threshold values are not required to estimate connectivity, analysis of their interactions might provide insight into the landscape being studied. Does a wetland appear disconnected, no matter how low the threshold is set for wet-to-inundated? Perhaps this indicates a geographically isolated wetland (based on surface interactions). Using this 
research and other techniques, as they are developed, metrics for connectivity could be developed which would improve our conversations, whether they be focused on legal issues, scientific investigation or management of surface water features and the life which depends upon that water.

The ability of water indices to predict the location of large open water features at a landscape-scale could be useful for studying surface areas which may be difficult, expensive or time-consuming to estimate on the ground. Satellite-based estimates could help determine when wetlands are most likely to be connected (or not), allowing for better timing of field work. At a basic level, the connectivity metrics proposed in this research could inform much-needed discussions on what connectivity is and how it can be measured.

Several areas for future research were evident during this study. Further adjustments to the threshold values for NDWI and MNDWI or sensitivity analysis of possible thresholds might improve the predictive value of the indices. For example, more extensive comparisons of NDWI and MNDWI results could help delineate surface areas with and without vegetation, thereby indicating locations of surface or near-surface water, especially where the vegetation is dense. Also, studies in non-wetland environments are warranted. Connectivity between streams and wetlands has been deemed essential for their functioning. The proposed techniques are general enough that they may be transferrable to a variety of hydrologic configurations. It would also be interesting to explore the use of small unmanned aerial vehicles or UAVs to capture imagery, rather than relying on Landsat satellites and the inherent problems with cloud cover. Under certain conditions, UAVs can fly below the clouds and could allow for more frequent capture of imagery, which would help to create a time series, thereby allowing for better estimates of hydrological 
permanence. In addition, lower altitude flights (with the appropriate sensors) could potentially provide data at a higher resolution than possible with Landsat 8.

In spite of the predictive value of NDWI and MNDWI ratios, significant hurdles were encountered. The most obvious was the lack of usable satellite imagery due to the presence of clouds over the study area. During the seven-month study period, there were frequent and sometimes heavy precipitation events. Clear imagery was only available on a few of the fourteen satellite fly-over days, rendering it impossible to estimate hydrological permanence during this period. Given this natural challenge with cloud cover likely during wet periods, it is possible that NDWI and MNDWI estimates could better assist with studies in arid regions or during the dry season, conditions in which cloud cover might be minimal. NDWI responses in this research show variations which might hint at the location of subsurface water, which is especially important in arid conditions.

A second challenge existed due to the man-made drainage systems on the Refuge. These structures route wetland outflows underneath roadways, making the flows invisible to satellite imagery. One of the demonstration questions for this study was whether water indices could be used to estimate the hydrologic connectivity between a wetland and nearby water feature. Because portions of the flow paths were invisible to the satellite, it would be more accurate to state that this study evaluated whether sample sites were partially connected or internally connected, i.e., connected to one another within a wetland environment. While not the original question, this is nonetheless an interesting metric. The ability to determine connectivity between Point A and Point B could have application beyond wetland environments, but was outside the scope of this research. 
A third reality is that Landsat OLI imagery is relatively coarse at 30-meters per pixel. The Landsat mission has reliable frequency and a deep cache of historical data, however, certain water features occur in a precise, limited spatial area, such as ponds or channeled flows. The reflectance values for these localized features are overwhelmed in the pixelaggregation process and the surface conditions are therefore not identifiable. Advances in satellite-borne sensors make it possible to process near- and mid-infrared spectral imagery at finer resolutions. A good example is the announcement that as of 1 April 2016, data products from the Terra satellite's Advanced Spaceborne Thermal Emission and Reflection Radiometer (ASTER) would be available from around the globe at no charge, including near-infrared imagery at 15-meter resolution (lpdaac.usgs.gov).

In conclusion, for wetland environments, NDWI and MNDWI water indices were shown to be effective in detecting large open water features and variations in surface moisture, over large swaths of land, without the need for resource-intensive ground surveying. Estimates of hydrologic connectivity and hydrologic permanence were generated with straightforward calculations using publically-available (free) data. Use of these techniques could directly improve the ability to manage and conserve wetlands in a costeffective manner. 


\section{References}

Adamus, P., Morlan, J., \& Verble, K. (2010). Manual for the Oregon Rapid Wetland Assessment Protocol (ORWAP). Version 2.0.2. Salem, OR: Oregon Department of State Lands.

Amoros, C., \& Roux, A. L. (1988). Interaction between water bodies within the floodplains of large rivers: function and development of connectivity. Münstersche Geographische Arbeiten, 29(1), 125-130.

Amoros, C., \& Bornette, G. (2002). Connectivity and biocomplexity in waterbodies of riverine floodplains. Freshwater Biology, 47(4), 761-776.

Arnold, J. G., Allen, P. M., \& Morgan, D. S. (2001). Hydrologic model for design and constructed wetlands. Wetlands, 21(2), 167-178.

Band, L. E., \& Moore, I. D. (1995). Scale: Landscape attributes and geographical information systems. Hydrological Processes, 9(3-4), 401-422. doi:10.1002/hyp.3360090312

Bennett, A. F. (1998). Linkages in the landscape: The role of corridors and connectivity in wildlife conservation. Gland, Switzerland: Iucn.

Beven, K. J., \& Kirkby, M. J. (1979). A physically based, variable contributing area model of basin hydrology/Un modèle à base physique de zone d'appel variable de l'hydrologie du bassin versant. Hydrological Sciences Journal, 24(1), 43-69.

Braun, C. L., \& Smirnov, S. N. (1993). Why is water blue? Journal of Chemical Education, 70(8), 612.

Brinson, M. M. (1993). A bydrogeomorphic classification for wetlands. Greenville, N.C.: East Carolina University.

Chang, H. (2007). Comparative streamflow characteristics in urbanizing basins in the Portland Metropolitan Area, Oregon, USA. Hydrological Processes, 21(2), 211-222.

Christy, J., \& Bauer, J. (Eds.) (2012). Wetlands in Oregon: Statewide polygon cover of wetlands. Accessed at http://oregonexplorer.info/wetlands/DataCollections/GeospatialData Wetlands

CIRC / OCCRI, Climate Impacts Research Consortium / Oregon Climate Change Research Institute (2016a). Warmest year on record. The Climate CIRCulator, 20 January 2016. Accessed at http://pnwcirc.org/warmest-year-on-record/

CIRC / OCCRI, Climate Impacts Research Consortium / Oregon Climate Change Research Institute (2016b). Wettest Winter. The Climate CIRCulator, 8 March 2016.

Accessed at http://pnwcirc.org/wettest-winter/

Clean Water Act, Title 40 - Protection of Environment, 33 U.S.C. \$1251 et seq. (1972).

Clean Water Section 404, Title 40 - Protection of Environment, 40 CFR \232, 233 (1988).

Clean Water Rule, Title 40 - Protection of Environment, 40 CFR Parts 110, 112, 116, et al. (2015).

Cowardin, L. M., Carter, V., Golet, F. C., \& LaRoe, E. T. (1979). Classification of wetlands and deepwater habitats of the United States. U.S. Fish and Wildlife Service FWS/OBS, 79(31), 131 pp.

Cowardin, L. M., \& Golet, F. C. (1995). U.S. Fish \& Wildlife Service 1979 wetland classification: A review. Vegetatio, 118(1-2), 139-152.

Davie, T. (2008). Fundamentals of hydrology. Taylor \& Francis.

Dodge, R. L., \& Congalton, R. G. (2013). Meeting Environmental Challenges with Remote Sensing Imagery. AGI. 
Entekhabi, D., Yueh, S., O’Neill, P., \& Kellogg, K. (2014). SMAP Handbook. JPL Publication JPL, 400-1567.

ESRI (2013). ArcGIS Desktop: Release 10.2 [computer software]. Redlands, CA: Environmental Systems Research Institute.

Famiglietti, J. S., Rudnicki, J. W., \& Rodell, M. (1998). Variability in surface moisture content along a hillslope transect: Rattlesnake Hill, Texas. Journal of Hydrology, 210(1), 259-281.

Feyisa, G. L., Meilby, H., Fensholt, R., \& Proud, S. R. (2014). Automated Water Extraction Index: A new technique for surface water mapping using Landsat imagery. Remote Sensing of Environment, 140, 23-35.

Forman, R.T.T. (1995). Land Mosaic. Cambridge: Cambridge University Press.

Freeman, M. C., Pringle, C. M., \& Jackson, C. R. (2007). Hydrologic connectivity and the contribution of stream headwaters to ecological integrity at regional scales. Journal of the American Water Resources Association (JAWRA) 43(1):5-14. DOI: 10.1111/j.17521688.2007.00002.x

Fritz, K. M., Johnson, B. R., \& Walters, D. M. (2006). Field operations manual for assessing the bydrologic permanence and ecological condition of headwater streams. U. S. Environmental Protection Agency, Office of Research and Development.

Gao, B. C. (1996). NDWI - A normalized difference water index for remote sensing of vegetation liquid water from space. Remote Sensing of Environment, 58(3), 257-266.

Gesch, D., Evans, G., Mauck, J., Hutchinson, J., Carswell Jr., W.J. (2009). The National Map - Elevation: U.S. Geological Survey Fact Sheet 2009-3053, 4 p.

Golden, H. E., Lane, C. R., Amatya, D. M., Bandilla, K. W., Kiperwas, H. R., Knightes, C. D., \& Ssegane, H. (2014). Hydrologic connectivity between geographically isolated wetlands and surface water systems: A review of select modeling methods. Environmental Modelling \& Software, 53, 190-206.

Google Maps (n.d.). Tualatin River National Wildlife Refuge. Accessed at www.google.com/maps/place/Tualatin+River+National+Wildlife+Refuge

Henderson, F. M., \& Lewis, A. J. (1998). Principles and applications of imaging radar. Manual of remote sensing, volume 2. John Wiley \& Sons.

Ho, L. T. K., Umitsu, M., \& Yamaguchi, Y. (2010). Flood hazard mapping by satellite images and SRTM DEM in the Vu Gia-Thu Bon alluvial plain, Central Vietnam. International archives of the photogrammetry, remote sensing and spatial information science, 38(Part 8), 275280.

Homer, C. G., Dewitz, J. A., Yang, L., Jin, S., Danielson, P., Xian, G., ... \& Megown, K. (2015). Completion of the 2011 National Land Cover Database for the conterminous United States - Representing a decade of land cover change information. Photogrammetric Engineering and Remote Sensing, 81(5), 345-354.

Hoyer, R., \& Chang, H. (2014). Assessment of freshwater ecosystem services in the Tualatin and Yamhill basins under climate change and urbanization. Applied Geography, 53, 402-416.

Huang, C., Peng, Y., Lang, M., Yeo, I. Y., \& McCarty, G. (2014). Wetland inundation mapping and change monitoring using Landsat and airborne LiDAR data. Remote Sensing of Environment, 141, 231-242.

Huisman, J. A., Hubbard, S. S., Redman, J. D., \& Annan, A. P. (2003). Measuring soil water content with ground penetrating radar. Vadose zone journal, 2(4), 476-491. 
Hwang, T., Band, L. E., Vose, J. M., \& Tague, C. (2012). Ecosystem processes at the watershed scale: Hydrologic vegetation gradient as an indicator for lateral hydrologic connectivity of headwater catchments. Water Resources Research, 48(6).

Hynes, H. B. N. (1975). Edgardo Baldi memorial lecture. The stream and its valley. Verhandlungen der Internationalen Vereinigung fur theoretische und angewandte Limnologie, 19, 1-15.

IBM Corp. (2015). IBM SPSS Statistics for Windows, Version 23.0 [Computer software]. Armonk, NY: IBM Corp.

INR / Institute for Natural Resources (2010). Medium Resolution [30-meter] Land Cover Map of Portland Metroplitan Area. Accessed at http://spatialdata.oregonexplorer.info/

INR-PSU, Institute for Natural Resources-Portland State University (2013). Work Plan, 2013 EPA Wetland Program Development Grant, INR-PSU, Project Title: Oregon Wetlands Explorer Statewide Wetland Prioritization Tool, 12 June 2013.

Jencso, K. G., McGlynn, B. L., Gooseff, M. N., Wondzell, S. M., Bencala, K. E., \& Marshall, L. A. (2009). Hydrologic connectivity between landscapes and streams: Transferring reach and plot scale understanding to the catchment scale. Water Resources Research, 45(4).

Jensen, J. R. (2005). Introductory digital image processing: A remote sensing approach. Upper Saddle River, NJ: Prentice Hall.

Kagan, Jimmy; Christy, John; Burscu, Theresa; Lev, Ester; \& Bauer, John (2013). Wetland Prioritization in Oregon: Methods to attribute priorities to the statewide wetland geodatabase [Powerpoint slides]. Institute for Natural Resources and The Wetlands Conservancy, August 2013.

Klemas, V. (2013a). Using remote sensing to select and monitor wetland restoration sites: An overview. Journal of Coastal Research, 29(4), 958-970.

Klemas, V. (2013b). Remote sensing of emergent and submerged wetlands: An overview. International Journal of Remote Sensing, 34(18), 6286-6320.

Lang, M., McDonough, O., McCarty, G., Oesterling, R., \& Wilen, B. (2012). Enhanced detection of wetland-stream connectivity using LiDAR. Wetlands, 32(3), 461-473.

Leibowitz, S. G. (2003). Isolated wetlands and their functions: An ecological perspective. Wetlands, 23(3), 517-531.

Leibowitz, S. G., \& Nadeau, T. L. (2003). Isolated wetlands: State-of-the-science and future directions. Wetlands, 23(3), 663-684.

Leibowitz, S. G., \& Vining, K. C. (2003). Temporal connectivity in a prairie pothole complex. Wetlands, 23(1), 13-25.

Leibowitz, S. G., Wigington, P. J., Rains, M. C., \& Downing, D. M. (2008). Non-navigable streams and adjacent wetlands: Addressing science needs following the Supreme Court's Rapanos decision. Frontiers in Ecology and the Environment, 6(7), 364-371. doi: $10.1890 / 070068$

Li, R. R., Kaufman, Y. J., Gao, B. C., \& Davis, C. O. (2003). Remote sensing of suspended sediments and shallow coastal waters. IEEE Transactions on Geoscience and Remote Sensing, 41(3), 559-566.

Lillesand, T., Kiefer, R. W., \& Chipman, J. (2008). Remote sensing and image interpretation. John Wiley \& Sons. 
Matthews, G. V. T. (1993). The Ramsar Convention on Wetlands: Its history and development. Gland: Ramsar convention bureau.

MEA, Millennium Ecosystem Assessment (2005). Ecosystems and Human Well-being: Wetlands and Water Synthesis. Washington, DC: World Resources Institute.

McFeeters, S. K. (1996). The use of the Normalized Difference Water Index (NDWI) in the delineation of open water features. International Journal of Remote Sensing, 17(7), 14251432.

Menne, M. J., Durre, I., Korzeniewski, B., McNeal, S., Thomas, K., Yin, X., ... \& Houston, T. G. (2012). Global historical climatology network-daily (GHCN-Daily), Version 3. NOAA National Climatic Data Center. Accessed at http://www.ncdc.noaa.gov/, doi:10.7289/V5D21VHZ.

Merriam, G. (1984). Connectivity: A fundamental ecological characteristic of landscape pattern. In Methodology in landscape ecological research and planning: proceedings, 1st seminar, International Association of Landscape Ecology, Roskilde, Denmark, Oct 15-19, 1984/ eds. J. Brandt, P. Agger. Roskilde, Denmark: Roskilde University Centre.

Microsoft (2010). Microsoft Excel [computer software]. Redmond, Washington: Microsoft. Mitsch, W. J., \& Gosselink, J. G. (2007). Wetlands. Hoboken, NJ: John Wiley \& Sons.

Murphy, P. N. C., Ogilvie, J., \& Arp, P. (2009). Topographic modelling of soil moisture conditions: A comparison and verification of two models. European Journal of Soil Science, 60(1), 94-109.

Najafi, M. R., Moradkhani, H., \& Jung, I. W. (2011). Assessing the uncertainties of hydrologic model selection in climate change impact studies. Hydrological Processes, 25(18), 2814-2826.

NOAA/National Oceanic and Atmospheric Administration $(2015,2016)$. Climate Data Online: Dataset Discovery. National Centers for Environmental Information, NOAA. Accessed at www.ncdc.noaa.gov

Palaniappan, M., \& Gleick, P. H. (2009). Peak water. The World's Water 2008-2009. The Biennial Report on Freshwater Resources, 1-16. Island Press.

Pietroniro, A., \& Leconte, R. (2005). A review of Canadian remote sensing and hydrology, 1999-2003. Hydrological Processes, 19(1), 285-301.

Pringle, C. M. (2001). Hydrologic connectivity and the management of biological reserves: A global perspective. Ecological Applications, 11(4), 981-998.

Pringle, C. (2003). What is hydrologic connectivity and why is it ecologically important? Hydrological Processes, 17(13), 2685-2689.

PRISM Climate Group (n.d.). PRISM climate data. Accessed at http://prism.oregonstate.edu

Python Software Foundation (2013). Python Version 2.7.5 [computer software]. Python Software Foundation. Available at www.python.org

Rango, A., \& Shalaby, A. I. (1998). Operational applications of remote sensing in hydrology: Success, prospects and problems. Hydrological Sciences Journal, 43(6), 947-968. DOI: 10.1080/02626669809492189

Rapanos, Rapanos v United States, 547 U.S. 715 (2006).

Riverside, United States v. Riverside Bayview Homes, 474 U.S. 121 (1985).

Rencz, A. N. (1999). Remote Sensing for the Earth Sciences. Manual of remote sensing, volume 3. John Wiley \& Sons. 
Renslow, M. S. (Ed.). (2012). Manual of airborne topographic lidar. Bethesda, Maryland: The American Society for Photogrammetry and Remote Sensing.

Reynolds, S. G. (1970). The gravimetric method of soil moisture determination Part IA study of equipment, and methodological problems. Journal of Hydrology, 11(3), 258-273.

Schmugge, T. J., Kustas, W. P., Ritchie, J. C., Jackson, T. J., \& Rango, A. (2002). Remote sensing in hydrology. Advances in Water Resources, 25(8), 1367-1385.

Singh, K., Ghosh, M., \& Sharma, S. R. (2016). WSB-DA: Water Surface Boundary Detection Algorithm Using Landsat 8 OLI Data. IEEE Journal of Selected Topics in Applied Earth Observations and Remote Sensing, 9(1), 363-368.

Smith, R. D., Ammann, A., Bartoldus, C., \& Brinson, M. M. (1995). An approach for assessing wetland functions using hydrogeomorphic classification, reference wetlands, and functional indices (No. WES/TR/WRP-DE-9). Army Engineer Waterways Experiment Station, Vicksburg, MS.

Soil Survey Staff (2015). Soil survey manual. C. Ditzler, \& L. West (Eds). Natural Resources Conservation Service. U.S. Department of Agriculture Handbook 18. Accessed at http://www.nrcs.usda.gov/wps/portal/nrcs/detail/soils/scientists/?cid=nrcseprd32 $\underline{9418}$

Sonenshein, R. S. (1996). Documentation of programs used to determine a wetlands hydroperiod from model-simulated water-surface elevations, report 96-455. Tallahassee, FL: USGS.

Soti, V., Tran, A., Bailly, J. S., Puech, C., Seen, D. L., \& Bégué, A. (2009). Assessing optical earth observation systems for mapping and monitoring temporary ponds in arid areas. International Journal of Applied Earth Observation and Geoinformation, 11(5), 344-351.

Stanford, J. A., \& Ward, J. V. (1993). An ecosystem perspective of alluvial rivers: Connectivity and the hyporheic corridor. Journal of the North American Benthological Society, 48-60.

SW ANCC, Solid W aste Agency of Northern Cook County v U.S. Army Corps of Engineers, 531 U.S. 159 (2001).

Tian, J., \& Philpot, W. D. (2015). Relationship between surface soil water content, evaporation rate, and water absorption band depths in SWIR reflectance spectra. Remote Sensing of Environment, 169, 280-289.

Tiner, R. W. (1999). Wetland indicators: a guide to wetland identification, delineation, classification, and mapping. CRC Press.

Tiner, R. (2003). Dichotomous Keys and Mapping Codes for Wetland Landscape Position, Landform, Water Flow Path, and Waterbody Type Descriptors. Accessed at http:/ / digitalmedia.fws.gov/cdm/singleitem/collection/document/id/1324/rec/9

Tiner, R. (2010). NWIPlus. National Wetlands Newsletter, 32(3).

TRWC, Tualatin River Watershed Council (2015). Tualatin Basin Information. Accessed at http://trwc.org/tualatin-basin-information/

Tualatin Riverkeepers (2007). Paddler Map. Accessed at tualatinriverkeepers.org

Tucker, C. J. (1980). Remote sensing of leaf water content in the near infrared. Remote Sensing of Environment, 10(1), 23-32.

TWC, The Wetlands Conservancy (2013a). Wetlands [Compilation of OSWP Wetlands in Oregon, John Bauer].

TWC, The Wetlands Conservancy (2013b). Watershed Units [Modified HUC8 boundaries in Oregon, John Bauer]. 
USACE / U.S. Army Corp of Engineers (2009). Recognizing Wetlands. Accessed at http://www.usace.army.mil/Portals/2/docs/civilworks/regulatory/rw bro.pdf

USEPA, U.S. Environmental Protection Agency (2015). Connectivity of Streams and Wetlands to Downstream Waters: A Review and Synthesis of the Scientific Evidence (Final Report). Washington, DC: U.S. Environmental Protection Agency, EPA/600/R-14/475F, 2015.

USFWS, U.S. Fish \& Wildlife Service (2010). NWIPlus: Geospatial Database for Watershed-level Functional Assessment. Accessed at http://www.fws.gov/northeast/wetlands/factsheets/NWIPlus FactSheet.pdf

USFWS, U.S. Fish \& Wildlife Service (2013). Tualatin River National Wildlife Refuge Comprehensive Conservation Plan. Accessed at http://www.fws.gov/tualatinriver/refugeplanning.htm

USFWS, U.S. Fish \& Wildlife Service (2014). NWI Overview. Accessed at http://www.fws.gov/wetlands/NWI/Overview.html

USFWS, U.S. Fish \& Wildlife Service (2015). FWD Cadastral Database. Accessed at http://www.fws.gov/gis/data/CadastralDB/index cadastral.html

USFWS, U.S. Fish \& Wildlife Service (2016). Tualatin River National Wildlife Refuge. Accessed at http://www.fws.gov/refuge/Tualatin River/

USGS, U.S. Geological Survey (2013). National Hydrography Geodatabase. Accessed May 2014 at http://viewer.nationalmap.gov/viewer/nhd.html?p=nhd

USGS, U.S. Geological Survey (2014a). Frequently Asked Questions about the Landsat Missions. Accessed at http://landsat.usgs.gov/landsat8.php

USGS, U.S. Geological Survey (2014b). NLCD 2011 Land Cover (2011 Edition, amended 20141010) - National Geospatial Data Asset (NGDA) Land Use Land Cover. Sioux Falls, SD: USGS. Accessed at http://www.mrlc.gov/nlcd2011.php

USGS, U.S. Geological Survey (2015a). The National Map - Elevation. Accessed September 2015 at http://viewer.nationalmap.gov/

USGS, U.S. Geological Survey (2015b) Earth Explorer (Landsat 8 OLI/TIRS). Accessed multiple dates in 2015 and 2016 at http://earthexplorer.usgs.gov/

Vannote, R. L., Minshall, G. W., Cummins, K. W., Sedell, J. R., \& Cushing, C. E. (1980). The river continuum concept. Canadian Journal of Fisheries and Aquatic Sciences, 37(1), 130137.

Ward, J. V. (1989). The four-dimensional nature of lotic ecosystems. Journal of the North American Benthological Society, 2-8.

Ward, J. V., Tockner, K., Arscott, D. B., \& Claret, C. (2002). Riverine landscape diversity. Freshwater Biology, 47(4), 517-539. doi:10.1046/j.1365-2427.2002.00893.x

Wenning, R. J., \& Fewell, B. (2014). Sound science and redefining the U.S. clean water act. Integrated Environmental Assessment and Management, 10(3), 321-322.

Western, A. W., Grayson, R. B., Bloschl, G., Willgoose, G. R., \& McMahon, T. A. (1999). Observed spatial organization of soil moisture and its relation to terrain indices. Water Resource Research, 35, 797-810.

Western, A. W., Blöschl, G., \& Grayson, R. B. (2001). Toward capturing hydrologically significant connectivity in spatial patterns. Water Resources Research, 37(1), 83-97.

WRCC, Western Regional Climate Center. (2016). Monthly Climate Summary. Accessed at http://www.wrcc.dri.edu/cgi-bin/cliMAIN.pl?or7127

Wiens, J. (1989). Spatial scaling in ecology. Functional Ecology 3(4), 383-97. 
Wiens, J. (1995). Landscape mosaics and ecological theory. In L. Hansson, L. Fahrig, \& G. Merriam (Eds.), Mosaic Landscapes and Ecological Processes (pp. 1-26). Springer Netherlands. Accessed at http://dx.doi.org/10.1007/978-94-011-0717-4 1

Wigington, P. J., Leibowitz, S. G., Comeleo, R. L., \& Ebersole, J. L. (2013). Oregon Hydrologic Landscapes: A Classification Framework. Journal of the American Water Resources Association, 49(1), 163-182. doi:10.1111/jawr.12009

Williams, Matt (2014, December 1). What Percent of Earth is Water? Astronomy Guide to Space: Universe Today. Accessed June 2016 at http://www.universetoday.com/

Wiltgen, Nick (2015, July 7). Northwest Heat Wave by the Numbers: Dozens of Monthly and All-Time Record Highs. Accessed at https://weather.com

Winter, T. C. (2001). The concept of hydrologic landscapes. Journal of the American Water Resources Association, 37(2), 335-349. doi:10.1111/j.1752-1688.2001.tb00973.x

Winter, T. C., \& LaBaugh, J. W. (2003). Hydrologic considerations in defining isolated wetlands. Wetlands, 23(3), 532-540.

Wolock, D. M., Winter, T. C., \& McMahon, G. (2004). Delineation and evaluation of hydrologic-landscape regions in the United States using geographic information system tools and multivariate statistical analyses. Environmental Management, 34(1), S71-S88.

$\mathrm{Xu}, \mathrm{H}$. (2006). Modification of normalised difference water index (NDWI) to enhance open water features in remotely sensed imagery. International Journal of Remote sensing, 27(14), 3025-3033.

Yan, W. Y., Shaker, A., Habib, A., \& Kersting, A. P. (2012). Improving classification accuracy of airborne LiDAR intensity data by geometric calibration and radiometric correction. ISPRS Journal of Photogrammetry and Remote Sensing, 67, 35-44.

Zhang, N., Hong, Y., Qin, Q., \& Liu, L. (2013). VSDI: a visible and shortwave infrared drought index for monitoring soil and vegetation moisture based on optical remote sensing. International Journal of Remote Sensing, 34(13), 4585-4609. 


\section{Appendix A. Special Use Permit}

Contact with the refuge was made through Dan Craver, Geographer / Refuge Information Analyst with U.S. Fish \& Wildlife Service in Portland, Oregon. On September 4, 2015, Richard (Curt) Mykut, Wildlife Biologist at the Tualatin River National Wildlife Refuge (TRNWR or the "Refuge"), agreed to meet with me on-site in Sherwood, Oregon to discuss the proposed thesis work. Mr. Mykut and I compared my research purpose, schedule and sampling expectations to the objectives, schedule and physical requirements at the Refuge. TRNWR access for "research and monitoring activities by students, universities, or other non-FWS organizations" requires permission, especially for off-path areas and offseason periods (1 October to 30 April). With input from my Portland State University advisor, Dr. Jiunn-Der Duh, I completed an application for a Special Use Permit (SUP). On October 2, 2015, I visited the Refuge again. Mr. Mykut helped select three locations, identified in the geodatabase extract with wetland IDs 151, 1785 and 2905. Two of these wetlands (Wetland 151 and Wetland 1785) were chosen because they were expected to be wet or "connected" during the study period, based on field observations, discussions with the on-site biologist and comparisons of satellite imagery from wet and dry periods, i.e., January and July 2015. One additional wetland (Wetland 2905) was selected which was expected to be dry or "not connected", using the same criteria.

The SUP was completed on 14 October 2015 at which time, Mr. Mykut discussed access guidelines, parking locations, provided a magnetic sign for my car "Wildlife Survey in Progress by permission of U.S. Fish \& Wildlife Service" plus security codes for entry gates at Wetland 1785 (near maintenance facility) and Wetland 2905 (on Pleasant Valley Road). Copies of the signed SUP and related maps were also provided to be kept in the vehicle at all times during on-site work. I agreed to inform Mr. Mykut via email (cc: to my advisor) before and after each on-site visit since most visits were conducted on my own, with the exception that my advisor joined me on 18 Feb 2016. At the end of the field work, I met with Curt once again to discuss wrap up of the project and to invite him and/or interested U.S. Fish \& Wildlife Services staff to attend my thesis defense. The SUP includes provisions for me to report findings to Refuge staff, to provide them with data related to the project, to remove any flags placed on-site and to return all materials provided to me. 


\section{Appendix B. Beaver and Nutria at WL1785}

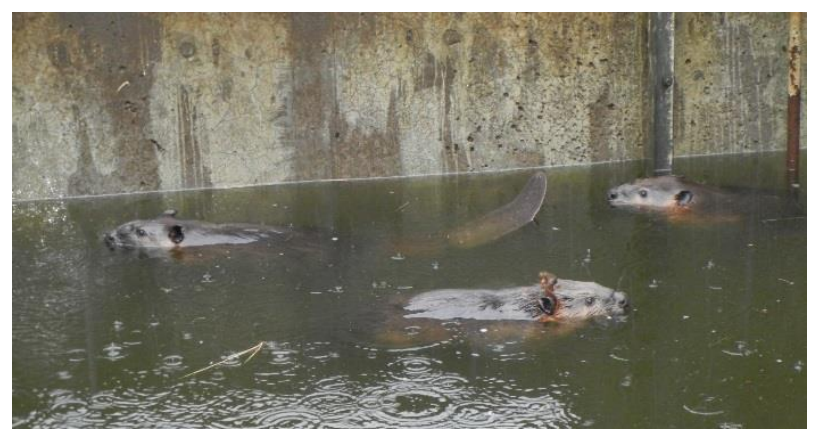

Wetland 1785 on 18 February 2016.

Three beaver swimming in catchment near outflow gate.

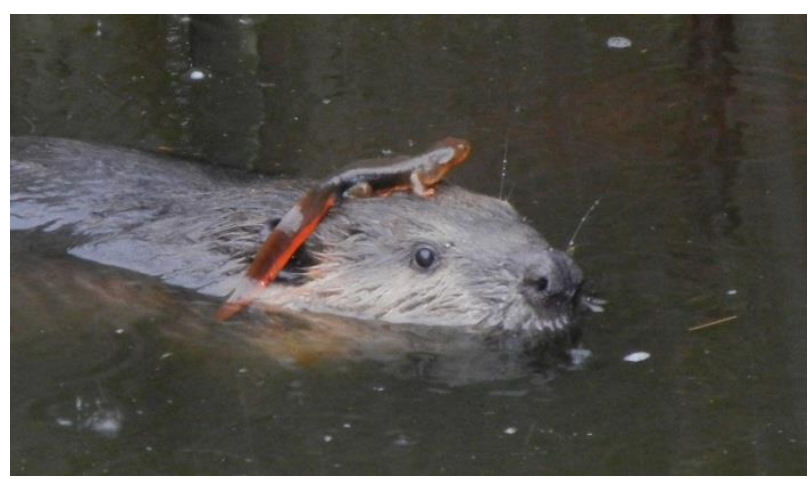

Wetland 1785 on 18 February 2016.

Rough-skinned newt on beaver's head in catchment near outflow gate.

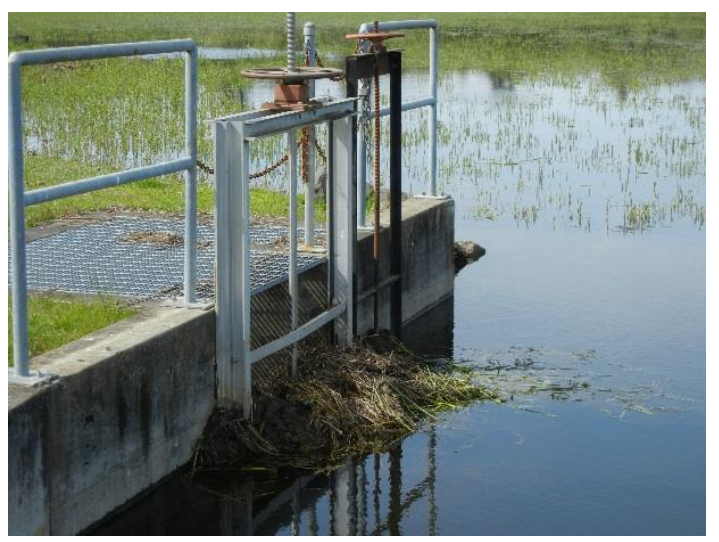

Wetland 1785 on 6 April 2015.

Beaver dam blocking outflow gate. Note: Top of concrete is about six feet from drain and channel beneath water.

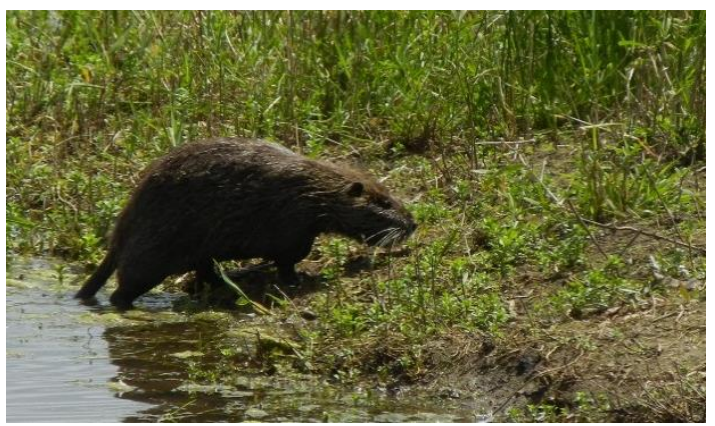

Wetland 1785 on 9 May 2015.

Nutria foraging along berm near outflow gate. 


\section{Appendix C. Site Conditions - Dry (14 Oct 2015)}

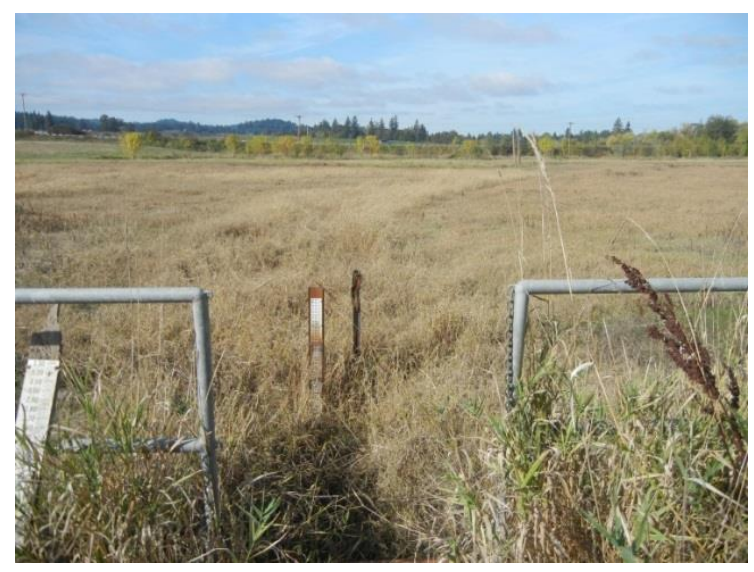

\section{Left: Wetland 151}

View from weir "upchannel" facing west.

Drainage toward weir / camera.
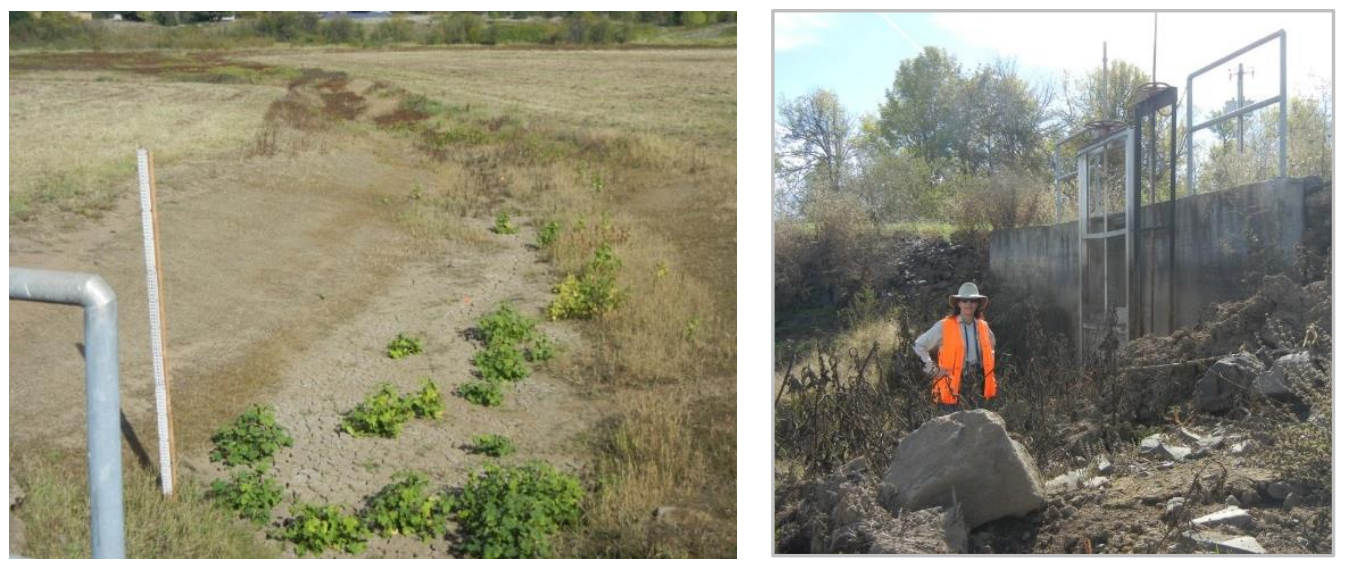

Above: Wetland 1785. L: View from weir "upchannel" facing northeast. Drainage toward weir / camera. R: View from channel facing southwest. Outflow drainage to right in photo. Concrete barrier about six (6) feet tall.

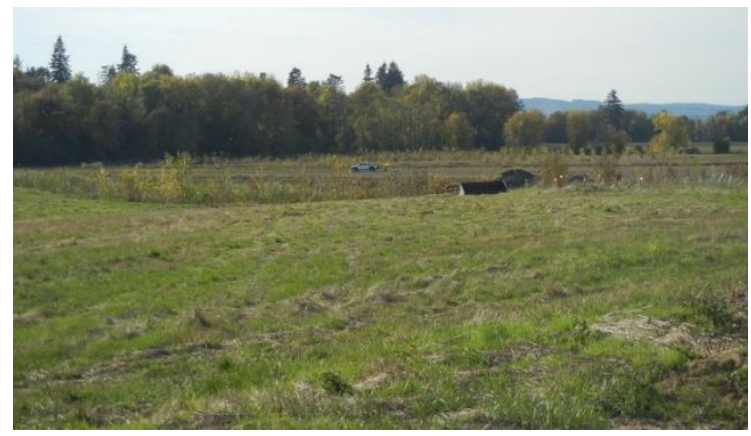

Wetland 2905

View from pour point area facing west.

Drainage away from camera, indicated by slight depression in foreground on left. 


\section{Appendix D. Site Conditions - Flooded (16 Dec 2015)}

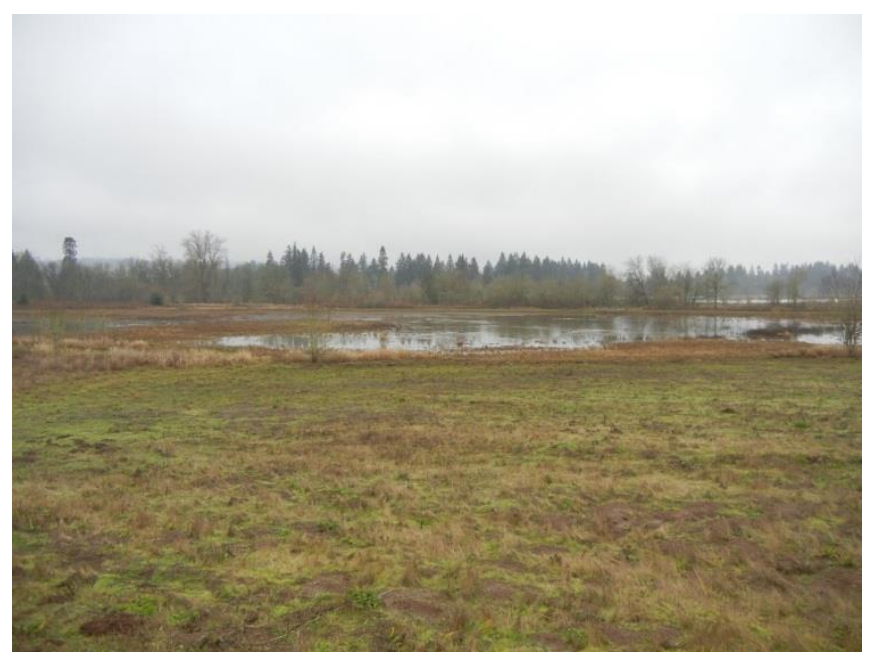

\section{Wetland 151}

View from southwest facing northeast.

Drainage away from camera toward weir in center right of water.

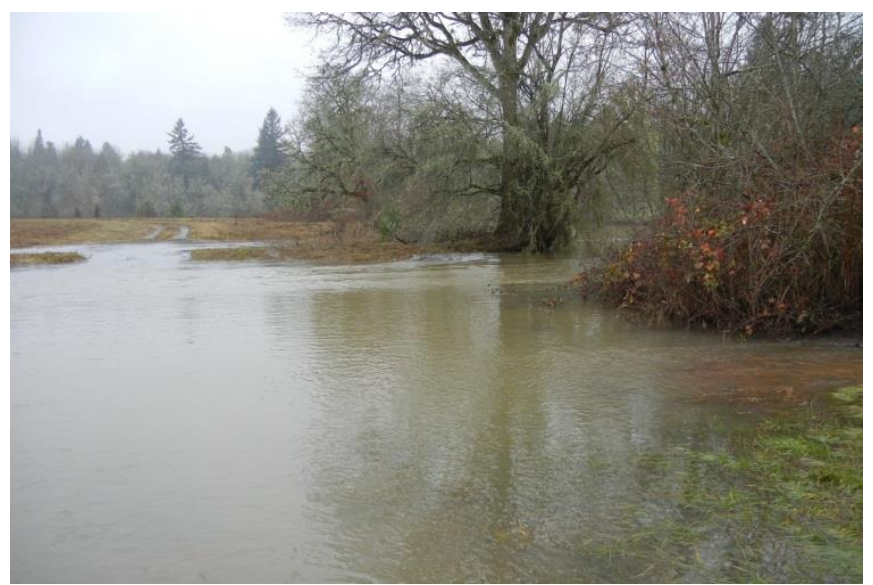

\section{Wetland 1785}

View of road to weir / gate. Tualatin River was flowing INTO the wetland.

All sampling sites were underwater in "the lake" (not shown).

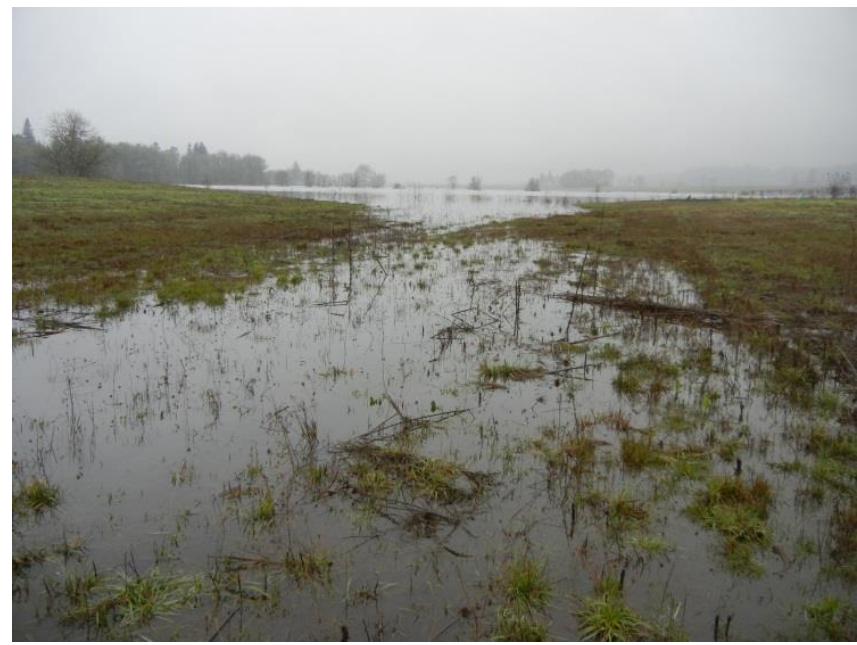

Wetland 2905

View from pour point area facing west.

Nearby wetland overflow had inundated the flow path "channel" from WL2905.

All sampling sites were inundated. 
Appendix E. Site Conditions - Wet (1 Jan 2016)

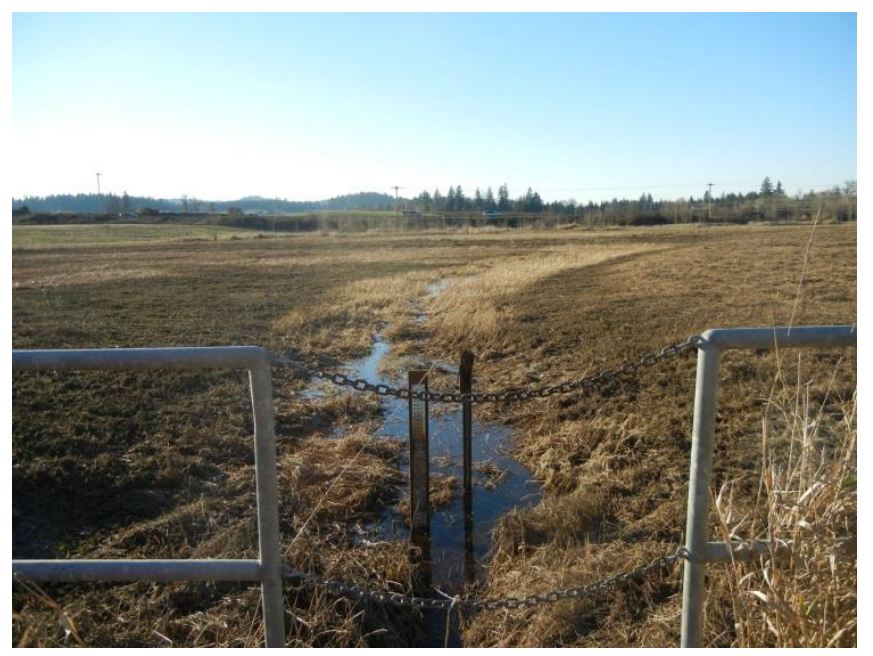

Wetland 151

View from southwest facing northeast.

Drainage toward weir in center right of water.

Flood gates compromised, only channels of water present (and ice patches in shallower water).

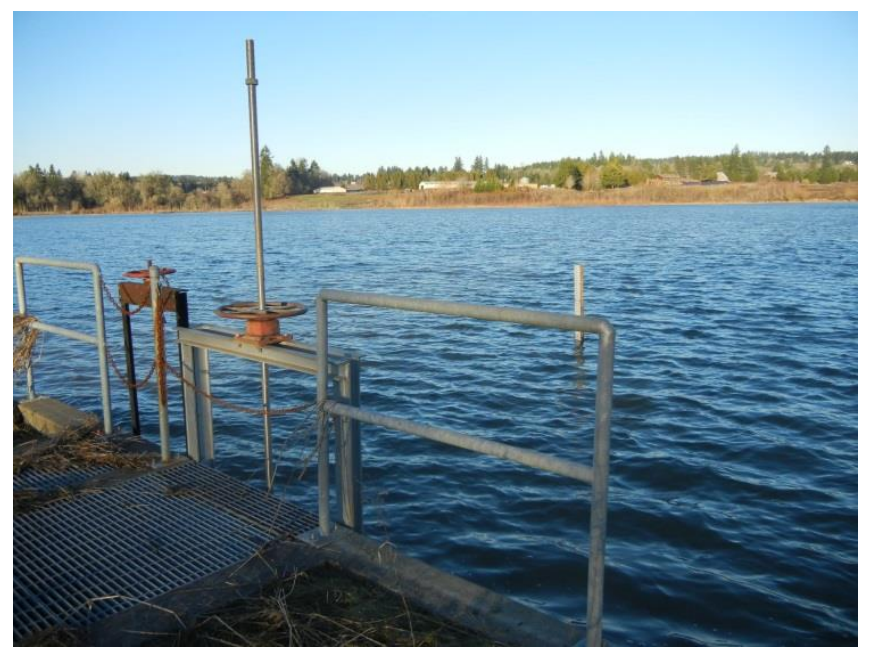

Wetland 1785 ("the lake")

View from weir "upchannel" facing north-northeast.

Drainage toward weir / camera.

All sampling sites underwater.

Wetland 2905

View from pour point area facing west.

Nearby wetland overflow has receded after flooding in December.

Sampling sites were exposed once again. 


\section{Appendix F. Soil Laboratory Examples}

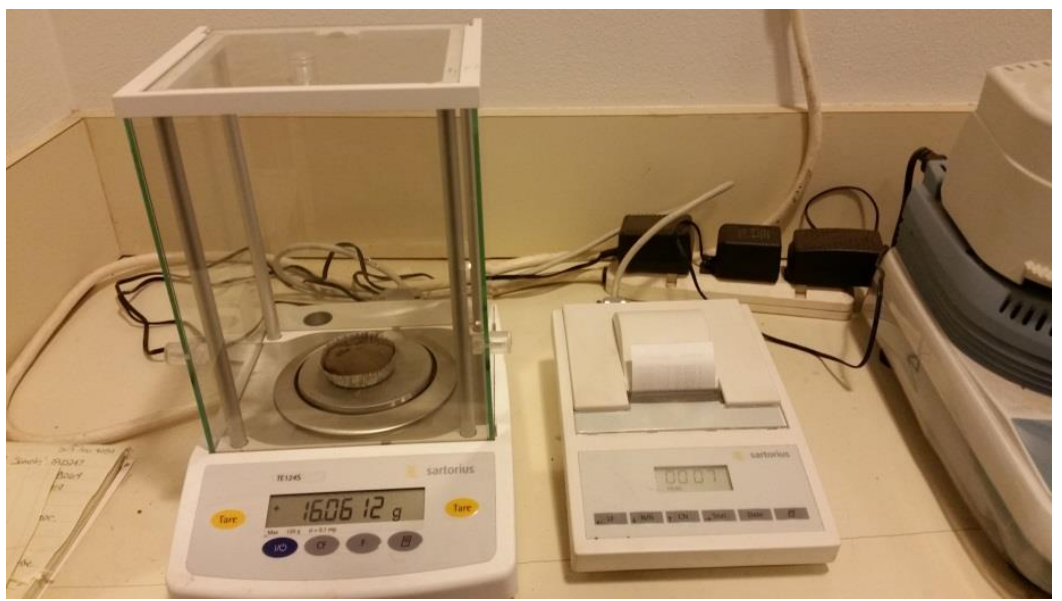

Soil Moisture Analyzer

Used to weigh samples when wet and again after drying.

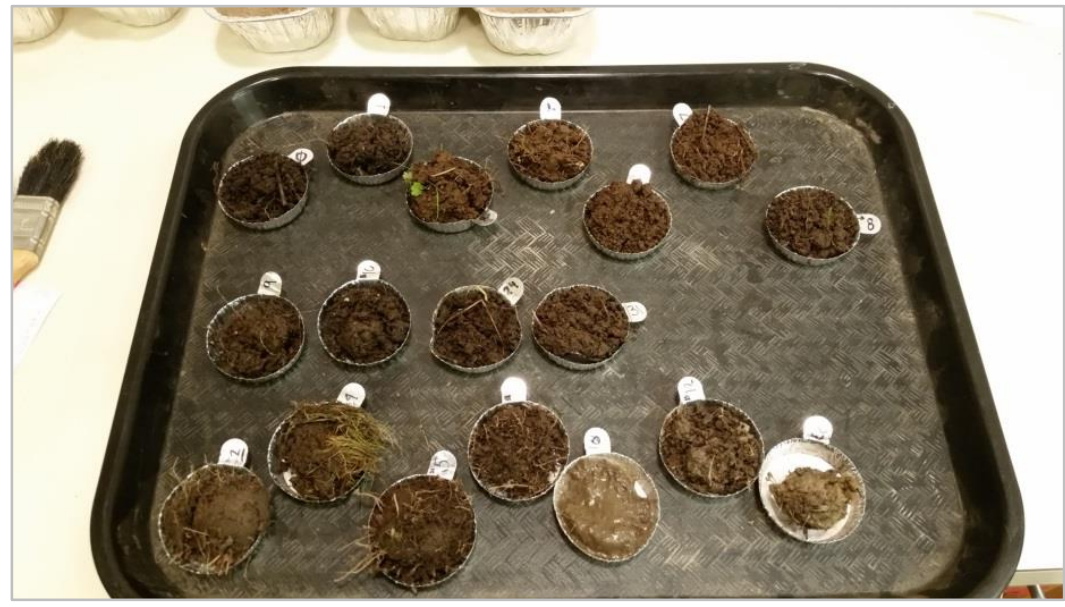

Samples - wet

13 Nov 2015

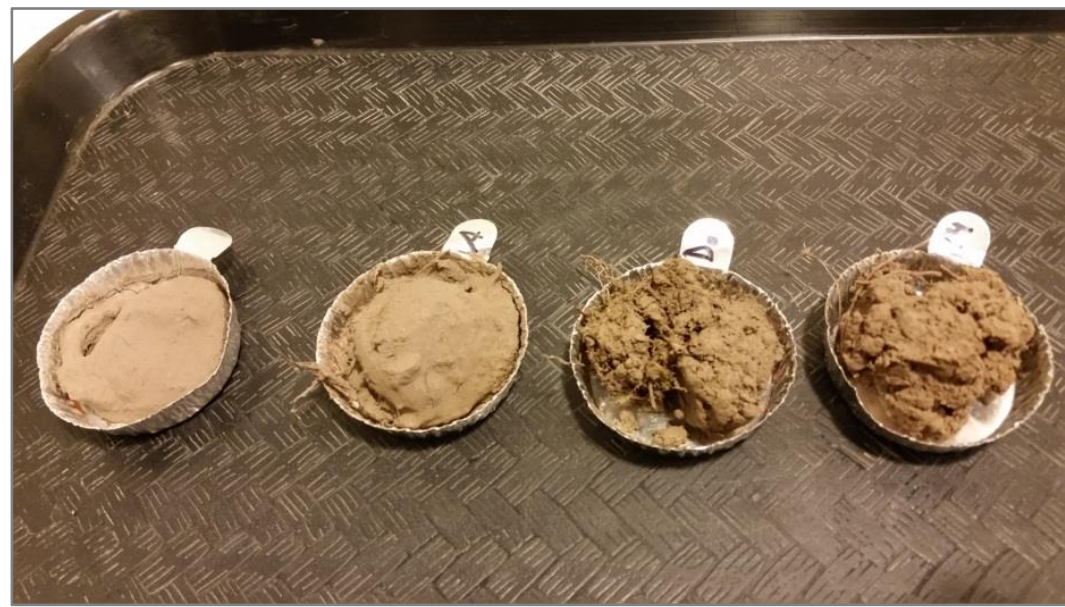

Samples - dry

5 Mar 2016 